\title{
WestVirginiaUniversity
}

THE RESEARCH REPOSITORY @ WVU

Graduate Theses, Dissertations, and Problem Reports

2010

\section{The influence of anxiety, depression, and negative affect on recall of dental pain}

Brandon N. Kyle

West Virginia University

Follow this and additional works at: https://researchrepository.wvu.edu/etd

\section{Recommended Citation}

Kyle, Brandon N., "The influence of anxiety, depression, and negative affect on recall of dental pain" (2010). Graduate Theses, Dissertations, and Problem Reports. 4621.

https://researchrepository.wvu.edu/etd/4621

This Dissertation is protected by copyright and/or related rights. It has been brought to you by the The Research Repository @ WVU with permission from the rights-holder(s). You are free to use this Dissertation in any way that is permitted by the copyright and related rights legislation that applies to your use. For other uses you must obtain permission from the rights-holder(s) directly, unless additional rights are indicated by a Creative Commons license in the record and/ or on the work itself. This Dissertation has been accepted for inclusion in WVU Graduate Theses, Dissertations, and Problem Reports collection by an authorized administrator of The Research Repository @ WVU.

For more information, please contact researchrepository@mail.wvu.edu. 
The Influence of Anxiety, Depression, and Negative Affect on Recall of Dental Pain

\title{
Brandon N. Kyle
}

\author{
Dissertation submitted to the Eberly College of Arts and Sciences \\ at West Virginia University \\ in Partial Fulfillment of Requirements for the Degree of \\ Doctor of Philosophy \\ In \\ Psychology
}

Daniel W. McNeil, Ph.D., Chair

Kevin Larkin, Ph.D.

William Fremouw, Ph.D.

Julie Patrick, Ph.D.

Bryan Weaver, M.D., D.D.S.

Department of Psychology

Morgantown, WV

2010

Key Words: Pain, Memory, Mood, Dentistry 


\begin{abstract}
The Influence of Anxiety, Depression, and Negative Affect on Recall of Dental Pain

Brandon N. Kyle
\end{abstract}

Research suggests mood can influence recall of emotionally-relevant information. Yet, despite multiple studies examining the association of anxiety and exaggerated prediction and recall of dental pain, the influence of other moods on prediction and recall of dental pain remains poorly investigated. Further, the potential moderation and mediation effects for dental fear, fear of pain, and mood state have not been properly researched. The present study investigated variables associated with predicted pain (pain expected during the dental procedure) and recalled pain in oral surgery patients. Data were provided by a sample of 157 patients undergoing tooth extraction under local anesthetic. Patients completed measures of depression, anxiety, and negative affect both at the time of surgery and at a 1-month follow-up. Dental fear and fear of pain also were assessed prior to extraction. Path analysis was used to examine relations among variables, including mediation effects of mood state between dental fear or fear of pain and report of pain; moderation effects of dental fear and fear of pain on report of pain were examined using regression equations. The best fitting models suggested mood prior to extraction was related to current pain prior to extraction $(\beta=.18-.23)$, but not predicted or recalled pain. Dental fear, however, was related to predicted pain $(\beta=.25-.26)$. Predicted pain was associated with recalled pain and also influenced recalled pain through its relation with pain during extraction. In a final exploratory model, the influence of negative affect on current pain became non-significant when accounting for the influence of anxiety and depression. Additionally, fewer prior extractions and shorter duration of dental pain prior to extraction were associated with more predicted pain; greater chronic pain rating and injection of an additional anesthetic were related to more recalled pain. Dental fear proved a theoretically and clinically relevant construct in the oral surgery context, especially in relation to prediction of pain; reduction of dental fear may reduce aversive experiences and report of pain during dental procedures. Future research should clarify more specific relations between mood and pain over time, including patterns of change or stability. 


\section{Acknowledgments}

My wonderful wife Melanie gave me her love and support during the time of my dissertation, and I hope that I may have the pleasure of returning the favor for the rest of our lives.

My parents, William and Sharon, always encouraged me in my dreams and to be the best I can; may this project be a testimony to the power of their good parenting.

Without my advisor, chair, and friend Dan McNeil, I would not be the researcher, clinician, or professional I am today.

Professor Cohoe always inspired me during my undergraduate years, and his influence on my development will resonate throughout my career.

My thanks and gratitude to my committee members: Kevin Larkin, William Fremouw, Julie Patrick, and Bryan Weaver. Their input has improved my project.

I would not have collected my data in such a timely fashion if it were not for the hard work of my research assistants: Tomorrow Wilson, Brandi Cheetham, Ashlee Quintin, Karen Myers, and Sharon Glassburn.

During all phases of the dissertation project, I have appreciated the contributions and support of the Anxiety, Psychophysiology, and Pain Research Laboratory in the Department of Psychology of West Virginia University.

This research was funded by a generous grant from the Department of Psychology Alumni Fund. 
Table of Contents

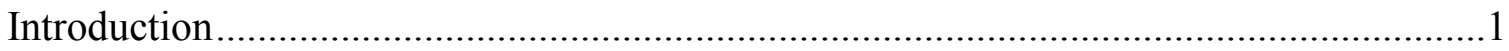

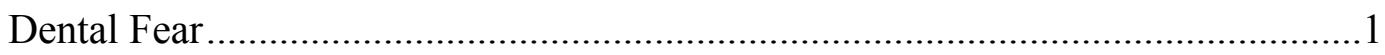

Influence of Mood on Memory .................................................................

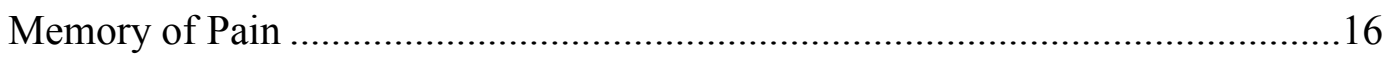

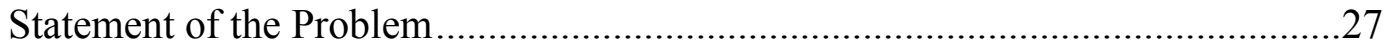

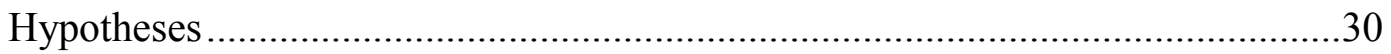

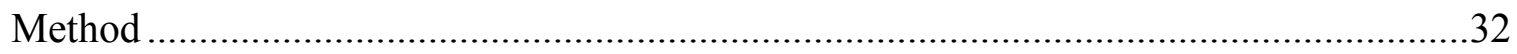

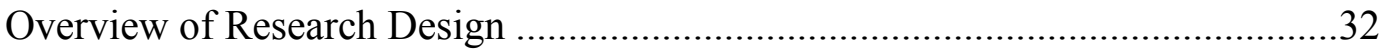

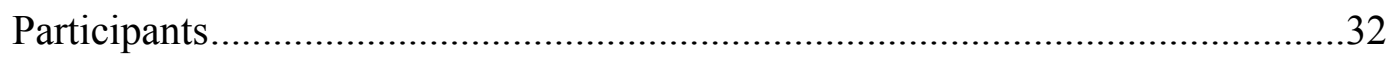

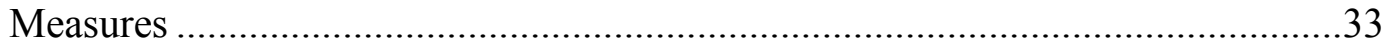

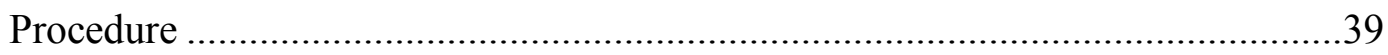

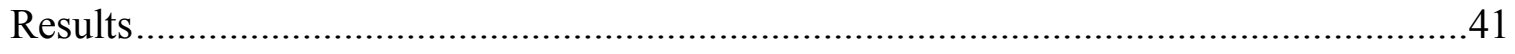

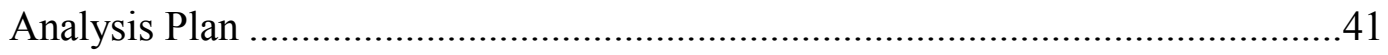

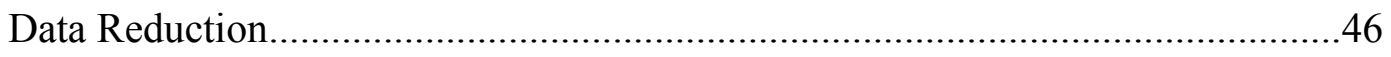

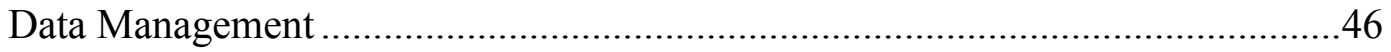

Path Model Analysis for Anxiety and Depression ......................................47

Path Model Analysis for Negative Affect....................................................49

Moderation Effects of Dental Fear and Fear of Pain .........................................51

Mediations Effects of Pre-Surgery Anxiety, Depression, and Negative Affect ....51

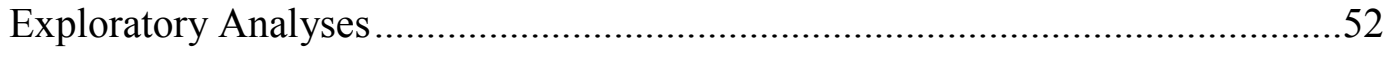

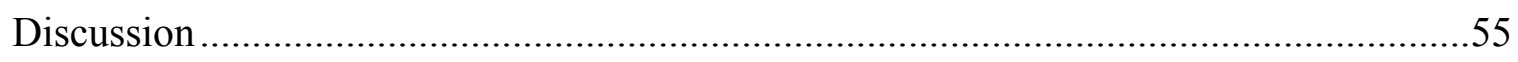

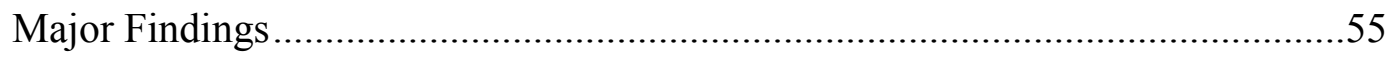




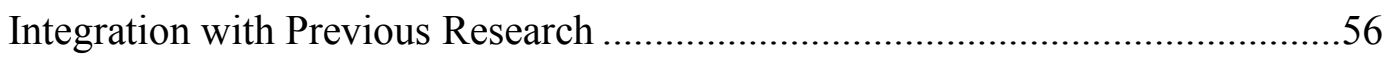

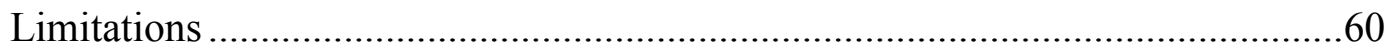

Future Directions, Applications, and Summary...................................................62

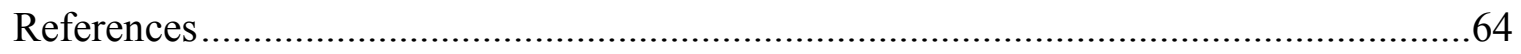

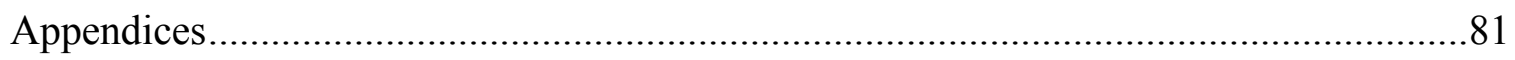

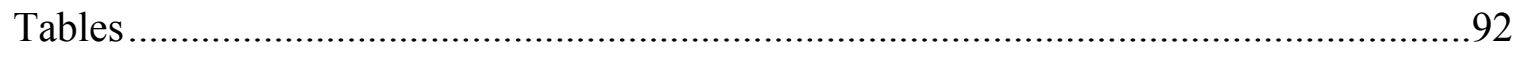

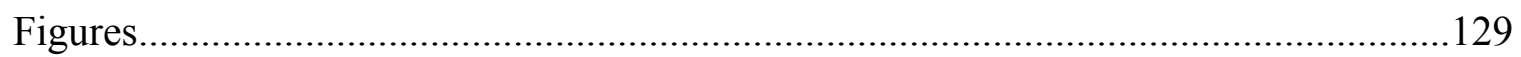


List of Tables

Table 1: Comparison of Participants Who Returned and Did Not Return Follow-Up

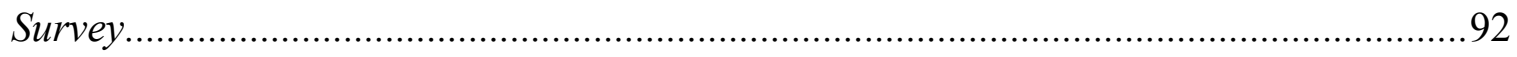

Table 2: Means and Frequencies for Additional Variables of Interest in Final Sample ...96

Tables 3: Means (Standard Deviations) of Path Model Variables for Final Sample ........98

Table 4: Means (Standard Deviations) for Extraction Nä̈ve Participants of Final Sample

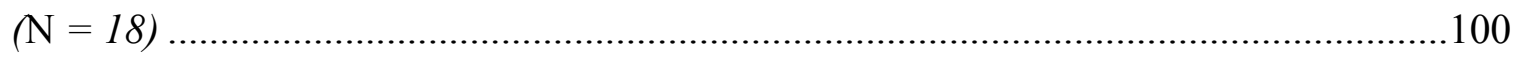

Table 5: Correlations of All Path Model Variables ......................................................102

Table 6: Goodness-of-Fit Indicators of Models for Anxiety and Depression ( $\mathrm{N}=157) .103$

Table 7: Summary of Path Coefficients for Initial Anxiety and Depression Model.........104

Table 8: Implied Correlations and Residual Correlations for Final Anxiety and Depression

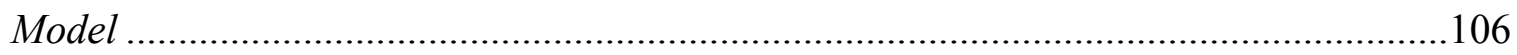

Table 9: Summary of Path Coefficients for Final Anxiety and Depression Model..........107

Table 10: Goodness-of-Fit Indicators of Models for Negative Affect $(\mathrm{N}=157)$............108

Table 11: Summary of Path Coefficients for Initial Negative Affect Model ....................109

Table 12: Implied Correlations and Residual Correlations for Final Negative Affect

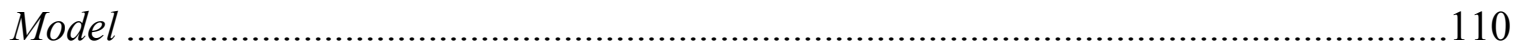

Table 13: Summary of Path Coefficients for Final Negative Affect Model .....................111

Table 14: Moderation Effects of Dental Fear and Recall Depression for Recalled Dental

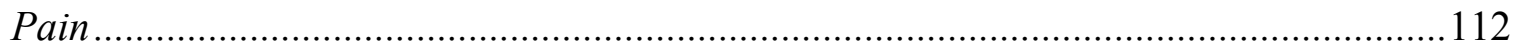

Table 15: Standardized Indirect Effects for Final Path Model with Anxiety and

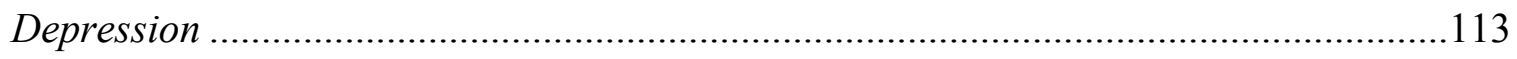

Table 16: Standardized Indirect Effects for Final Path Model with Negative Affect ......114 


\section{List of Tables (Continued)}

Table 17: Sample Correlations with VAS Pain Ratings

Table 18: Implied Correlations and Residual Correlations for Final Anxiety and Depression

Model with VAS Pain Ratings.....

Table 19: Summary of Path Coefficients for Final Anxiety and Depression Model with

$V A S$

Table 20: Implied Correlations and Residual Correlations for Final Negative Affect Model with

VAS Pain Ratings.

Table 21: Summary of Path Coefficients for Final Negative Affect Model with VAS......119

Table 22: Correlations for Additional Variables of Interest

Table 23: Implied Correlations and Residual Correlations for Final Anxiety and Depression Model with Additional Variables..... 122

Table 24: Summary of Path Coefficients for Final Anxiety and Depression Model with Additional Variables 123

Table 25: Implied Correlations and Residual Correlations for Final Negative Affect Model with Additional Variables 124

Table 26: Summary of Path Coefficients for Final Negative Affect Model with Additional

Variables 125

Table 27: Implied Correlations and Residual Correlations for Exploratory Model .......126

Table 28: Summary of Path Coefficients for Exploratory Model 127 


\section{List of Figures}

Figure 1: Initial Path Model with Anxiety and Depression .........................................131

Figure 2: Final Path Model with Anxiety and Depression ..........................................132

Figure 3: Initial Path Model with Negative Affect .......................................................133

Figure 4: Final Path Model with Negative Affect .......................................................134

Figure 5: Moderation Effects of Dental Fear on Recall Depression for Recalled Dental

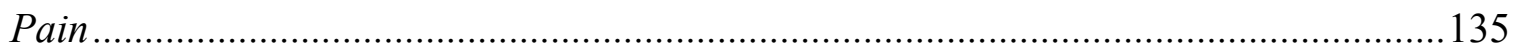

Figure 6: Final Path Model with Anxiety and Depression with Visual Analogue Scale Pain

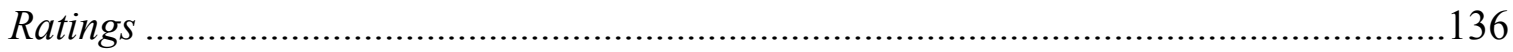

Figure 7: Final Path Model with Negative Affect with Visual Analogue Scale Pain

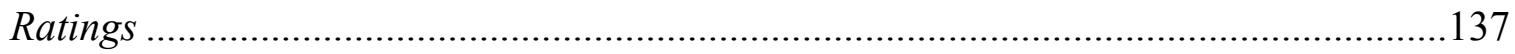

Figure 8: Final Anxiety and Depression Model with Additional Variables of Interest ...138

Figure 9: Final Negative Affect Model with Additional Variables of Interest .................139

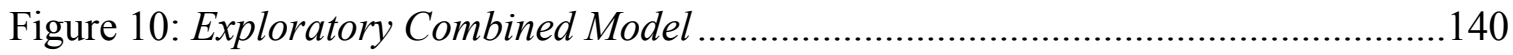


The Influence of Anxiety, Depression, and Negative Affect on Recall of Dental Pain

\section{Dental Fear}

In spite of numerous advances made in the field of dental care, dental fear presents a problem for a significant number of individuals. Dental fear involves fear of stimuli and situations associated with the dentist, which can include critical remarks for poor oral health, losing control, pain, dental injections, and the sensations of the dental drill (Melamed, 1979). As with other anxiety disorders, dental fear exists along a continuum of severity from fearlessness to phobia. Using criteria from the Diagnostic and Statistical Manual of Mental Disorders, Fourth Edition, Text Revision (DSM-IV-TR), dental phobia can best be conceptualized as a bloodinjection-injury subtype of specific phobia (American Psychiatric Association [APA], 2000). The symptoms of specific phobias include: (a) excessive and persistent fear that is cued by a specific stimulus or context, (b) anxiety response to the feared stimulus that can include a panic attack, (c) recognition that the fear is unreasonable or excessive, (d) avoidance or endurance with extreme distress of the stimulus, and (e) impairment of functioning.

Before proceeding further, it is important to note that fear and anxiety are best conceptualized as two related but distinct states (Craske, 2003; Morris, 1999). Fear involves the experience of a negative and highly arousing emotion immediately and specifically associated with aversive stimuli proximal in space and time; anxiety refers more to a diffuse negative but less arousing mood, associated both with less precise aversive stimuli that are more distant and with an assessment of one's available coping resources. From a behavioral perspective, as Craske (2003) has noted, the overt-motor fight-or-flight escape responses associated more with fear differ from the avoidance responses associated more with anxiety. 
Although a complete and thorough review of the literature differentiating the constructs of fear and anxiety falls beyond the scope of this document, a brief and summarized review reveals several important differences. First, when factor analyzing scales that measure symptoms of anxiety (and sometimes depression), two related but separate factors typically emerge: a fear factor characterized by physiological hyperarousal and a feeling of immediately impending danger, and an anxiety factor characterized by hypervigilant apprehension and a feeling of worry (Brown, Chorpita, \& Barlow, 1998; Joiner et al., 1999; Mineka, Watson, \& Clark, 1998). Second, some independence appears to exist in the heritability pattern of fear and the heritability of anxiety (Craske, 2003). Third, fear can more easily be classified as a basic emotion, involving more imagery than verbal activity, with a fairly universal pattern of facial expression and characteristic pattern of autonomic activity (Craske; 2003; Ekman, Levenson, \& Friesen, 1983); anxiety is a complex mood derived from the interface of more basic emotions with covert verbal (cognitive) appraisals, thus, being more of an affective-cognitive construct (Izard, 1992). Fourth, fear and anxiety can be differentiated based on learning mechanisms and neural substrates (Fanselow, 1994; Grillon, 2002; Grillon, 2008). Fear is more closely associated with the periaqueductal gray area and amygdala in the brain and learned as an adaptive, phasic response to conditioned cues that suggest a clear and present threat. Anxiety, on the other hand, is associated with the bed nucleus of the stria terminalis and hippocampus and learned as a generalized response to context conditioning when threat is more uncertain or unpredictable and less cued.

Relevant to the present study, fear and anxiety also have been similarly differentiated in their relation to pain (Carleton \& Asmundson, 2009). Additionally, an investigation by Rhudy and Meagher (2000) suggested fear raises (perhaps through defensive endogenous opioid- 
mediated analgesia) and anxiety lowers (perhaps through preparatory hypergivilance) pain threshold, although fear was potentially confounded with habituation through repeated exposure to noxious stimuli.

Although the present study attempted to use the terms fear and anxiety properly, blending of the two constructs remained. Grillon (2008) suggested individuals suffering from a specific phobia (typically a more fear-based disorder) can experience anxiety when anticipating a future potential encounter with the stimulus of their phobia (e.g., individuals with dental fear can anxiously await the entrance of the dentist and the insertion of dental tools into their mouths). The line between fear and anxiety becomes particularly difficult to delineate when the variables are measured over time, and one can experience anxiety in anticipation or recall of experiencing fear. Complicating matters for the present study, differentiation between the two constructs often is not made in the literature, and many authors use the terms interchangeably. To avoid inferences that went beyond the data, citations of prior research retained the authors' original language unless clearly incorrect (e.g., labeling physiological hyperarousal in response to an immediately proximal and clearly aversive stimulus as anxiety).

Prevalence and negative outcomes of dental fear. As early as the 1950s in the United States, Friedson, and Feldman (1958) reported that of the 32\% of respondents surveyed who reported dental non-attendance during the prior year, $9 \%$ cited dental anxiety-related concerns as a reason for non-attendance. Perhaps even more importantly, approximately one out of five respondents who did not receive dental care when they believed it was needed reported that dental anxiety was the reason for non-attendance. A decade later, Gale and Ayer (1969) reported that as many as 12 million Americans did not receive dental care because of psychological concerns. Of individuals surveyed via telephone by Gatchel, Ingersoll, Bowman, Robertson, and 
Walker (1983), almost 30\% admitted having a moderate or high level of fear related to dentistry. Similar to Friedson and Feldman, high levels of dental fear were associated with dental nonattendance in over half of the individuals surveyed by Gatchel et al., and nearly two-thirds of non-attendees reported dental fear was the primary reason for not visiting the dentist. Prevalence of dental fear and anxiety was evident extending into the 21 st century, as $5.8 \%$ of 1,226 originally non-anxious adult participants reported dental anxiety during the course of a 5-year longitudinal study (Maggirias \& Locker, 2002a). The consistency of dental fear also has been supported by a study which examined investigations of dental fear over the course of 50 years (Smith \& Heaton, 2003). The level of dental fear reported in 19 studies by over 10,000 participants, in spite of ever-improving dental technologies, remained relatively constant across the half-century.

One of the more consistent aspects of dental fear and anxiety is a greater likelihood of dental avoidance. In a study of dentally fearful patients, higher levels of dental fear were reported by patients who avoided dental care compared to those who did receive regular dental care (Abrahamsson, Berggren, Hakeberg, \& Carlson, 2001). Conversely, in a survey of 531 office employees in London, Liddell, and May (1984) reported that participants who reported regular dental attendance expressed significantly less dental anxiety than participants reporting irregular or no attendance. More than $20 \%$ of irregular attendees cited anxiety as the primary reason for their dental avoidance.

Unfortunately, avoidance of dental care can be associated with a variety of negative outcomes. Individuals who anxiously avoid dental care are more likely to be missing more teeth, to experience a negative impact of oral health on work and conversing with others, and to attribute adverse social outcomes to their poor oral health (Abrahamsson et al., 2001). The 
negative outcomes of poor oral health from dental non-attendance may even extend to other physical health domains, as periodontal disease has been linked to cardiovascular diseases and adverse pregnancy outcomes (DeStefano, Anda, Kahn, Williamson, \& Russell, 1993; Fowler, Breault, \& Cuenin, 2001; Kinane \& Bouchard, 2008). Thus, greater levels of dental fear and anxiety place people at risk of dental avoidance, which subsequently increases the risk of poor health outcomes.

Fear of pain and dental fear. In a chapter on dental fear, Melamed (1979) explained the uniqueness of dental fear: "there is a 'rational' component which stems from varying amounts of discomfort experienced during dental visits. Unlike most clinical phobias, dental fear may be acquired through straightforward classical conditioning... The dentist represents one of the few socially sanctioned inflictors of noxious stimulation in our culture" (p. 172). Melamed recognized the potential for pain to play a large role in the acquisition of dental fear, and research has largely supported the importance of pain's part in dental fear (Hittelman \& Bahn, 2006; McNeil \& Berryman, 1989; Scott \& Hirschman, 1982).

In a study of 34 dentally anxious and 34 control patients, Lautch (1971) reported that dentally anxious patients were more likely to have experienced a traumatic dental experience. Similarly, a greater percentage of more dentally fearful college students than less dentally fearful students reported that they had experienced pain during dental appointments early in life; less than $10 \%$ of more dentally anxious students did not report painful early experiences at the dentist (Bernstein, Kleinknecht, \& Alexander, 1979). Wardle (1982) reported that, among patients who expressed dental fear while awaiting services at a dental hospital, $76 \%$ listed pain as a reason for their fear. These results have been extended to patients who sought specialized dental services with sedation because of dental fears, as 52 of the 70 patients treated cited fear of pain as a cause 
of their dental fear (Hall \& Edmondson, 1983). Demonstrating the primacy of fear of pain as a component of dental fear, McNeil and Berryman (1989) reported that fear of pain entered first (i.e., ahead of social fears, claustrophobia, and mutilation fears) into a stepwise multiple regression equation predicting dental fear. Finally, in a study examining the learning history of dentally anxious individuals, Davey (1989) reported that individuals who reported dental anxiety were more likely to have experienced painful dental treatment. Moreover, participants who reported a prior painful dental incident but minimal dental anxiety were more likely to have experienced multiple positive dental visits before the painful visit, suggesting that conditioning effects were buffered through latent inhibition. Davey (1989) also noted, however, that this latent inhibition could be overcome by an especially painful dental experience.

Some research even indicates that dental fear and anxiety are related to exaggerated response to dental pain. In an epidemiological study of 1,422 dental patients, participants who reported greater dental anxiety were significantly more likely to report pain after dental procedures (Maggirias \& Locker, 2002b). Using a threat of shock paradigm similar to aversive conditioning procedures from animal research, Bradley, Silakowski, and Lang (2008) reported that individuals with higher dental fear displayed greater and quicker arousal responses to an acoustic startle probe during periods of cued threat of shock, suggesting greater fear of pain for participants with greater dental fear. Klepac, McDonald, Hauge, and Dowling (1980) reported that level of dental fear did not differentiate college student participants on their sensation threshold (stimulus intensity when a sensation was first reported), pain threshold (stimulus intensity when a sensation of pain was first reported), or tolerance level (stimulus intensity when a participant refused to accept any more intense stimulations) for electrical shock delivered to the arm or tooth. Participants with higher levels of dental fear, however, did rate the tooth shock, 
but not the arm shock, as significantly more painful. Dental fear influenced tooth shock pain tolerance, but not report of pain intensity, in a study of dental patients (Klepac, Dowling, \& Hauge, 1982). More dentally fearful participants had lower tolerance for tooth shock, but dental fear did not influence tolerance for arm shock. Although differing in the modality in which the difference occurred, the two studies by Klepac and colleagues indicated that individuals with dental fear reacted uniquely to dentally-relevant pain.

Although fear of pain has been identified as one important component of dental fear, it remains unclear as to how their overlap translates into associations with other variables of interest. Without such clarity, it has remained difficult to identify the degree to which fear of pain should be targeted in treatment of dental fear, as well as to establish the unique contributions of each construct in accounting for variance in other variables.

Pain, anxiety, and different dental procedures. Not all dental procedures are equal in their ability to elicit a fear or pain response. Oral surgery and tooth extraction provoke the greatest anxiety and fear responses relative to other procedures such as restorations, cleanings, or crown preparations (Minigh, Fizer, McCormick, McPherson-Canizales, \& McNeil, 2008; Stabholz \& Peretz, 1999; Wong \& Lytle, 1991). In a similar manner, dental patients who receive more invasive dental treatments (e.g., extractions, root canal treatments) have a greater probability of reporting pain, reporting pain more frequently, and reporting more intense pain (Maggirias \& Locker, 2002b). Finally, patients undergoing more anxiety-provoking dental work (i.e., root canal and extraction) predict they will experience significantly more pain than patients undergoing less anxiety-provoking procedures (Eli, Bar-Tal, Fuss, \& Silberg, 1997). As the proposed study involved studying oral surgery patients undergoing tooth extraction, the constructs of pain, fear, and anxiety were particularly relevant. 
Dental fear and memory of dental pain. Although the relation between dental pain and dental fear hardly is a one-to-one relation, memory of prior painful dental treatment plays an important role in explaining the development of dental fear and anxiety that lead to dental avoidance (Bernstein et al., 1979; Davey, 1989; Lautch, 1971). Other research suggests that individuals with greater dental fear and anxiety, likely in part based on memory of prior experience, predict more pain during subsequent dental procedures (Klages, Ulusoy, Kianifard, $\&$ Wehrbein, 2004; Wardle, 1984). Yet, the pain that patients, particularly those who are more dentally fearful and anxious, predict during dental procedures often over-estimates the pain they report experiencing initially (Earl, 1994; Eli et al., 1997; Wardle, 1984; Watkins, Logan, \& Kirchner, 2002).

One possible explanation for inaccurate prediction of dental pain, as well as related dental fear and avoidance, is inaccurate recall of prior dental pain. Memory as a construct, in general, can be quite inaccurate and subject to a variety of biases (e.g., Tversky \& Kahneman, 1974). Indeed, individuals can report with confidence memories of events that never happened when properly cued, even if they are aware of contextual cues potentially impacting their memory (Roediger \& McDermott, 1995). Although a variety of factors can influence recall of prior events, one which has received much attention in the literature is mood (Morris, 1999). Given the relation of dental fear to prediction and recall of dental pain, it is vital to understand the role mood might play in biasing the memory and expectation of dental pain. Before proceeding to a review of literature examining the mood-memory relation for dentally fearful and anxious patients, the relevant literature on mood and memory in general will be briefly reviewed. 


\section{Influence of Mood on Memory}

Depression and memory. The effect of depressed mood on memory has been the topic of numerous investigations, theoretical speculations, and review articles (Burt, Zembar, \& Niederehe, 1995; Mineka \& Nugent, 1995; Morris, 1999; Singer \& Salovey, 1988). Empirical work has ranged widely along several dimensions. For example, some studies have induced temporary mood states in student volunteers (e.g, Teasdale, Taylor, \& Fogarty, 1980), while others have focused on clinically depressed psychiatric patients (e.g., Clark \& Teasdale, 1982). Some investigations have emphasized episodic memory in asking participants to recall life events (e.g., Madigan \& Bollenbach, 1982); other investigations have used more esoteric methods, such as focusing on recall of word lists presented during an experiment, and extended generalizations to everyday memory processes (e.g., Teasdale \& Russell, 1983). Such depth and breadth of literature has allowed for both broad and specific conclusions about the influence of depressed mood on memory.

Earlier theories about depression and memory (e.g., Bower, 1981) suggested that an individual's memory could be biased by mood in several ways (Singer \& Salovey, 1988). First, recall of material should be better when mood at recall matches mood during learning (or encoding), a concept known as state-dependent recall. Second, individuals should be more likely to recall material that matches their current mood, a phenomenon referred to as recall congruency. Third, material which is congruent with mood at the time of encoding should be learned best, which can be referred to as encoding congruency. In other terms, depressed mood can become a discriminative stimulus that increases the likelihood of a recall response for material associated with depressed mood. 
Several preliminary investigations summarized by Bower (1981) supported the ideas of state-dependent recall, recall congruency, and encoding congruency. Evaluating work stimulated by or related to Bower's theories, Singer and Salovey summarized the literature in a review in 1988. Across studies that both induced mood or examined naturally occurring mood, Singer and Salovey concluded that the depression-memory relation was evident in the literature but not consistent across all studies. More specifically, support for state-dependent recall and recall congruency was mixed (encoding congruency received the most consistent support), and there was not an equal balance in the number of studies using induced moods and naturally occurring moods. Singer and Salovey also noted that a general pattern emerged across studies: depressed mood exhibited an effect more through decreasing likelihood of recall of affectively positive memories than through increasing the number of affectively negative memories recalled.

A later meta-analysis of studies investigating naturally occurring depression lent further support to Singer and Salovey (1988), finding a consistent relation between depressed mood and impaired memory for material positive in valence (Burt et al., 1995). Reviews (e.g., Mineka \& Nugent, 1995; Morris, 1999) and investigations (e.g., Mogg, Bradbury, \& Bradley, 2006) since Singer and Salovey and Burt et al. have continued to support the theory that depressed mood increases the likelihood for recall of affectively congruent material over incongruent material.

Anxiety and memory. In theory, the mood-memory congruency for depression suggested by Bower (1981) also should be true for anxiety: anxious mood should facilitate memory for material evaluated as threatening or dangerous (Mineka \& Nugent, 1995). Although some early research reported that anxious individuals more easily recalled anxiety-associated material (e.g., Nunn, Stevenson, \& Whalan, 1984), other research that did not report biased memory for anxiolytic stimuli in anxious individuals or reported poorer recall for anxiety-related material 
(e.g., Watts, Trezise, \& Sharrock, 1986) made it apparent that the effects of anxiety on memory might not be the same as those of depression (Mogg, Mathews, \& Weinman, 1987).

At least two explanations have been offered as to why memory biases in anxious individuals have been less consistent in the literature: anxious individuals attend to and process threatening information in a unique manner, and the characteristics of different anxiety disorders prohibit broad generalizations for memory biases in anxiety in general (Coles \& Heimberg, 2002). Regarding attention and information processing differences, it has been suggested that anxious individuals initially attend to threatening information in an automatic and less purposeful manner before deliberately and effortfully avoiding further elaboration of threat-relevant stimuli (Cañadas-Pérez, Nieto-Escámez, Roldán-Tapia, \& López-Crespo, 2007; Coles \& Heimberg, 2002). The two stages of processing, referred to as vigilance-avoidance, relate to implicit memory (i.e., recall of unintentionally learned material that is measured indirectly) and explicit memory (i.e., recall of consciously learned material that is measured directly), respectively. Thus, anxious individuals should demonstrate an implicit, but not explicit, memory bias. Evidence for a vigilance-avoidance effect of anxiety on memory, however, has been inconsistent and not well-supported. Anxious individuals are more likely to display memory bias for threatening material on free-recall tasks, which typically require greater elaboration during encoding, than on recognition tasks (Coles \& Heimberg, 2002). Moreover, the vigilanceavoidance model runs contrary to the tendency of anxious individuals to extensively and repeatedly ruminate on threatening information (MacLeod \& Mathews, 2004).

Research has been more supportive of the hypothesis that differences in anxiety-induced memory biases are related to differences among anxiety disorders. Particularly, panic disorder has been linked to biased recall of more threat-relevant information than neutral information 
(Coles \& Heimberg, 2002; MacLeod \& Mathews, 2004). A smaller quantity of research in posttraumatic stress disorder (PTSD) and obsessive-compulsive disorder also has indicated a memory bias. Particularly with individuals suffering from PTSD, trauma-related material may be more easily recalled, and information processing and memory for non-trauma cues may be impaired relative to controls (Kapsi, McNally, \& Amir, 1995; McNally, Metzger, Lasko, Clancy, \& Pitman, 1998). Evidence for memory bias in generalized anxiety disorders and social phobia has been less consistent. Possible reasons for differences among the disorder include the use of more externally valid stimuli for different disorders (i.e., it can be more difficult to tailor stimuli to the wide range of worry concerns of individuals with generalized anxiety), or the different nature (i.e., greater imagery, emotional experience, and specificity) of panic and trauma memories than worry or social anxiety memories (Coles \& Heimberg, 2002; MacLeod \& Mathews, 2004; Wenzel, Pinna, \& Ruin, 2004). Perhaps differences in the level and memory influences of fear and anxiety across different anxiety disorders play a role as well. Fear might enhance memory for specific cues associated with the emotion, to the detriment of other information presented simultaneously with the cue; anxiety might enhance memory for anxiolytic information through heightened vigilance.

In addition to research focusing specifically on anxiety, several investigators have suggested memory can be enhanced or strengthened when material to be encoded is associated with strong emotion. Christianson and Loftus (1991) reported more accurate memory of central details, but less accurate memory of peripheral details, for emotional events (i.e., picture of a woman after a bicycle wreck) relative to a neutral event (i.e., picture of a woman riding a bicycle). The better memory for central details of the emotional event could not be attributed simply to peculiarity, either, as memory for an unusual event (i.e., picture of a woman carrying a 
bicycle) was not enhanced. Replication and extension, with control and measurement of eye fixations (Christianson, Loftus, Hoffman, \& Loftus, 1991), further suggested that enhanced memory for central details of emotional events was not due solely to increased attention devoted to emotional stimuli. Relatedly, Schmidt and Bohannon (1988), in defending the potential for flashbulb memories (detailed memories associated with shocking information), suggested that strong emotion at the time of encoding may help create a memory that is non-state-dependent in ease of retrieval. The research of Christianson and colleagues has suggested that the relation between emotions and memory is complex, with memory neither wholly enhanced nor wholly impaired by emotion.

In summary, although the empirical support has not been as consistently strong as for depression, anxiety can have an influence on memory similar to that of depression, with anxious mood increasing the probability of recall of threatening stimuli. The likelihood of observing mood-congruent memory bias for anxiety increases when using free-recall tasks, studying individuals with panic, or utilizing more externally valid stimuli. Further, it also is important to examine the relation of anxiety and memory in investigations of dental recall, especially for more aversive procedures (i.e., tooth extraction) that may influence memory by virtue of being a particularly distinctive and emotional event for some patients (e.g., Christianson et al., 1991).

Specific phobia and memory. Specific phobia should be specially mentioned because a topic of interest in the proposed study, dental fear, can be considered a specific phobia. Discussion of studies investigating specific phobia have been notably absent from three reviews of anxiety and memory (Cañadas-Pérez et al., 2007; Coles \& Heimberg, 2002; MacLeod \& Mathews, 2004). Coles and Heimberg justified this omission by citing the heterogeneity of the specific phobias and the minimal number of studies examining memory bias in individuals with 
diagnosable specific phobia. One of the diagnostic criteria for specific phobia, though, can include a panic attack, and the threat-relevant stimuli for specific phobia might lend themselves better to a memory with more imagery and specificity (APA, 2000). Additionally, Friedlander, Marder, Sung, and Child (2004) reported that dental patients often experience panic attacks.

Overlap of anxiety and depression. The similarity of effects of anxiety and depression on memory bias represents one of many areas of overlap for the two constructs. The disorders frequently occur comorbidly, share many symptoms (e.g., sleep difficulties, irritability, fatigue), and demonstrate similar neurotransmitter dysregulation (i.e., serotonin) which respond to similar medications (Frances et al., 1992; Nutt, 1997). Correlations for anxiety and depression measured at the same time have ranged from $r=.65$ to .77 (Gençöz, 2002; Pelle, Denollet, Zwisler, \& Pedersen, 2009), and an $r=.70$ has been reported for chronic pain patients (Nelson \& Novy, 1997).

One possible explanation for the commonalities of anxiety and depression is that the two share an underlying factor: negative affect (Brown et al., 1998; Clark \& Watson, 1991; Mineka et al., 1998). Negative affect can be defined as a tendency to experience unpleasant mood states (Watson \& Clark, 1984). Although anxiety and depression can be identified as separate, specific emotions (Donahue, 2005; Watson, O’Hara, \& Stuart, 2008; Williams, Peeters, \& Zautra, 2004), individuals with anxiety and depressive disorders express a similar level of negative affect, a level significantly higher than that reported by individuals not suffering from anxiety or depression (Zinbarg et al., 1994). When measured by questionnaires, correlations between anxiety and negative affect have ranged from $r=.55$ to .74 , and between depression and negative affect from $r=.46$ to .67 (Gençöz, 2002; Pelle et al., 20009). At the diagnostic level, Watson, Clark, and Carey (1988) reported that the correlation between any anxiety disorder diagnosis and 
negative affect was $r=.32$; the correlation between a diagnosis of depression and negative affect was $r=.50$. Finally, in a factor analysis of anxiety and depression in chronic pain patients, first order factors of anxiety and depression had correlations ranging from $r=.63$ to .75 with a second order factor of negative affect.

In examining the influence of depression and anxiety on memory, and memory of dental patients specifically, it remains to be thoroughly investigated if negative affect might explain the similarity of their influence on memory. Reviews of the effects of anxiety and depression on memory have recommended studying simultaneous influence of the moods on memory (Coles \& Heimberg, 2002; Mineka \& Nugent, 1995). Research suggests negative affect influences the greater reporting of somatic complaints of anxious and depressed individuals (Barsky, 2002; Clark \& Watson, 1991; Watson \& Pennebaker, 1989). Similarly, the meta-analysis of Burt et al. (1995) indicated memory bias might be better attributed to status as a mental health patient than depression alone, hinting at a common factor across patients. Over-stimulation of the hypothalamic-pituitary-adrenal (HPA) axis also presents a common physiological pathway for depression and anxiety to influence memory through the stress of negative affect. More specifically, stress from the experience of negative mood states can stimulate the HPA axis to create excessive levels of cortisol in the body; high levels of cortisol subsequently damage the hippocampus, a brain structure important for the consolidation of memory (Blackburn-Munro, 2004; Campbell \& MacQueen, 2004; McEwen, 2001). Clearly, the effects of depression and anxiety, as well as the influence of the underlying construct of negative affect, need to be examined simultaneously in research investigating the influence of mood on memory. 


\section{Memory of Pain}

In an early review of the broad area of memory of pain, Erskine, Morley, and Pearce (1990) offered several tentative conclusions. Erskine et al. suggested that the experience of pain and subsequent recall of that pain are only modestly correlated, on average $r=.65$, and the strength of correlation varies widely from one study to the next. Recall for acute pain might be more accurate than recall for chronic or repeated but time-limited pain (e.g., headache or menstrual) because memory for a novel and salient single event relies more on episodic memory, whereas memory for a chronic and stable condition also draws on semantic memory. Most importantly for the present study, Erskine et al. reported that mood and affect can influence memory of pain. Studies reviewed revealed that pain at the time of recall biased report of previous pain, and anxiety biased memory for pain unpleasantness. Erskine et al. did note, however, that only a handful of studies had examined the mood-memory relation for pain, and expressed hope that future studies would continue the work of these earlier investigations.

Two years after Erskine et al. (1990), in a text on psychology in dental care, Eli (1992) briefly discussed the empirical literature to date dealing specifically with memory of dental pain. Overall, Eli reported that: a) higher levels of dental anxiety are associated with increased recall of dental pain, b) the recalled pain correlates more strongly with expectation of pain than actual experience of pain for more dentally anxious patients, and c) more dentally anxious patients recall incidents that are more unpleasant than those recalled by less dentally anxious patients. Thus, patient mood, particularly dental anxiety, was associated with differential recall of the pain experienced during prior dental experiences.

Eli (1992) also mentioned that results from studies of dental pain do not match those reported in studies of other types of pain (i.e., recurrent menstrual or headache). Eli noted, as 
discussed above (c.f. Melamed, 1979), that dental procedures can have an anxiety-eliciting component unique in nature compared to other potentially painful situations. Thus, studies dealing exclusively with memory for pain and unpleasantness during dental procedures will be reviewed, with a brief summary of memory for other types of pain. Also, for clarity of discussion, current pain will refer to pain experienced prior to a dental procedure, predicted pain to pain expected during a dental procedure, experienced pain to pain reported to have occurred during a dental procedure, and recalled pain to memory of pain during a previous dental procedure.

Memory of dental pain. The first investigations examining memory of dental pain were two related studies by Kent (1985) and Kent and Warren (1985). Both investigations involved asking patients presenting to a general dental practice for routine procedures to rate their dental anxiety using the Dental Anxiety Scale (DAS) and both their predicted and experienced pain using a Visual Analogue Scale (VAS). Three months later, the patients were mailed a follow-up survey and asked to complete the DAS again and use the VAS to rate their recalled pain.

Kent (1985) examined the relations among predicted, experienced, and recalled pain for the entire sample $(N=44)$, as well as for less dentally anxious patients who scored below a 7 on the DAS $(n=17)$ and more dentally anxious patients who scored above a 9 on the DAS $(n=10)$. The low anxiety patients had a significant correlation between their experienced and recalled pain scores, while the high anxiety patients had a non-significant and negative correlation. For the whole sample, there was a significant discrepancy between experienced and recalled pain, but not between predicted and recalled pain; patients both predicted and recalled more pain than experienced. The experienced-predicted discrepancy, however, was significantly greater for 
high anxiety patients relative to low anxiety patients, suggesting dental anxiety influenced the reconstructive memory process of recalling dental pain.

Further, for 87 patients who altered their report of dental anxiety scores from procedure to follow-up, neither pain experienced nor pain recalled was related to an increase or decrease in dental anxiety (Kent \& Warren, 1985). The discrepancy between predicted and experienced pain, though, did influence change in dental anxiety: patients whose dental anxiety decreased experienced significantly less pain than predicted, but patients whose dental anxiety increased did not demonstrate a significant predicted-experienced pain difference. These results highlight the importance of considering complex bi-directional influences between anxiety and pain, in which the experience of pain has less influence on mood than the experience of pain in relation to expectations.

In a third study, Kent (1989) examined patient recall of a prior dental experience before and after a scheduled appointment with a general dental practitioner. In addition to rating dental anxiety on the DAS, patients rated their current state anxiety and unpleasantness of the prior incident on a VAS. Half of the 100 patients answered the questions before their appointment, when state anxiety was significantly higher than after their appointment. Patients with greater dental anxiety rated the recalled prior experience as more unpleasant, and patients recalled the prior experience as being more unpleasant when experiencing greater state anxiety before the procedure. Both trait-like dental anxiety and state anxiety influenced the unpleasantness of a prior dental memory.

Arntz, Van Eck, and Heijmans (1990), in a sample of 40 dental patients, specifically examined the influence of a prior dental procedure on a later dental procedure that occurred an average of 10 days later. Dental anxiety was measured using the DAS, and other measures were 
recorded using a VAS. Before each procedure, patients rated their prediction of pain and anxiety during treatment, as well as current anxiety level. After both procedures, patients rated their experienced pain and anxiety, as well predictions for the next treatment (after the second procedure, a hypothesized third treatment). A follow-up survey, asking for recall of the second treatment and predictions for future treatment, was mailed to participants 5 months after the second procedure. Artnz et al. reported that, although patients with high dental anxiety did not experience more pain than patients with low dental anxiety, patients with high dental anxiety predicted more pain before both treatments and overestimated their pain. Patients with low dental anxiety were reasonably accurate in their predictions of pain. Moreover, patients with high dental anxiety recalled significantly more pain from the second treatment than they experienced, whereas patients with low dental anxiety did not. In contrast to the results for pain, patients with high dental anxiety experienced significantly greater anxiety during treatment, predicted more anxiety, and overestimated their anxiety more than patients with low dental anxiety. Artnz et al. discussed how the results of the study indicated that, despite similarities in pain experienced, prediction and recall of pain for patients with more dental anxiety remain elevated relative to those of patients with less dental anxiety. Recall, and subsequently prediction, of pain is more congruent with mood than with experience.

Using a different approach to examine mood and memory of dental pain, Beese and Morley (1993) calculated Cohen's $\kappa$ as a measure of agreement between ratings immediately after and two weeks after wisdom teeth extraction for 49 patients. Both times, patients completed a multi-dimensional rating of pain, the McGill Pain Questionnaire (MPQ), and the University of Wales Institute of Science and Technology (UWIST) Mood Adjective Checklist (UMACL). Prior to completing the questionnaires the second time, patients were cued to recall 
their mood during extraction, cued to recall their pain during extraction, or instructed to select words they remembered selecting the first time they completed the measures. Patients cued for pain had a significantly better recall of their mood $(\kappa=.73)$ than patients in the other two conditions; no other cueing effects were revealed. Overall, recall for mood was better than recall for pain, but this effect was driven largely by the enhanced recall of mood in the pain-cued condition. Whereas $\kappa$ coefficients generally fell within the "fair" range, correlations coefficients ranged from $r=.51$ to $r=.83$, leading the investigators to suggest memory for pain is inaccurate in specificity but more reliable in generalities. The results of the study also highlight the painmood-memory connection, as concentrating on recalling pain increased accuracy of mood recall. Studies also have highlighted the connection between predicted, experienced, and recalled dental pain and state anxiety at the same measurement points. Eli and colleagues (Eli, Baht, Kozlovsky, \& Simon, 2000; Eli, Schwartz-Arad, Baht, \& Ben-Tuvim, 2003) examined anxiety and pain relations in two studies of oral surgery patients. In a study of 37 patients, Eli et al. (2003) used a VAS to record pain predicted during an initial exam, pain predicted the day of surgery, pain recalled 1 week post-operatively, pain recalled 4 weeks post-operatively, and four accompanying ratings of state anxiety. At all times except 1 week after surgery, state anxiety was significantly correlated with rating of pain at the time of measurement. With a similar methodology, Eli et al. (2000) examined ratings immediately before, immediately after, and 4 weeks after surgery for 60 patients. As in Eli et al. (2003), anxiety at each time point was significantly correlated with pain ratings. Additionally, stepwise regression equations revealed that state anxiety at the time of each pain rating was most closely associated with that pain rating. In both Eli studies, ratings of pain and anxiety were significantly higher immediately prior to surgery and decreased afterwards, with a significant increase from report of experienced pain 
post-surgery to recall of pain after 4 weeks in Eli et al. (2000). These two studies highlight the congruence between patients' anxious mood and patients' prediction, experience, and recall of pain.

Muglali and Komerik (2008) reported a pattern of results fairly similar to those of Eli et al. (2000) and Eli et al. (2003), although follow-up involved only a 1 week period. In a sample of 120 oral surgery patients, anxiety was rated before, after, and 1 week after surgery using the Spielberger State-Trait Anxiety Inventory (STAI). Predicted, experienced, and recalled pain were rated on a VAS. Patient pain and state anxiety decreased from pre-operation to postoperation, but recall of pain after one week was greater than experienced pain reported immediately after surgery. Trait anxiety was significantly correlated with pain prediction and state anxiety before surgery, but not with post-operative pain or state anxiety. Finally, preoperative state anxiety and predicted pain were strongly correlated, and pain recalled after 1 week was significantly correlated with immediate post-operative state anxiety. Thus, anxiety proximal to the time of oral surgery was related to later recall of pain.

Expanding on the concept of mood proximal to oral surgery relating with later report of pain, Gedney, Logan, and Baron (2003) conducted a study examining recall of pain intensity and pain unpleasantness both 1 week and 18 months after root canal therapy in 49 patients. Immediately before treatment, patients rated their state and trait anxiety using the STAI and their prediction of pain intensity and unpleasantness using a VAS. After surgery, patients rated experienced pain using a VAS. Follow-up recalled pain ratings at 1 week and 18 months were collected via a phone interview using a 5-point numeric rating scale (NRS). Four hierarchical regression equations were constructed to explain the variance in 1-week and 18-month recalled pain intensity and unpleasantness; state anxiety, trait anxiety, predicted pain intensity and 
unpleasantness, experienced pain intensity and unpleasantness, and 1-week recalled pain intensity and unpleasantness (in the case of 18-month recalled pain intensity and unpleasantness) were entered as predictor variables. Only 1-week pain intensity recall was significantly related to pain experienced during surgery, specifically pain intensity. All other recalled pain was significantly associated with pre-treatment state anxiety. Additionally, 18-month recalled pain unpleasantness was associated with recalled pain unpleasantness at 1 week. The results of Gedney et al. (2003) highlight the important influence anxiety during encoding can have on recall of dental pain, as well as the reconstructive process of memory, as recall of unpleasantness at one time point had an influence on recall of unpleasantness at a later time point.

Most relevant to the proposed study is an investigation by McNeil et al. (2010), as the proposed study is a programmatic extension of this prior project. A final sample of 152 patients presenting to the Oral and Maxillofacial Surgery Clinic of the West Virginia University School of Dentistry for emergency tooth extraction were recruited to participate. While seated in the operatory prior to surgery with only local anesthesia, patients used a 0 to 100 NRS to rate their state dental pain, state anxiety, predicted dental pain, and predicted anxiety. Patients also completed the Dental Fear Survey (DFS) and Short Form - Fear of Pain Questionnaire (SF-FPQ) prior to extraction. Immediately after extraction, patients rated their pain and anxiety experienced during the most painful part of the extraction. Participants were mailed a follow-up survey 2 weeks later, asking them to recall their pain and anxiety during the most painful part of the extraction. A total of 90 patients returned the final survey in exchange for an incentive of \$10 USD, and data were complete for 79 participants. Using a sex-based split-half of DFS scores, participants were grouped into a high and low dental fear group. A multivariate analysis of variance (MANOVA) approach to repeated measures revealed a significant effect of dental 
fear on both pain and anxiety ratings. More dentally fearful patients reported more current pain prior to extraction, although across participants experienced pain was significantly less than current pain prior to extraction and pain recalled after two weeks. Regarding anxiety, participants in the high dental fear group reported significantly greater current state anxiety before extraction, predicted more anxiety, and recalled more anxiety, but did not experience a significantly different level of anxiety during extraction than participants in the low dental fear group. Patients in the high dental fear group also recalled significantly more anxiety than they reported immediately after extraction. Additionally, fear of pain and dental fear were significantly correlated, and the correlation between ratings of anxiety and pain increased significantly over time. Regression equations further suggested experienced pain and recalled anxiety were the variables most closely associated with recalled pain, and trait dental fear, experienced anxiety, and recalled pain were the variables most closely related to recalled anxiety. Overall, the results of McNeil et al. (2010) suggest that greater dental fear is related to increased current pain prior to extraction and greater state anxiety; recall of pain was exaggerated across groups. Also anxiety and pain were related states, becoming assimilated in memory over time.

Expectation of dental pain and unpleasantness. Studies examining predicted dental pain also can offer support for a mood-memory bias. Predictions of pain are typically based at least in part on past experience, and Artnz and Van den Hout (1988) have suggested that prediction of pain demonstrates a strong recency effect. Over-prediction of aversive stimuli, and painful stimuli in particular, can serve an adaptive function by allowing an individual to avoid stimuli which might exceed their tolerance level (Arntz \& Lousberg, 1990; Artnz, Van Eck, de Jong, \& Van den Hout, 1990; Rachman \& Bichard, 1988). Over-prediction requires multiple corrective 
experiences before accuracy of prediction increases, however, and over-prediction can become maladaptive when escape and avoidance (i.e., two responses typical of patients with greater dental fear and anxiety) prevent learning and improved accuracy of prediction following exposure to an aversive stimulus.

Kent (1984), in a study of dental anxiety and pain predicted prior to and experienced during routine dental work, measured the dental anxiety (using the DAS) and pain reports (using a VAS) of 76 patients attending the offices of general dental practitioners for either a check-up or restoration (i.e., "filling"). Comparing patients in the highest third of dental anxiety scores to patients in the lowest third of dental anxiety scores, Kent reported that the more dentally anxious patients predicted more pain than less dentally anxious patients, particularly when they were to receive a restoration. The two groups did not differ in the discrepancy between the predicted and experienced pain when undergoing a routine check-up, but a significant discrepancy existed between predicted and experienced pain for more dentally anxious patients, relative to less anxious patients, when having a tooth restored. It was suggested that highly anxious patients, in their overestimation, might have recalled more painful prior visits in a manner congruent with their anxious state.

Wardle (1984) reported a pattern of results very similar to Kent (1984), examining a group of 49 patients in an oral surgery clinic undergoing tooth extraction. Patients rated their waiting room anxiety, prediction and experience of injection pain, and prediction and experience of extraction pain on a 5-point scale. All patients predicted significantly more pain than they experienced, both for the injection and the extraction. Patients with higher anxiety ratings predicted, but did not experience, greater pain than patients with lower anxiety ratings. Also, patients with greater anxiety prior to extraction showed a larger discrepancy between their 
predicted and experienced pain scores. Thus, patients with greater dental anxiety tend to be particularly inaccurate in their predictions of pain.

Memory of other acute pain. Studies of other types of acute pain also offer support for a bias in recall of dental pain. Specifically, these other studies can be grouped into three categories: memory of medical-related pain, memory of labor and delivery pain, and memory of experimentally-induced pain.

Several studies of memory for medical pain have provided additional support for the mood-memory bias of dental pain by demonstrating biased recall, particularly mood-biased recall, for other acute and health-related pain. Without regard to emotional state, Redelmeier and Kahneman (1996) reported that recall of pain varied greatly for colonoscopy and lithotripsy patients; recall of pain was significantly related to the peak pain intensity and the pain intensity during the end of the procedure, but recall was not significantly related to procedure duration. A later investigation questioned whether recall of pain experienced during vascular surgery reflects semantic memory as much as it reflects episodic memory (Terry, Niven, Brodie, Jones, \& Prowse, 2008). Individuals who only read informational leaflets about surgery gave two similar qualitative descriptions of vascular surgery pain, over a period of 4 to 6 weeks, compared to patients asked to report actual experienced and recalled vascular surgery pain. Additionally, in both children receiving chemotherapy through lumbar puncture and adults presenting to the hospital for cardiac chest pain, greater anxiety and distress when in pain was associated with inflated recall of pain 1 week (children) and 6 months (adults) later (Chen, Zeltzer, Craske, \& Katz, 2000; Everts et al., 1999).

Research on memory of pain in relation to childbirth has been split, with some studies suggesting women can be accurate in their recall of childbirth pain after even 3 to 4 years 
(Niven, 1988; Rofé \& Algom, 1985), but other investigations suggesting women tend to recall less pain (Lowe \& Roberts, 1988; Norvell, Gaston-Johansson, \& Fridh, 1987). In a review of the literature, Niven and Murphy-Black (2000) reported that although significant methodological problems across most studies limited ability to draw strong conclusions, some aspects of labor pain can be decreased during recall or perhaps not encoded in memory. In general, childbirth represents a unique form of pain that can be accompanied by a strong emotional response, much like dental pain. Although the valence of the emotion during labor and delivery can be opposite to the valence of emotion during dental procedures, that a biased recall of pain also can occur for birthing pain suggests a common mood-memory link (c.f., Christianson \& Loftus, 1991; Christianson et al., 1991).

Finally, studies of laboratory-induced pain have offered, through increased internal validity, evidence for potential bias in recall of pain. In a series of psychophysical experiments with varying intensities of heat and durations of time, Rainville, Doucet, Fortin, and Duncan (2004) reported that sensory memory for pain intensity quickly is consolidated into an imprecise but more stable short-term memory of categorical information. Two studies by Gedney and Logan $(2004 ; 2006)$ suggested that negative affect at the time of a forehead cold-pressor task was related to exaggerated recall of pain after 6 months and greater report of pain on a second forehead cold-pressor task 9 months later. Gedney and Logan (2006) also demonstrated the important influence of recall on future behavior, as 6 month recall of pain intensity during a cold-pressor task was more strongly associated with reported pain intensity on a second coldpressor task 9 months later than pain intensity experienced during the first cold-pressor task. That is, recall of prior experience was more closely related to future behavior than past behavior on the same task. 
Memory of chronic pain. Important differences exist between acute pain and chronic pain (Gatchel \& Epker, 1999; Wolff, 1983). Acute pain typically serves an adaptive and natural function by signaling that a somatic insult has occurred and needs to be addressed. Chronic pain, however, persists for a longer duration ( $\geq 3$ to 6 months) than acute pain and occurs without continued evidence of physical injury (Turk, Monarch, \& Williams, 2004; Wolff, 1983). Most relevantly, recall of chronic pain typically involves rating a relatively stable experience over time, rather than a distinct episode of acute pain, and presents a greater opportunity for an individual's semantic memory of his or her pain condition to exert as much influence as his or her episodic memory (Erskine et al., 1990). Still, similarities across studies of recall of acute and chronic pain highlight general effects of mood on memory of pain.

Chronic pain patients tend to overestimate their recall of pain, relative to baseline ratings, and the level of pain recalled more closely matches predicted than experienced pain (Linton \& Götestam, 1983; Linton \& Melin, 1982). Moreover, greater pain at the time of recall is associated with higher levels of recalled pain (Bryant, 1993; Eich, Reeves, Jaeger, \& GraffRadford, 1985; Stone, Schwartz, Broderick, \& Shiffman, 2005). Finally, the biased recall of pain stimuli in chronic pain patients has been associated with depressed mood, whereby the experience of emotional distress in addition to chronic pain particularly is associated with increased recall of pain (Jamsion, Sbrocco, \& Parris, 1989; Pincus, Pearce, McClelland, \& Isenberg, 1995).

\section{Statement of the Problem}

More thorough investigation of affective influences on recall of dental pain could prove important for a number of reasons. First, despite advances in analgesic medications and techniques, societal levels of dental fear have remained consistent over the past 50 years (Smith 
$\&$ Heaton, 2003). It is increasingly apparent that pain must be conceptualized from a biopsychosocial model (Asmundson \& Wright, 2004; Gatchel, 1999), in which pain is experienced as a combination of biological, psychological, and social factors. In short, the construct of pain and relevant psychological constructs, particularly mood, are intertwined (Chapman, 2004; Robinson \& Riley, 1999), and research must continue to investigate how psychological factors influence the experience of pain and vice versa. Second, better understanding of how specific psychological constructs influence pain responses, including recall of pain, will inform the design of interventions intended to minimize the aversiveness of dental procedures and to improve the accuracy of pain recall. Factors that are closely related to memory of pain could be targets of efforts intended to reduce exaggerated recall of pain. Third, decreased aversiveness during dental procedures and more accurate recall of dental pain could minimize conditioning of dental fear and anxiety, reduce exaggerated prediction of future dental pain, and prevent escape/avoidance of dental procedures important for maintaining good oral health.

Research has suggested a link between fear and anxiety and memory of dental pain, such that more dental pain is recalled after a delay of at least two weeks (McNeil et al., 2010), and increased prediction and recall of pain is even greater for individuals who are higher in dental fear or have greater state anxiety at the time of dental treatment (Arntz et al., 1990; Gedney et al., 2003; Kent, 1985). While incorporating measures of fear and anxiety, prior investigations of prediction and recall of dental pain have seldom included measures of depression and negative affect. Yet, depression can influence memory (Singer \& Salovey, 1988), and negative affect might represent an underlying factor influencing both depression and anxiety in memory (Brown et al., 1998; Clark \& Watson, 1991), as well as exaggerated recall of somatic complaints 
(Barsky, 2002). Preliminary research also has suggested a direct link between negative affect and exaggerated recall of pain (Gedney \& Logan, 2004; 2006). Even when anxiety and other moods are more thoroughly investigated, rarely are state levels of these constructs measured during a dental procedure and during recall. Research on mood and memory, however, suggests that mood at the time of encoding and at the time of retrieval can influence memory (Singer \& Salovey, 1988). Due to the limited work examining the influence of state anxiety, depression, and negative affect at both the time of dental work and recall, a single investigation that examines these variables simultaneously is needed.

In addition to examining the influence of different moods on prediction and recall of pain for dental patients, special attention should be paid to the impact of mood on prediction and recall of dental pain for patients endorsing greater levels of dental fear. Patients expressing higher levels of dental fear are likely to experience greater levels of state anxiety at the dental appointment (e.g., McNeil et al., 2010), as well as have more exaggerated prediction and recall of dental pain (Arntz et al., 1990; Kent, 1985). In informing future treatment for dentally fearful patients, it is worthwhile to examine if other moods besides anxiety have an influence on prediction and recall of dental pain for patients with heightened dental fear.

One mechanism through which dental fear might exert an influence on prediction and recall of dental pain is current mood state. State anxiety at the time of prediction and recall is significantly associated with prediction and recall of pain (Eli et al., 2000; Eli et al., 2003). It is important to examine if state anxiety, along with other mood states, mediates the relation between dental fear and prediction or recall of dental pain. Elucidation of a mediation effect would provide a clear target for interventions hoping to reduce the impact of dental fear on anticipation or memory of dental pain. 
Finally, as fear of pain is a major component of dental fear (Bradley et al., 2008; McNeil \& Berryman, 1989), it is important to determine the similarities and differences of the two constructs in their influence on prediction of, recall of, and mood associated with dental pain. If fear of pain plays a large and overlapping role with dental fear in these domains, it would be suggestive of a specific treatment target when attempting to reduce and treat pathological dental fear. At the same time, similar or dissimilar patterns of influence for dental fear and fear of pain would offer further information regarding the relation of the two constructs.

\section{Hypotheses}

The current investigation of the influence of anxiety, depression, and negative affect on recall of dental pain had three major hypotheses:

1. State anxiety, depression, and negative affect immediately prior to oral surgery and during recall would be more strongly associated with dental pain predicted and recalled than pain experienced during oral surgery. Specifically, dental patients who reported more anxiety, depression, and negative affect would predict and recall greater levels of pain. Previous research indicates state anxiety is more strongly associated with recalled pain than experienced pain (Gedney et al., 2003), and related research suggests other mood states also can influence and bias memory (e.g., Singer \& Salovey, 1988). It also was hypothesized, as with state anxiety and report of pain in Eli et al. (2000) and Eli et al. (2003), that report of greater anxiety, depression, and negative affect would be related to greater report of current dental pain prior to oral surgery. Additionally, it was hypothesized that trait dental fear and fear of pain assessed pre-surgery would be associated with state mood pre-surgery (McNeil et al., 2010), as well as with current pain (McNeil et al., 2010), predicted pain (Arntz et al., 1990), experienced pain (Klepac et al., 
1980), and recalled pain (Arntz et al., 1990). Finally, it was expected that current pain would influence prediction of pain because of the recency effect in pain report (Artnz \& Van den Hout, 1988), and predicted pain in turn would influence experienced and recalled pain (Kent, 1985).

2. State anxiety, depression, and negative affect would be more strongly related to predicted and recalled pain during oral surgery for patients who endorsed greater levels of dental fear and fear of pain. That is, the interaction of trait-like dental fear and fear of pain with mood would explain additional variance in predicted and recalled pain during oral surgery, above and beyond variance explained by dental fear, fear of pain, or mood alone. Past studies (Arntz et al., 1990; Kent, 1985; McNeil et al., 2010) have revealed higher levels of state anxiety, predicted pain, and recalled pain for patients with greater dental fear. It was expected that increased reporting of unpleasant mood would be more likely to bias prediction and recall of pain for dental patients already indicating a greater likelihood to experience the aversive state of fear in association with dental stimuli.

3. Mood at the time of verbal report would serve as a partial mediator through which the factors of dental fear and fear of pain influenced prediction and recall of pain during oral surgery. State anxiety, depression, and negative affect immediately prior to oral surgery would mediate the relation of dental fear and fear of pain with pain predicted before oral surgery and pain recalled one month later. As state anxiety is strongly related to prediction and recall of dental pain (Eli et al., 2000; Eli et al., 2003), it was important to explore if moods are the more temporally proximal variables through which the higher order constructs of dental fear and fear of pain influence pain responding. 


\section{Method}

\section{Overview of Research Design}

The experimental design replicated and extended a prior study by McNeil et al. (2010). In addition to information about mood at the time of tooth extraction, participants were asked about their mood at the time of recall. The design involved an initial data collection with participants presenting for tooth extraction to the West Virginia University School of Dentistry Oral and Maxillofacial Surgery Clinic. A follow-up component of the study occurred for each participant one month after his or her initial participation at the clinic. All participants with complete data were included in analyses, which involved path analysis models. The research protocol was approved by the West Virginia University Institutional Review Board, and informed consent was gained from all participants.

\section{Participants}

Based on the recommendation of Thompson (2000), a sample of at least 100 participants was required to have a ratio of participants to measured variables of at least 10:1, with 10 being the most measured variables in the initial path analysis models. As 100 was the recommended minimum and it was necessary to account for attrition and unusable data, 455 patients were approached for participation in clinic. A total of 354 patients agreed to participate, and a final sample of 157 participants with complete data was recruited from patients presenting to the West Virginia University School of Dentistry Oral and Maxillofacial Surgery Clinic for tooth extraction. In order to be eligible to participate, patients needed to be at least 18 years of age (to provide informed consent) and be able to respond to questions about the oral surgery experience immediately following tooth extraction (i.e., patients unable to respond to investigator inquiries because of anesthetic or amnesic effects of medications received were excluded from the study). 
Patients who had a pervasive developmental disability, were overtly psychotic, or were not functionally literate to complete questionnaires were excluded. Eligible patients were approached about participation after entering the dental operatory. An investigator briefly explained the study to patients before asking them to read an informed consent and protected health information (PHI) form. All participants were debriefed in the operatory, and all participants who returned a final, mail-in assessment form received \$10 USD for their participation. See Appendix A for a flow chart of study participants describing how many patients were approached to participate, completed the oral surgery clinic portion of the study, completed the follow-up survey, and were included in the final sample. Reasons for patient exclusion at each stage are listed as well.

\section{Measures}

Dental Fear Survey. A 20-item measure, the Dental Fear Survey (DFS) assesses how much an individual fears different situations and stimuli associated with dental services (Kleinknecht, Klepac, \& Alexander, 1973). Although some questions relate more to contextual anxiety responses, the majority relate to more specific, cued fearful responses; thus, the term dental fear is used to refer to the measure. Participants rated their typical reaction to the situation or stimulus described by each item on a scale of 1 to 5 . Total scores can range from 20 to 100 , and higher scores indicate greater dental fear. In prior research with highly dentally fearful individuals (Johansson \& Berggren, 1992; Moore, Berggren, \& Carlson, 1991), the average DFS score has ranged from 75.8 to 76.6 ( $S D=12.9$ to 14.3 ); in contrast, the average DFS score for a large student sample was $M=38.6(S D=13.9)$ (McGlynn McNeil, Gallahger, \&Vrana, 1987). The average DFS score in the prior study of WVU oral surgery patients by McNeil et al. (2010) was $M=45.5(S D=19.0)$. In a large student sample, internal consistency reliability was high $(\alpha$ 
$=.95)$, and test-retest reliability was good over the course of 8 to 13 weeks $(r=.88)$ (McGlynn et al., 1987). Kleinknecht and Bernstein (1978) reported that individuals who scored a 4 or 5 on DFS item 20 (an item rating general dental fear which correlates strongly with the rest of the scale, $r=.89$ ), compared to individuals who scored a 1 or 2 , reported more pain during dental procedures, did not demonstrate as consistent a decreased palmar sweat response during the dental situation, and displayed more general movement activity in the waiting room. The DFS demonstrated the greatest predictive validity for avoidance behavior: patients lower in dental fear missed significantly fewer $(z=2.81, p<.05)$ scheduled dental appointments $(7.82 \%)$ than patients higher in dental fear (23.53\%). See Appendix B for a copy of the DFS.

Short Form - Fear of Pain Questionnaire. The Fear of Pain Questionnaire-III (FPQ-III), developed by McNeil and Rainwater (1998), is a 30-item assessment of how much an individual fears the pain associated with a variety of painful situations. Participants rate each situation on a 1 to 5 scale, and higher scores indicate greater fear of pain. The FPQ-III has demonstrated excellent internal consistency $(\alpha=.92-.95)$, as well predictive validity for identifying participants who escaped or avoided a pain task. The FPQ-III has demonstrated good convergent validity with the Pain Anxiety Symptoms Scale $(r=.34)$ compared to the trait version of the State-Trait Anxiety Inventory $(r=.17, z=2.19, p<.05)$ (Roelofs, Peters, Deutz, Spijker, \& Vlaeyen, 2005). Finally, in a study by McNeil and Berryman (1989), a preliminary version of the FPQ-III, the FPQ-I, significantly accounted for approximately $13 \%$ of the variance in dental fear (measured by the DFS) in the first step of a stepwise multiple regression analysis. The FPQI total score and the DFS total score also demonstrated some overlap $(r=.36)$, indicating the constructs are related but separate. 
For brevity and efficiency, the current study used the 9-item short form of the FPQ-III, the SF-FPQ (Kennedy \& McNeil, 2001). Total scores can range from 9 to 45 . Previously, patients undergoing tooth extraction at the WVU Oral Surgery Clinic had an average SF-FPQ score of $M=24.6(S D=7.5)($ McNeil et al., 2010). The SF-FPQ has good internal consistency reliability $(r=.86)$; its total score correlates strongly with FPQ-III total score $(r=.77)$, and it maintains a factor structure similar to the FPQ-III. The SF-FPQ also has demonstrated an appropriate level of overlap $(r=.51)$ with dental fear, as measured by the DFS (McNeil et al., 2010). See Appendix C for a copy of the SF-FPQ.

Center for Epidemiological Studies Depression Scale - Revised. The Center for Epidemiological Studies Depression Scale Revised (CESDR) provides a 20-item assessment of symptoms of depression (Eaton, Smith, Ybarra, Muntaner, \& Tien, 2004; Radloff, 1977). Participants responded to each item, representing a symptom of depression, by indicating on a 5point scale how often they experienced the symptom during the past week (ranging from "rarely or none of the time (less than one day)" to "nearly every day for two weeks"). Total scores can range from 0 to 80 . The CESDR has demonstrated good internal consistency reliability across a variety of samples $(\alpha=.87-98)$. Eaton et al. (2004) reported a mean CESDR score of 17 for a small $(N=27)$ sample of East Baltimore residents, and an average score of 35 for patients in a psychiatric hospital serving the same population of East Baltimore residents.

Additionally, the CESDR is derived from the original CES-D, which has demonstrated good internal consistency reliability with both general population $(\alpha=.84-.85)$ and psychiatric patient samples $(\alpha=.90)$. The CESDR and original CES-D also are closely correlated, $r=.88$ (Eaton et al., 2004). Although designed to assess current depression, which is expected to naturally fluctuate for a variety of reasons, the CES-D has shown test-retest reliability of $r=.51$ 
to .67 over a 2 to 8 week period and a test-retest reliability of $r=.32$ to 54 over a 3 to 12 month interval. Weissman, Sholomskas, Pottenger, Prusoff, and Locke (1977) reported that acutely depressed individuals scored much higher on the CES-D $(M=38.10, S D=9.01)$ than community individuals $(M=9.10, S D=8.60)$. Similarly, Radloff $(1977)$ reported community sample norms ranging from 7.94 to $9.25(S D=7.53$ to 8.58$)$. CES-D scores also correlated with clinician ratings of depression using the Hamilton Rating Scale $(r=.49-.85)$ and with patient self-report of psychiatric outpatient behavior using the Symptoms Checklist $(r=.72-.87)$. See Appendix D for a copy of the CESDR.

Positive and Negative Affect Schedule. A 20-item questionnaire developed by Watson, Clark, and Tellegen (1988), the Positive and Negative Affect Schedule (PANAS) assesses positive and negative affect across a range of time frames, depending on the instruction wording. Participants indicated on a 5-point scale (from "very slightly or not at all" to "very much") how well each of 20 adjectives describes how they feel, with higher scores indicating greater positive and negative affect. Internal consistency reliability ranges from $\alpha=.86$ to .90 for positive affect and from $\alpha=.84$ to .87 for negative affect. Test-retest reliability over eight weeks was $r=.68$ for positive affect and $r=.71$ for negative affect when a time frame of "in general, that is, on average" was used. When a momentary time frame was used, as in the present study, test-retest reliability was $r=.54$ for positive affect and $r=.45$ for negative affect. Additionally, when the PANAS scales were compared to responses to a set of mood terms reported by Zevon and Tellgen (1982), convergent correlations ranged from $r=.89$ to .95 and discriminant correlations ranged from $r=-.02$ to -.18 . Further, Crawford and Henry (2004) found the PANAS to be reliable and valid in a large, non-clinical sample in the United Kingdom, and Ostir, Smith, Smith, and Ottenbacher (2005) found the PANAS was a reliable assessment with patients who received 
medical inpatient rehabilitation. In the present study, participants completed the entire PANAS, but only the negative affect subscale was included in analyses. The average negative affect scale score for a student sample in Watson et al. (1988) was $M=14.8(S D=5.4)$; average negative affect scale scores for Veterans Affairs substance abusers and psychiatric inpatients, on the other hand, have been reported as $M=23.7(S D=10.1)$ and $M=21.1(S D=9.0)$, respectively (Watson \& Clark, 1994). See Appendix E for a copy of the PANAS.

Numerical rating scale. A numerical rating scale (NRS) was used to measure participant report of pain and anxiety. The term anxiety was used, as opposed to fear, as patients made ratings in the context of the dental operatory and at home, in anticipation of potential (but not yet specifically cued or identified) future threat. Participants rated their pain and anxiety verbally on a scale of 0 to 100, using the anchors "no pain" or "no anxiety" to "most intense pain you can imagine" or "most intense anxiety you can imagine." Price, Bush, Long, and Harkins (1994) reported that although a NRS does not display true ratio properties, it does demonstrate internal consistency across experimental and clinical pain. Additionally, the correlation between a visual analogue scale (VAS; which has ratio scale properties) and 0 to 100 NRS scores in previous research has been high $(r=.86)$ and similarly influenced by anxious or depressed mood (Kremer, Atkinson, \& Ignelzi, 1981). In prior research with WVU Oral Surgery Clinic patients undergoing tooth extraction (McNeil et al., 2010), average current pain was $43.6(S D=36.6)$, average predicted pain was $35.3(S D=32.4)$, average experienced pain was $28.2(S D=32.5)$, and average recalled pain after two weeks was $35.2(S D=34.2)$. Additionally, average presurgery state anxiety was $34.8(S D=35.3)$.

A NRS offers advantages which warranted its inclusion and primacy of use in the present study. First, some patients (as high as 11\%) have difficulty understanding how to report pain on 
a VAS, compared to $2 \%$ for a NRS (Kremer et al., 1981). Second, both physicians and patients report a preference for a NRS over a VAS, and the relative simplicity of the NRS favors its dayto-day use in medical and dental contexts (Kremer et al., 1981; Price et al., 1994). Third, use of both a VAS and NRS allows for comparison of results from the present study to results from a wider range of other studies using either scale. See Appendix F for a copy of the different NRSs.

Visual analogue scale. A visual analogue scale (VAS) also was used to measure participant report of pain and anxiety on a $100 \mathrm{~mm}$ dolorimeter continuum with the same anchors as the NRS. The VAS has ratio scale properties and high $(r=.97)$ test-retest reliability (length of time not provided) for measurement of laboratory-induced pain between two experimental sessions (Price et al., 1994; Price, McGrath, Rafii, \& Buckingham, 1983). Price et al. (1994) and Price et al. (1983) used logarithmic functions to mathematically demonstrate the internal consistency of the VAS by matching VAS ratings of experimental pain and clinical pain. Additionally, VAS responses have been correlated with physician rating of improvement for pain patients undergoing treatment $(r=.70$; Price et al., 1983) and with total scores from both the long $(r=.73-.87)$ and short $(r=.78-.85)$ form of the McGill Pain Questionnaire for postsurgical patients (Melzack, 1987).

Previous research with patients undergoing periodontal or endodontic procedures using a VAS for ratings of pain or anxiety have produced average predicted dental pain scores ranging from 36.9 to 48.0 , average experienced dental pain ranging from 24.2 to 24.8 , average recalled dental pain ranging from 22.9 to 27.5 , average pre-surgery state anxiety ranging from 34.9 to 55.5, and average state anxiety at four week recall ranging from 11.6 to 11.8 (Eli et al., 2000; Eli et al., 2003; Gedney et al., 2003). See Appendix G for a copy of the different VASs. 


\section{Procedure}

Oral surgery clinic. See Appendix H for a flow chart representing the different time points of data collection and what data were collected during each assessment period. After entering the operatory and sitting in a dental chair, prior to receiving treatment, participants were approached by the primary investigator or a trained research assistant. Participants under 18 years of age, with pervasive developmental disability, or displaying overt psychotic symptoms were screened out of the study before the researcher explained the study to the patient. Patients who declined participation were asked the reason for their declination, and patients who agreed to participate were given forms providing information about their rights as participants and confidentiality of their protected health information. After the researcher explained the forms verbally to the patient, informed consent was gained. Information regarding patient mailing address, phone number(s), and email address also was obtained to allow for delivery of a followup survey.

Next, the researcher conducted a brief demographic interview with the patient. Participants were asked their gender, age, sex, race/ethnicity, what medications they were currently taking, non-dental current acute pain (i.e., lasting $<6$ months), current chronic pain (i.e., lasting $\geq 6$ months), history of oral surgery (i.e., tooth extraction, root canal, gum surgery), and duration of current dental pain. Following the demographic interview, patients rated current dental pain and how much pain they predicted during surgery using a VAS and NRS. The participants also rated their pre-surgery, current level of anxiety using a VAS and NRS, current level of positive and negative affect using the PANAS, and current level of depression using the CESDR. Functional literacy was assessed by asking participants to read the instructions and first item of the PANAS; participants who could not read the instructions or respond appropriately to 
the first item were excluded from the study. Additionally, to measure fear of pain and dental fear, patients completed the SF-FPQ and DFS.

Immediately after surgery, patients rated experienced dental pain during the most painful portion of the procedure using a VAS and NRS. At this point, participants unable to respond because of anesthetic or amnesic effects of medications received were excluded from the study. Information also was collected from the clinic staff regarding duration of the procedure, who performed the procedure (i.e., student, graduate, faculty), number and location of teeth extracted, reason for extraction, whether surgery or incision occurred as part of the extraction, medications used during the procedure, initial anesthetics, re-injection of initial anesthetic, additional local anesthetics, type and location of initial nerve block, and additional nerve blocks.

Follow-up. Follow-up surveys were mailed to participants one month after their extraction. This length of time represented an intermediate interval relative to previous research in which patient recall of pain was assessed after as short a duration as 1 or 2 weeks (Gedney et al., 2003; McNeil et al., 2010) or after as long a duration as 3 months (Kent, 1985) or even 18 months (Gedney et al., 2003). The follow-up survey asked participants to report their current level of negative affect using the PANAS, current level of depression using the CESDR, current level of anxiety using a VAS and NRS, and current level of dental pain using a VAS and NRS. Information about diagnosis and symptoms of "dry sockets," or alveolar osteitis (i.e., sharp and sudden pain 2 to 5 days following extraction due to inflammation of the alveolar bone), and any follow-up with the dentist (or other medical or dental providers) was collected as well.

Additionally, participants reported the level of pain they recalled experiencing during the most painful part of the extraction using a VAS and NRS. Participants who did not respond to the follow-up survey by one week after the one month anniversary of their extraction received a 
reminder telephone call and email, and participants who had not responded by two weeks after their one month anniversary were mailed a second follow-up survey. After the investigator received a participant's completed survey, payment of \$10 USD was mailed to the participant, along with a letter of thanks.

Results

\section{Analysis Plan}

Hypothesis 1. To test the first hypothesis of the study, two path analysis models, derived from the relations specified by the hypothesis, were examined using AMOS version 6.0. See Appendices I and $\mathrm{J}$ for graphic representation of the models (with error variances not included). One model (Appendix I) included the measures of anxiety and depression, and the other (Appendix J) included the measures of negative affect. Hypothesized relations among variables were represented by lines, or paths, connecting the variables. Absence of a path between two variables indicated no hypothesized significant relation. Examination of model fit, subsequent model modifications, and relations among variables in the final models allowed for conclusions regarding the relations specified by the hypothesized models.

Interpretation of path analysis models involves two general steps (Klem, 1995; Klem, 2000; Tabachnick \& Fidell, 2007). First, one must examine model fit, which refers to how well the relations among variables specified by the model match the relations present in the data. The more closely the hypothesized model approximates the reality represented by the data, the better the fit of the model. Mathematically, fit can be determined by comparing the correlation matrix generated by a model (the implied correlation matrix) to the sample correlation matrix (the observed correlation matrix) and to matrices generated by other hypothetical models (such as models presuming independence among all variables). 
As Klem (2000), Tabachnick and Fidell (2007), and Thompson (2000) have noted, a variety of statistics can be used to assess model fit. Some indices calculate the proportion of variance accounted, some compare the fit of the estimated model to a related model, some are based on residuals, and some give credit for parsimony by accounting for the number of parameters estimated to achieve fit. Not all indices will agree, and "the researcher should be guided by the preponderance of the evidence" (Klem, 2000, p. 244). The following indices of fit were used in the present study: $\chi^{2}$ (smaller values desired, with $p>.30$ ), a measure of the difference between observed and implied correlation matrices; $\chi^{2} / \mathrm{df}$ (values $<2$ desired); Goodness of Fit Index (GFI, values > .95 desired), a measure of the proportion of variance accounted for by the estimated matrix (much like $R^{2}$ in a linear regression equation); Standardized Root Mean Square Residual (SRMR, values $<.05$ desired), a measure of the average differences between the observed and implied variance-covariance matrices; and Comparative Fit Index (CFI, values $>.95$ desired), a measure accounting for sample size that compares model fit to a model that presumes independence of the variables. When it was not possible to calculate the GFI or SRMR because of missing data, as with the additional variables used in exploratory models, the Incremental Fit Index (IFI) and Root Mean Square Error of Approximation (RMSEA) were used. The IFI (values $>.95$ desired) also compares model fit to a model that presumes independence of the variables, and the RMSEA (values $<.06$ desired) focuses on population fit and compares model fit to a model in which all variables are related.

As fit of the hypothesized model often is not as good as desired, the initial model may be modified by changing the relations specified among model variables. Commonly, path model modifications include adding paths to indicate a significant relation or removing paths to suggest no significant relation; variables may be added or removed as well. Modification indices 
provided by AMOS output suggest paths that, if added, would significantly improve model fit as measured by $\chi^{2}$, and non-significant paths may be dropped to improve model fit by increasing parsimony. Ultimately, model modifications must be driven by research and theory, not statistics alone.

After good model fit has been established, the second step of interpretation is to examine the relations among variables (Klem, 1995; Klem, 2000; Tabachnick \& Fidell, 2007). These relations were calculated using Maximum Likelihood Estimates (MLEs), as MLE procedures give the best parameter estimates (Raykov, Tomer, \& Nesselroade, 1991) and are robust to violations of normality (Klem, 2000). Critical Ratios (CR = MLE/SE of MLE) greater than 1.96 were interpreted as significant at $p<.05$ level (Tabachnick \& Fidell, 2007). The parameter estimates can be interpreted like beta weights in regression equations to determine the direction and strength of relations among variables. Squared multiple correlations (SMCs) also allowed for determination of the proportion of variance accounted for in endogenous (predicted) variables within the model.

Hypothesis 2. The second hypothesis of the study, regarding moderation effects of dental fear and fear of pain, was tested using regression equations as outlined by Baron and Kenny (1986), Howell (2002), and Tabachnick and Fidell (2007). To address issues of multicollinearity and extreme main effect values, the predictor variables (i.e., dental fear, fear of pain, pre-surgery and recall anxiety, pre-surgery and recall depression, and pre-surgery and recall negative affect) first were centered (Howell, 2002). In six separate equations, predicted pain was regressed on one of the pre-surgery state affect variables (i.e., pre-surgery negative affect, depression, or anxiety), with either dental fear or fear of pain as an additional predictor, as well as the interaction of the pre-surgery affect variable and dental fear or fear of pain. Twelve similar 
regression equations for recalled pain were used to examine moderation effects of dental fear or fear of pain on pre-surgery and recall state emotion. For equations with a significant $R^{2}, \beta$ values were examined to determine the contribution of each variable in explaining variance in predicted or recalled pain; significant $\beta$ values for interaction terms indicated moderation effects.

Significant moderation effects were interpreted by using the regression equation to graph values of the dependent variable at different values (the mean, and one standard deviation above and below the mean) of the two predictor variables.

Hypothesis 3. Mediation effects suggested by the third hypothesis of the study were examined in the final path analysis models via indirect effects of dental fear and fear of pain on predicted pain and recalled pain through pre-surgery anxiety, depression, and negative affect. Indirect effects involve the influence of one variable on a second variable through relations with other variables. Indirect effects can be calculated by multiplying path coefficients and then adding the products of each route through which the first variable may influence the second variable (Klem, 1995).

Mediation, conceptualized by Baron and Kenny (1986) as a case where one variable (the mediator) accounts for the relation between two other variables, represents a special case of indirect effects (Preacher \& Hayes, 2004). To be considered mediation: a) the predictor variable must be significantly related to both the mediator and dependent variable, $b$ ) the mediator must be significantly related to the dependent variable, and c) the influence of the predictor variable on the dependent variable via the mediator variable must be significant. Although Baron and Kenny (1986) primarily expressed interest in complete mediation (i.e., the direct relation between the predictor and dependent variable becomes non-significant when mediation effects are accounted for), partial mediation (i.e., the direct relation remains significant in addition to 
significant mediation effects) is more typical and of greater interest (Howell, 2002; Preacher \& Hayes, 2004). Additionally, mediation represents a special case of indirect effects because indirect effects can involve more than three variables and because a variable could have a significant indirect effect without originally having a significant direct effect (Preacher \& Hayes, 2004).

As the current project was concerned with mediation, indirect effects tests for mediation were examined only when the predictor variable (dental fear or fear of pain) and mediator (presurgery anxiety, depression, or negative affect) were significantly related with each other and with the dependent variable (predicted or recalled pain), as indicated by significant correlations. Significant mediation effects were determined by dividing the product of indirect effects paths by the standard error, a method referred to as the Soebel test and outlined by Howell (2002) and Preacher and Hayes (2004). More specifically, in reference to Appendices I and J, if the relations indicated by paths $\mathrm{a}, \mathrm{b}$, and $\mathrm{c}$ were significant (as measured in the correlation matrices), then the product of paths $\mathrm{a}$ and $\mathrm{b}$ was divided by the standard error. Testing for mediation in this manner reduces risk of Type II error, as compared to using multiple regression equations, because fewer calculations are needed.

Exploratory analyses. Finally, exploratory analyses were conducted to determine if the models calculated using NRS pain ratings fit data of VAS pain ratings; to incorporate relevant variables of interest into the final anxiety and depression model and the final negative affect model; and to incorporate both the anxiety and depression and the negative affect models into a final model that included other relevant variables of interest. 


\section{Data Reduction}

Participant data were entered into a database using SPSS version 14.0. Missing data were imputed using individual means in cases in which a participant had completed at least $80 \%$ of a measure. There were no cases of participants failing to provide a response for at least $80 \%$ of a measure. A series of comparisons with $t$-tests and $\chi^{2}$ tests for individuals with complete data for the clinic portion of the study who returned $(N=178)$ or did not return $(N=124)$ the follow-up survey revealed that participants who returned the survey reported less current dental pain in clinic, predicted less dental pain, were older, reported greater chronic pain ratings when they endorsed chronic pain, were more likely to be taking any type of medication, and were more likely to be taking psychoactive medication (Table 1).

\section{Data Management}

Multivariate outliers for the final sample of 157 participants (after 21 participants who returned surveys but had unusable data were dropped from the sample) were screened by checking the data for participant leverage values greater than $2 k / N$, where $k$ equals the number of predictor variables (Tabachnick \& Fidell, 2007). There were 11 participants considered multivariate outliers for the anxiety and depression model and 10 participants considered outliers for the negative affect model using the $2 k / N$ formula. As analyses with and without these participants yielded similar model fit indices and path coefficients, outliers were retained in analyses for greater power and external validity. Descriptive statistics for the final sample are displayed in Tables 2 and 3 .

Examination of descriptive statistics revealed mean scores mostly consistent with values reported in prior research. DFS and SF-FPQ scores were similar to those of participants in McNeil et al. (2010), and DFS scores also were within one standard deviation of student samples 
in McGlynn et al. (1987). Participant CESDR scores were similar, although slightly higher, than CESD scores of community samples in Radloff (1977) and Weissman et al. (1977); CESDR scores were lower than those of community sample in Eaton et al. (2004). Prior to surgery, negative affect scores were close to those of mental health patients, but scores had returned to levels similar to those of student samples by follow-up (Watson \& Clark, 1994; Watson et al., 1988). Both pre-surgery and follow-up anxiety scores were close to those in prior research (Eli et al., 2000; Eli et al., 2003; McNeil et al., 2010). All pain reports were similar to those of patients in McNeil et al. (2010), although predicted and recalled pain were slightly higher than in other prior studies (Eli et al., 2000; Eli et al., 2003; Gedney et al., 2003).

Additionally, descriptive statistics for extraction naïve participants are displayed in Table 4, as a comparison to the entire sample. Brief visual examination of mean scores suggested extraction naïve participants were generally higher in average scores than the rest of the sample, particularly for predicted and recalled pain. Finally, sample correlations for path model variables are displayed in Table 5. Regarding the relations among state affect variables, all three constructs were significantly correlated at both times of measurement.

Path Model Analysis for Anxiety and Depression

Initial model. The hypothesized initial model is displayed in Figure 1, and fit indices are reported in Table 6. Parameter estimates are displayed in Table 7. As can be seen from the various fit indices, the initial anxiety and depression model displayed a poor fit with the data. Particularly noteworthy was the non-significance and small size of coefficients for paths from recall anxiety and depression to recalled pain.

Model modifications. Post-hoc model modifications were performed to develop a better fitting model, and fit indices for each of the modified models are displayed in Table 6. First, 
paths from dental fear and fear of pain to current pain were dropped in Model 2, as less relation between these variables and report of current pain was expected based on inconsistent effects of dental fear on current pain responses in Klepac et al. (1980) and Klepac et al. (1982). Model fit was still poor, so the paths from dental fear and fear of pain to experienced pain were dropped in Model 3, as dental fear has exerted non-significant influence on experienced dental pain in prior research (McNeil et al., 2010). Fit for Model 3 remained poor, and paths from dental fear and fear of pain to recalled pain were dropped in Model 4 because the variables were measured more distally in time. Additionally, McNeil et al. (2010) reported no relation between dental fear and recalled pain, and Muglali and Komerik (2008) reported no relation between pre-operative trait anxiety and post-operative report of dental pain. Still, model fit of Model 4 was poor, and Model 5 was created by dropping paths from pre-surgery anxiety and depression to experienced pain, as some prior research has suggested affect at the time of report of is most closely related to report of pain (Eli et al., 2000; McNeil et al., 2010). Model fit for Model 5 was poor, however, and paths from pre-surgery anxiety and depression to recalled pain dropped in Model 6 as they were measured more distally in time (Eli et al., 2000). Model fit remained poor, and the paths from recall anxiety and depression remained non-significant and small in magnitude. Without significant predictive value, the variables of recall anxiety and depression were dropped. Good model fit was achieved for the final anxiety and depression model, and examination of modification indices suggested the addition of any paths to the model would not result in statistically significant improvement in model fit.

The final anxiety and depression model is displayed in Figure 2, with implied and residual correlations listed in Table 8; parameter estimates are listed in Table 9. Fear of pain and dental fear were significantly correlated. Fear of pain was associated with greater pre-surgery 
depression and just missed being significantly inversely associated with pre-surgery anxiety; fear of pain was not significantly related to predicted pain. Dental fear, on the other hand, was associated with both pre-surgery anxiety and predicted pain, but not with pre-surgery depression. Both pre-surgery anxiety and pre-surgery depression were associated with current dental pain, but neither was significantly associated with predicted dental pain. In addition to being related to dental fear, predicted pain also was predicted by current pain. Further, predicted pain was associated with experienced pain and recalled pain. Experienced pain also was related to recalled pain. Finally, SMCs indicated that $21 \%$ of the variance in predicted pain and $40 \%$ of the variance in recalled pain was accounted for by the final anxiety and depression model.

\section{Path Model Analysis for Negative Affect}

Initial model. The hypothesized initial negative affect model is displayed in Figure 3, with parameter estimates in Table 11. As with the initial anxiety and depression model, the fit indices displayed in Table 10 revealed poor fit for the hypothesized model. Similar to anxiety and depression, recall negative affect lacked a significant relation to recalled dental pain.

Model modifications. In comparing the relations of negative affect to those of anxiety and depression, the pattern of model modifications followed that of the anxiety and depression models. Fit indices for each of the modified models are displayed in Table 10. First, paths from dental fear and fear of pain to state pain were dropped in Model 2, as less relation between these variables and report of current pain was expected (Klepac et al., 1982; Klepac et al., 1980). Model fit was still poor, so the paths from dental fear and fear of pain to experienced pain were dropped in Model 3, based on the non-significant relation of dental fear and experienced dental pain in prior research (McNeil et al., 2010). Fit remained poor, and paths from dental fear and fear of pain to recalled pain were dropped in Model 4, as the variables were measured more 
distally in time and prior research has reported less relation between trait fear or anxiety measures and post-operative report of pain (McNeil et al., 2010; Muglali \& Komerik, 2008). Model fit for Model 4 was poor, and Model 5 was created by dropping the path from pre-surgery negative affect to experienced pain because affect at the time of report of has been most closely related to report of pain in previous studies (Eli et al., 2000; McNeil et al., 2010). As model fit was still poor, the path from pre-surgery negative affect to recalled pain dropped in Model 6 because recalled pain was measured more distally in time from negative affect (Eli et al., 2000). Fit for Model 6 remained poor, however, and the path from recall negative affect to recalled pain remained non-significant and small in magnitude. Without predictive value, the variable of recall negative affect was dropped from the final negative affect model, as recall depression and anxiety were dropped from the final anxiety and depression model. Good model fit was achieved, with no modification indices to suggest the addition of paths to improve model fit.

The final model is displayed in Figure 4, with fit indices in Table 10 offering evidence of excellent fit, similar to the final anxiety and depression model. Implied and residual correlations are listed in Table 12, with parameter estimates listed in Table 13. Again, dental fear and fear of pain were significantly correlated. Dental fear, but not fear of pain, was significantly related to pre-surgery negative affect and predicted pain; fear of pain just missed being significantly inversely associated with predicted pain. Negative affect was related to current pain, which also was associated with predicted pain. As with the anxiety and depression model, predicted pain was related to experienced pain and recalled pain. Experienced pain also was associated with recalled pain. Finally, SMCs revealed that $21 \%$ of the variance in predicted pain and $40 \%$ of the variance in recalled pain was accounted for by the model, close to the SMC values for the anxiety and depression final model. 


\section{Moderation Effects of Dental Fear and Fear of Pain}

Dental fear. Regression equations testing for moderation effects on predicted dental pain for dental fear and pre-surgery state mood were non-significant. Dental fear also exerted no moderation effects on the relations of pre-surgery state mood, recall anxiety, or recall negative affect and recalled dental pain. The interaction of dental fear and recall depression in relation to recalled pain, however, was significant (Table 14). Based on the procedures outlined by Howell (2002) and Tabachnick and Fidell (2007), a plot using mean and standard deviation values of dental fear and recall depression was created to explore the pattern of moderation effects. At lower values of dental fear, greater recall depression was associated with greater recalled pain. At higher values of dental fear, however, the opposite pattern occurred: greater recall depression was associated with less recalled pain.

Fear of pain. Regression equations used to examine the impact of fear of pain on the relation of state mood and predicted dental pain revealed no significant moderation effects. Similarly, the interaction of fear of pain and state mood exerted no significant influence on recalled dental pain.

\section{Mediation Effects of Pre-surgery Anxiety, Depression, and Negative Affect}

To examine mediation effects, correlations among variables in Table 5 were first examined to determine for which variables mediation, as conceptualized by Barron and Kenny (1986), was possible. Based on non-significant correlations with dental fear, fear of pain, and state mood, no mediation effects involving recalled dental pain were possible. Mediation effects involving predicted dental pain also were not possible for fear of pain or pre-surgery depression. Thus, mediation effects of dental fear, pre-surgery anxiety, and pre-surgery negative affect on predicted pain were tested by examining indirect effects of dental fear on predicted pain through 
pre-surgery anxiety and negative affect. The two products of the path coefficients, divided by their standard errors, yielded non-significant $t$ values $(t=1.49$ for dental fear and anxiety; $t=$ 1.20 for dental fear and negative affect, all $p$ 's $>.05$ ), which indicated non-significant partial mediation effects.

To further explore indirect effects, total standardized indirect effects for the final models are displayed in Tables 15 and 16. Indirect effects of note were those of dental fear on current pain, predicted pain, experienced pain, and recalled pain. Fear of pain, however, exerted much less indirect influence on reports of pain across time. Also of interest was the indirect influence of predicted pain on recalled pain through experienced pain, in addition to the direct association of predicted and recalled pain. Such a pattern of direct and indirect effects indicated prediction of pain of pain was directly related to recalled pain, but predicted pain also led to an increase in experienced pain that further led to an increase in recalled pain.

Exploratory Analyses

$V A S$ in final models. To examine whether the pattern of results with path models using VASs for pain ratings was similar to the results when NRSs were used, as well as to partially check that model modifications did not take advantage of peculiarities in the sample's NRS data, the final anxiety and depression model and final negative affect model were calculated using VAS pain ratings. The resulting models are displayed in Figures 6 and 7, with input sample correlations and implied and residual correlation matrices in Tables 17, 18, and 20. Parameters are listed in Tables 19 and 21. As can be seen in the figure captions, model fit remained excellent for both models. Additionally, path coefficients and SMCs were almost identical across models. 
Addition of other variables of interest to final models. To examine the relation between additional variables of interest and both predicted and recalled pain, correlations were used to test for significant relations (Table 22). Four variables were identified as being significantly associated with predicted pain: age, number of previous extractions, duration of current dental pain, and chronic pain intensity rating. Additionally, seven variables were related to recalled pain: use of opioids, chronic pain intensity rating, re-injection of initial anesthetic, use of an additional anesthetic, use of an additional nerve block, duration of extraction procedure, and self report (but not formal diagnosis) of alveolar osteitis symptoms.

The additional variables significantly related to predicted and recalled dental pain were included in the final anxiety and depression model and final negative affect model to determine if the variables retained their significant associations with predicted and recalled pain in the context of the other model variables. Only four variables (number of previous extractions, duration of current dental pain, chronic pain intensity rating, and use of an additional anesthetic) retained their significant relations with predicted or recalled pain; the associations of the other additional variables with predicted and recalled pain became non-significant.

The final models were calculated with just these four additional variables and are displayed in Figures 8 and 9, with fit indices indicating the good fit of the final models was generally retained. Implied and residual correlations are displayed in Tables 23 and 25 and path coefficients are shown in Tables 24 and 26. Fewer previous extractions and shorter duration of current dental pain were associated with more predicted pain. Additionally, higher ratings of chronic pain in the clinic and use of an additional anesthetic during extraction remained related to more recalled pain. The other path coefficients retained their significance or non-significance and magnitude, similar to that of the original final models. SMCs indicated the amount of 
variance accounted for in predicted (26\% to $28 \%)$ and recalled pain (54\%) increased with inclusion of the additional variables.

Exploratory combined model. Finally, an exploratory path model was created by incorporating the final anxiety and depression model with the final negative affect model, as well as number of previous extractions, duration of current dental pain, chronic pain rating, and use of an additional anesthetic. As indicated in Table 22, dental fear and chronic pain rating were significantly correlated and allowed to correlate in the exploratory combined model.

The exploratory model is displayed in Figure 10. An examination of fit indices revealed an adequately fitting model. Implied and residual correlations are displayed in Table 27, with path coefficients in Table 28. Dental fear and fear of pain remained significantly correlated $(r=$ $.51, p<.001)$, but dental fear and chronic pain rating did not $(r=.13, p<.25)$. Dental fear remained significantly related to pre-surgery anxiety and pre-surgery negative affect, but it was no longer significantly related to predicted pain. Fear of pain was significantly associated with pre-surgery depression, but again it just missed being significantly inversely related to presurgery anxiety and predicted pain. Both pre-surgery anxiety and pre-surgery depression, but not pre-surgery negative affect, retained their significant relations with current dental pain. In addition to dental fear, current dental pain, duration of current dental pain, and number of previous extractions were associated with predicted dental pain. Predicted pain was related to both experienced pain and recalled pain. Experienced pain, use of an additional anesthetic, and chronic pain rating also were significantly associated with recalled pain. 


\section{Discussion}

\section{Major Findings}

Hypotheses. Regarding the first hypothesis of the study, neither at pre-surgery nor at recall were anxiety, depression, or negative affect more closely associated with predicted or recalled pain than experienced pain. State mood was not even directly significantly related to predicted or recalled pain. Trait dental fear, however, directly and indirectly influenced predicted pain and indirectly influenced recalled pain. Predicted pain also was directly related to current pain, and recalled pain was associated with both predicted and experienced pain.

Minimal support was afforded the second hypothesis of the study. Dental fear moderated the effects of recall depression on recalled pain, such that greater recall depression was associated with more recalled pain at lower levels of dental fear but with less recalled pain at higher levels of dental fear. The moderation effects were in the opposite direction than predicted, however, and the complete regression equation for the moderation analysis accounted for only $5 \%$ of the variance in recalled pain. No other moderation effects of dental fear or fear of pain were found for either predicted or recalled pain.

None of the mediation effects of the third hypothesis were found. As determined from correlation matrices, mediation as defined by Baron and Kenny (1986) was only possible between dental fear and predicted pain via pre-surgery anxiety or pre-surgery negative affect. Tests of the indirect effects, however, were non-significant. Although not hypothesized, other indirect effects were present, as indicated by total standardized indirect effects. Dental fear had indirect effects on current, predicted, experienced, and recalled pain; predicted pain had an indirect influence on recalled pain as well. Thus, although dental fear and fear of pain were significantly correlated, their pattern of relations to other variables differed. 
Exploratory analyses. When VAS ratings of pain were substituted in the final anxiety and depression model and final negative affect model, the pattern of results was very similar to the pattern for NRS pain ratings. As VAS and NRS ratings evidenced similarity, and so too did anxiety, depression, and negative affect: the three constructs were significantly correlated both at pre-surgery and at one month recall.

When incorporating additional variables of interest into the final models, good fit was maintained with fewer previous extractions and shorter duration of dental pain prior to extraction related to more predicted pain and with higher chronic pain rating and use of additional anesthetic associated with more recalled pain. Other path coefficients remained similar to those of the original final models.

Finally, exploratory analyses indicated the combined model retained the associations between predicted pain and number of previous extractions and duration of dental pain prior to extraction, as well as between recalled pain and rating of chronic pain and use of an additional anesthetic during extraction. When anxiety, depression, and negative affect were combined in one model, however, the relation between negative affect and current dental pain became nonsignificant. Additionally, dental fear no longer significantly was related to predicted pain. Integration with Previous Research

Although state mood exerted some influence on current pain, the lack of significant relation with predicted or recalled pain contrasts with prior research both on dental pain (Eli et al., 2003; Eli et al., 2000; Gedney et al., 2003; Muglali \& Komerik, 2008), as well as on mood and memory (Coles \& Heimberg, 2002; Singer \& Salovey, 1988). All participants underwent tooth extraction, which tends to elicit a significant report of fear and pain (Maggirias \& Locker, 2002b; Minigh et al., 2008; Stabholz \& Peretz, 1999; Wong \& Lytle, 1991), and a ceiling effect 
may have been present that created less range in participant self-report. Previous studies documenting a mood-pain relation, however, have used patients undergoing oral surgery (e.g., Eli et al., 2003) or root canal therapy (Gedney et al., 2003). Additionally, participants endorsed a wide range of pain ratings. Thus, a ceiling effect was unlikely.

Several other explanations for the discrepancy with some past research are more probable. West Virginia is a mostly rural state, contained entirely within Applachia (Muntaner \& Barnett, 2000). As the sample was composed mainly of West Virginia residents, sample characteristics may have influenced relations among variables differently than in studies utilizing samples from more urban demographics. Additionally, the final sample may have been particularly unique in that the clinic was the only of its kind in the area offering extractions at little or no cost for under-insured or uninsured individuals. For example, the average number of previous extractions for the final sample was close to five, perhaps enough multiple corrective experiences to reduce over-estimation of pain (Arntz \& Lousberg, 1990; Artnz et al., 1990; Rachman \& Bichard, 1988). Indeed, more previous extractions were significantly related to less predicted pain. Also, recall of pain occurred one month after tooth extraction, a shorter duration than some previous studies (e.g., Gedney et al., 2003; Kent, 1985), although a longer duration than in McNeil et al. (2010). Perhaps a longer duration of time is necessary for the influence of mood to match the influence of experience on recall of pain, particularly for a singular event of acute pain (Erskine et al., 1990). Also, there was a restricted range in patient rating of depression, with fewer severely depressed patients.

Alternatively, perhaps the results of the present study clarify and temper findings of previous research. Experienced pain has been significantly associated with recalled pain in some prior research (McNeil et al., 2010), and recall of dental pain has been classified as reliable in 
general (Beese \& Morley, 1993). Erskine et al. (1990) also suggested a moderate relation between experience and recall of pain. In the present study, experienced pain was related to recalled pain, but the association was not one-to-one. Predicted pain did exert significant influence on recalled pain, as would be expected (Kent, 1985), suggesting variables other than experience can be significantly associated with recalled pain. As this was the first study to examine the relations of mood with predictions and recall of dental pain with path analysis, it is possible that mood exerts less influence when all relations can be calculated simultaneously. Erskine et al. (1990) also has suggested that memory for single episode of acute pain, as in the present study, may be less susceptible to bias than memory of chronic or recurrent pain.

Although dental fear and fear of pain evidenced minimal moderation effects, dental fear was directly associated with greater pre-surgery anxiety and predicted pain, and indirectly related to recalled pain, as in previous research (Arntz et al., 1990; Kent, 1985; McNeil et al., 2010). Newly adding to the literature were the relations between dental fear and greater presurgery negative affect, as well as fear of pain and greater pre-surgery depression. Additionally, dental fear had an indirect effect on recalled pain, despite a lack of a direct relation in either the path models or correlation table. Mediation effects with state mood, as traditionally conceptualized by Baron and Kenny (1986), however, were not present as past research might suggest (Eli et al., 2003; Eli et al., 2000).

The differential relations of dental fear and fear of pain to other variables also were revealing. Though the constructs showed overlap, as in past research (McNeil \& Berryman, 1989; McNeil et al., 2010), they displayed different relations to pre-surgery mood and predicted pain, with dental fear related more to anxiety and negative affect but fear of pain related more to depression. The overlap and differences of fear of pain and dental fear suggested that fear of 
pain may be a significant aspect of dental fear, but fear of pain does not wholly explain the exaggerated prediction or recall of pain associated with greater dental fear.

Although the analyses were exploratory in nature, and interpretations must be made with caution, the similarity of models using VAS and NRS ratings may suggest that future research could rely on NRS pain ratings, which can more easily be administered and interpreted. Also, number of previous extractions, duration of current dental pain, chronic pain rating, and injection with additional anesthetic proved important variables to consider in explaining variance in predicted and recalled pain. Anxiety, depression, and negative affect were correlated, although less than in past research (Gençöz, 2002; Pelle et al., 20009), and it is noteworthy that the influence of negative affect on current pain became non-significant in the combined model. The similarities of the final anxiety and depression model and final negative affect model suggested that the measured variable of negative affect may underlie both anxiety and depression in a dental context (cf. Brown et al.,1998; Clark \& Watson , 1991), although inter-correlations were lower.

Finally, regarding the general literature on both memory of dental pain and the influence of mood on memory, the present study adds in several ways. Relations of predicted, experienced, and recalled pain in the final models (as well as simple visual inspection of the mean ratings) revealed the expected pattern of prediction relating closely with recall of pain (Eli, 1992; Kent, 1985). Additionally, dental fear did influence prediction and recall of pain, suggesting emotion did influence memory. The affective influence on memory is perhaps similar to the influence of strong emotion on memory of childbirth pain suggested by Niven and Murphy-Black (2000), with positively valenced emotions surrounding childbirth decreasing recall of pain while negatively valenced emotion of tooth extraction increases recall of pain. 
Alternatively, it might be the case that the influence of emotion on memory decreases recall for the peripheral details and increases recall for central details (i.e., pain is a peripheral detail for childbirth but a central detail for tooth extraction) (Christianson \& Loftus, 1991; Christianson et al., 1991). Perhaps the greater association between experienced and recalled dental pain reflects more the strengthening of memory for central details associated with aversive emotion, rather than a biasing of memory.

\section{Limitations}

A significant limitation for the present study was sample size. Although there were enough participants to meet the minimum suggested number of participants per measured variable Thompson (2000), sample size reasonably could have been increased to 200 participants to have 20 participants per each of the 10 measured variables in the initial anxiety and depression model. As such, the path analyses potentially could have been underpowered, impacting their ability to detect smaller but significant effects.

In a similar vein, moderation analyses ideally would have been conducted by running the same models for groups with greater and lesser dental fear and fear of pain, then comparing parameters and fit indices. Doing so would have required more participants, however, enough to have approximately 100 to 200 participants per each group. The pattern of results may have changed if moderation analyses could have been conducted differently.

A smaller sample size also prevented the separation of the participants into a training and hold-out sample to ensure that model modifications did not take advantage of relations unique to the sample. Ideally, the initial model would have been tested and modified using approximately half the participants, with the final model then tested on the other half of the participants. To do so, however, would have required at least double the number of participants collected, and 
potentially up to 400 patients who returned the follow-up survey. Based on return rates in the present study, obtaining a sample of 400 participants might have required collecting over 750 patients in clinic. Further regarding return rates, attrition occurred between collecting data from participants in the clinic and collecting complete follow-up surveys, despite multiple efforts (e.g., financial incentive, phone calls, emails, second mailings) to encourage participants to complete the follow-up. Differences on several variables between participants who returned and did not return the surveys indicates that individuals for whom complete data were available and who comprised the final sample differed slightly from the average patient presenting for tooth extraction. Thus, results might have been different if return rates for the follow-up survey were higher.

Two important theoretical issues also limited the present study: measurement of the construct of pain, as well as the measurement of and blurred time frame of state versus trait affect. Some prior research of affect and dental pain (e.g., Gedney et al., 2003) has separated pain into the dimensions of pain intensity and pain unpleasantness, suggesting recall of pain unpleasantness may be impacted more by affect than recall of pain intensity. Thus, the results of the present study may have been different if there had sufficient sample size to power analyses with pain unpleasantness as well as pain intensity.

Also, as Grillon (2008) suggested, anxiety and fear can be difficult to differentiate and measure separately, as the constructs blend into each other. The dental fear participants endorsed on the DFS also might indicate greater levels of dental anxiety, as individuals could experience apprehension and hypervigilance in anticipation of an unpredictable encounter with stimuli listed on the DFS. Or, the state anxiety measured on the NRS and VAS prior to extraction could represent a more phasic hyperarousal in response to specific cues in the operatory (e.g., smells, 
sight of instruments on dental tray). Unfortunately, the state of the literature, as well as the nearly indiscriminate use of the terms fear and anxiety in the lay vernacular, prevented a clearer delineation between fear and anxiety in the present study. Additionally, some of the measures used differed in the time frame they assessed various emotional states (i.e., anxiety and negative affect were assessed at the present moment, depression was assessed over the past week, and dental fear and fear of pain were assessed more as a general trait). The decision was made to classify anxiety, depression, and negative affect as mood states, more transient and less consistent over time; dental fear and fear of pain were considered more trait-like cognitiveaffective-motivational dispositions towards dental and painful stimuli. In the stressful context of the dental operatory pre-extraction, however, blending of states and traits may occur with biased responding. Relations among variables also were likely affected by shared method variance, as constructs of interest were measured by self-report on paper-and-pencil questionnaires.

\section{Future Directions, Applications, and Summary}

To be able to conduct adequately powered analyses with testing of moderation with multiple groups and verify model modifications with a hold-out sample, future research would ideally seek larger sample sizes. Increased power could help ensure that the lack of significant associations in the present study reflects lack of significant relations at the population level. The finals models of the present study, as well as the exploratory model, may provide a starting point for such analyses.

Another research approach that might prove useful would be to measure patient recall at multiple follow-ups. A lack of significant relations between mood and recalled pain in the present study might reflect a lack of sufficient time for recalled pain to "incubate." Although earlier measurements of recalled pain could influence later measurements of recalled pain, it 
would be illuminating to better determine the pattern of relations between affect and pain report over time. When measuring responses across time, particularly in clinic, it also would provide a more complete representation of participant behavior to sample responses in modalities other than verbal report (i.e., overt-motor responses such as shifting frequently in the dental chair, physiological responses such as heart rate or skin conductance).

In general, the literature needs to better clarify differences between fear and anxiety, as well as between state and trait affect. The constructs may have different influences on report of pain, and generalizations across studies will remain difficult until it can be established more clearly what constructs are being measured in each study.

Clinicians may extrapolate at least two applications from the findings of this project. Reducing prediction of pain, especially for individuals with little prior extraction experience or who present shortly after onset of dental pain, may help reduce exaggerated recall. One mechanism through which prediction of pain may be reduced is reduction of dental fear. Also, when presented with patients with more chronic pain or requiring injection of additional anesthetic, dental professionals should recognize the patient is at risk of exaggerated recall of pain, especially if they are more dentally fearful. Care should be exercised to make the subsequent extraction experience as non-aversive as possible.

In summary, state mood did not have a significant influence on prediction or recall of pain during tooth extraction. Dental fear, however, was significantly related to pre-surgery anxiety, pre-surgery negative affect, and predicted pain. Dental fear also was indirectly related to recalled pain. The results speak to the importance of the construct of dental fear in dental research, as well as to its relevancy as a clinical state that warrants the attention of practitioners in clinic. 


\section{References}

Abrahamsson, K., Berggren, U., Hakeberg, M., \& Carlsson, S. (2001). Phobic avoidance and regular dental care in fearful dental patients: a comparative study. Acta Odontologica Scandinavica, 59, 273-279.

American Psychiatric Association. (2000). Diagnostic and statistical manual of mental disorders (4th ed., Text revision). Washington, DC: Author.

Artnz, A., \& Lousberg, R. (1990). The effects of underestimated pain and their relationship to habituation. Behaviour Research and Therapy, 28, 15-28.

Artnz, A., Van Eck, M., de Jong, P., \& Van den Hout, M. A. (1990). The relationship between unpredicted pain and escape. Behaviour Research and Therapy, 28, 87-90.

Arntz, A., Van Eck, M., \& Heijmans, M. (1990). Predictions of dental pain: The fear of any expected evil is worse than the evil itself. Behaviour Research and Therapy, 28, 29-41.

Asmundson, G. J. G., \& Wright, K. D. (2004). Biopsychosocial approaches to pain. In T. Hadjistavropoulos \& K. D. Craig (Eds.), Pain: Psychological perspectives (pp. 35-57). Mahwah, NJ: Lawrence Erlbaum.

Baron, R. M., \& Kenny, D. A. (1986). The moderator-mediator variable distinction in social psychological research: Conceptual, strategic, and statistical considerations. Journal of Personality and Social Psychology, 51, 1173-1182.

Barsky, A. (2002). Forgetting, fabricating, and telescoping: the instability of the medical history. Archives of Internal Medicine, 162, 981-984.

Beese, A., \& Morley, S. (1993). Memory for acute pain experience is specifically inaccurate but generally reliable. Pain, 53, 183-189. 
Bernstein, D. A., Kleinknecht, R. A., \& Alexander, L. D. (1979). Antecedents of dental fear. Journal of Public Health Dentistry, 39, 113.

Blackburn-Munro, G. (2004). Hypothalamo-pituitary-adrenal axis dysfunction as a contributory factor to chronic pain and depression. Current Pain and Headache Reports, 8, 116-124.

Bower, G. H. (1981). Mood and memory. American Psychologist, 36, 129-148.

Bradley, M. M., Silakowski, T., \& Lang, P. J. (2008). Fear of pain and defensive activation. Pain, 137, 156-163.

Brown, T. A., Chorpita, B. F., \& Barlow, D. H. (1998). Structural relationships among dimensions of the DSM-IV anxiety and mood disorders and dimensions of negative affect, positive affect, and autonomic arousal. Journal of Abnormal Psychology, 107, 179-192.

Bryant, R. (1993). Memory for pain and affect in chronic pain patients. Pain, 54, 347-351.

Burt, D., Zembar, M., \& Niederehe, G. (1995). Depression and memory impairment: A metaanalysis of the association, its pattern, and specificity. Psychological Bulletin, 117, 285305.

Campbell, S., \& MacQueen, G. (2004). The role of the hippocampus in the pathophysiology of major depression. Journal of Psychiatry and Neuroscience, 29, 417-426.

Cañadas-Pérez, F., Nieto-Escámez, F. A., Roldán-Tapia L., \& López-Crespo, G. (2007). Consequences of anxiety on memory processes (I): Introductory and clinical aspects. In H. Buschman, J. L. Díaz, J. Holenz, A. Párraga, A. Torrens, et al. (Eds.), Antidepressants, antipsychotics, anxiolytics: From chemistry and pharmacology to clinical application (vol. 1 \& 2, pp. 803-829). Weinheim, Germany: Wiley-VCH. 
Carleton, R. N., \& Asmundson, G. J. G. (2009). The multidimensionality of fear of pain: Construct independence for the Fear of Pain Questionnaire-Short Form and the Pain Anxiety Symptoms Scale-20. The Journal of Pain, 10, 29-37.

Chapman, C. R. (2004). Pain perception, affective mechanisms, and conscious experience. In T. Hadjistavropoulos \& K. D. Craig (Eds.), Pain: Psychological perspectives (pp. 59-85). Mahwah, NJ: Lawrence Erlbaum.

Chen, E., Zeltzer, L., Craske, M., \& Katz, E. (2000). Children's memories for painful cancer treatment procedures: Implications for distress. Child Development, 71, 933-947.

Christianson, S. A., Loftus, E. F. (1991). Remembering emotional events: The fate of detailed information. Cognition and Emotion, 5, 81-108.

Christianson, S. A., Loftus, E. F., Hoffman, H., Loftus, G. R. (1991). Eye fixations and memory for emotional events. Journal of Experimental Psychology: Learning, Memory, and Cognition, 17, 693-701.

Clark, D. M., \& Teasdale, J. D. (1982). Diurnal variation in clinical depression and accessibility of memories of positive and negative experiences. Journal of Abnormal Psychology, 91, $87-95$.

Clark, L. A., \& Watson, D. (1991). Tripartite model of anxiety and depression: Psychometric evidence and taxonomic implications. Journal of Abnormal Psychology, 100, 316-336.

Coles, M., \& Heimberg, R. (2002). Memory biases in the anxiety disorders: Current status. Clinical Psychology Review, 22, 587-627.

Craske, M. (2003). Functions of fear versus anxiety. In Origins of phobias and anxiety disorders: Why more women than men? (pp. 21-31). Oxford, UK: Elsevier. 
Crawford, J. R., \& Henry, J. D. (2004). The Positive and Negative Affect Schedule (PANAS): Construct validity, measurement properties and normative data in a large non-clinical sample. British Journal of Clinical Psychology, 43, 245-265.

Davey, G. (1989). Dental phobias and anxieties: Evidence for conditioning processes in the acquisition and modulation of a learned fear. Behaviour Research and Therapy, 27, 5158.

DeStefano, F., Anda, R., Kahn, H., Williamson, D., \& Russell, C. (1993). Dental disease and risk of coronary heart disease and mortality. BMJ (Clinical Research Ed.), 306, 688-691.

Donahue, R. D. (2005). The structural relationships among generalized anxiety, obsessionscompulsions, and depression at the syndrome and sub-syndrome level. Behaviour Research and Therapy, 43, 1587-1609.

Earl, P. (1994). Patients' anxieties with third molar surgery. British Journal of Oral and Maxillofacial Surgery, 32, 293-297.

Eaton, W., Smith, C., Ybarra, M., Muntaner, C., \& Tien, A. (2004). Center for Epidemiologic Studies Depression Scale: Review and revision (CESD and CESD-R). In M. E. Maruish (Ed.), The use of psychological testing for treatment planning and outcomes assessment: Volume 3: Instruments for adults (3rd ed., pp. 363-377). Mahwah, NJ: Lawrence Erlbaum.

Eich, E., Reeves, J. L., Jaeger, B., \& Graff-Radford, S. B. (1985). Memory for pain: Relation between past and present pain intensity. Pain, 23, 375-379.

Ekman, R., Levenson, R. W., Friesen, W. V. (1983). Autonomic nervous system activity distinguishes among emotions. Science, 221, 1208-1210. 
Eli, I. (1992). The experience of pain - psychological aspects. In Oral psychophysiology: Stress, pain, and behavior in dental care (pp. 41-58). Boca Raton, FL: CRC Press.

Eli, I., Baht, R., Kozlovsky, A., \& Simon, H. (2000). Effect of gender on acute pain prediction and memory in periodontal surgery. European Journal of Oral Sciences, 108, 99-103.

Eli, I., Bar-Tal, Y., Fuss, Z., \& Silberg, A. (1997). Effect of intended treatment on anxiety and on reaction to electric pulp stimulation in dental patients. Journal of Endodontics, 23, 694697.

Eli, I., Schwartz-Arad, D., Baht, R., \& Ben Tuvim, H. (2003). Effect of anxiety on the experience of pain in implant insertion. Clinical Oral Implants Research, 14, 115-118.

Erskine, A., Morley, S., \& Pearce, S. (1990). Memory for pain: A review. Pain, 41, 255-265.

Everts, B., Karlson, B., Währborg, P., Abdon, N., Herlitz, J., \& Hedner, T. (1999). Pain recollection after chest pain of cardiac origin. Cardiology, 92, 115-120.

Fanselow, M. S. (1994). Neural organization of the defensive behavior system responsible for fear. Psychonomic Bulletin and Review, 1, 429-438.

Fowler, E.B., Breault, L.G., \& Cuenin, M.F. (2001). Periodontal disease and its association with systemic disease. Military Medicine, 166, 85-89.

Frances, A., Manning, D., Marin, D., Kocsis, J., McKinney, K., Hall, W., et al. (1992). Relationship of anxiety and depression. Psychopharmacology, 106, S82-S86.

Friedlander, A., Marder, S., Sung, E., \& Child, J. (2004). Panic disorder psychopathology, medical management and dental implications. Journal of the American Dental Association, 135, 771-778.

Friedson, E., \& Feldman, J. J. (1958). The public looks at dental care. Journal of the American Dental Association, 57, 325-335. 
Gale, E., \& Ayer, N. M. (1969). Treatment of dental phobias. Journal of the American Dental Association, 73, 1304-1307.

Gatchel, R. J. (1999). Perspectives on pain: A historical overview. In R. J. Gatchel \& D. C. Turk (Eds.), Psychosocial factors in pain: Critical Perspectives (pp. 3-17). New York: Guilford Press.

Gatchel, R. J., \& Epker, J. (1999). Psychosocial predictors of chronic pain and response to treatment. In R. J. Gatchel \& D. C. Turk (Eds.), Psychosocial factors in pain: Critical perspectives (pp. 412-434). New York: Guilford Press.

Gatchel, R. J., Ingersoll, B. D., Bowman, L., Robertson, M. C., \& Walker, C. (1983). The prevalence of dental fear and avoidance: A recent survey study. Journal of the American Dental Association, 107, 609-610.

Gedney, J., \& Logan, H. (2004). Memory for stress-associated acute pain. Journal of Pain, 5, 8391.

Gedney, J., \& Logan, H. (2006). Pain related recall predicts future pain report. Pain, 121, 69-76. Gedney, J., Logan, H., \& Baron, R. (2003). Predictors of short-term and long-term memory of sensory and affective dimensions of pain. Journal of Pain, 4, 47-55.

Gençöz, T. (2002). Discriminant validity of low positive affect: is it specific to depression? Personality and Individual Differences, 32, 991-999.

Grillon, C. (2002). Startle reactivity and anxiety disorders: Aversive conditioning, context, and neurobiology. Biological Psychiatry, 52, 958-975.

Grillon, C. (2008). Models and mechanisms of anxiety: evidence from startle studies. Psychopharmacology, 199, 421-437. 
Hall, N., \& Edmondson, H. D. (1983). The aetiology and psychology of dental fear. British Dental Journal, 154, 247-252.

Howell, D. C. (2002). Statistical methods for psychology (ed. 5). Pacific Grove, CA: Duxbury.

Hittelman, E., \& Bahn, S. (2006). Nonpharmacological approaches to managing pain and anxiety. In I. D. Mostofsky, A. G. Forgione, \& D. B. Giddon (Eds.), Behavioral dentistry (pp. 189-201). Malden, MA: Blackwell.

Izard, C. E. (1992). Basic emotions, relations among emotions, and emotion-cognition relations. Psychological Review, 99, 561-565.

Jamison, R. N., Sbrocco, T., \& Parris, W. C. V. (1989). The influence of physical and psychosocial factors on accuracy of memory for pain in chronic pain patients. Pain, 37, 289-294.

Johansson, P., \& Berggren, U. (1992). Assessment of dental fear: A comparison of two psychometric instruments. Acta Odontologica Scandinavica, 50, 43-49.

Joiner, T. E., Steer, R. A., Beck, A. T., Schmidt, N. B., Rudd, M. D., \& Catanzaro, S. J. (1999). Physiological hyperarousal: Construct validity of a central aspect of the tripartite model of anxiety and depression. Journal of Abnormal Psychology, 108, 290-298.

Kapsi, S. P., McNally, R. J., \& Amir, N. (1995). Cognitive processing of emotional information in posttraumatic stress disorder. Cognitive Therapy and Research, 19, 433-444.

Kennedy, S. G., \& McNeil, D. W. (2001). A short form of the Fear of Pain Questionnaire-III. Unpublished manuscript, West Virginia University, Morgantown.

Kent, G. (1984). Anxiety, pain and type of dental procedure. Behaviour Research and Therapy, 22, 465-469.

Kent, G. (1985). Memory of dental pain. Pain, 21, 187-194. 
Kent, G. (1989). Memory of dental experiences as related to naturally occurring changes in state anxiety. Cognition and Emotion, 3, 45-53.

Kent, G., \& Warren, P. (1985). A study of factors associated with changes in dental anxiety. Journal of Dental Research, 64, 1316-1318.

Kinane, D., \& Bouchard, P. (2008). Periodontal diseases and health: Consensus Report of the Sixth European Workshop on Periodontology. Journal of Clinical Periodontology, 35, 333-337.

Klages, U., Ulusoy, O., Kianifard, S., \& Wehrbein, H. (2004). Dental trait anxiety and pain sensitivity as predictors of expected and experienced pain in stressful dental procedures. European Journal of Oral Sciences, 112, 477-483.

Kleinknecht, R. A., \& Bernstein, D. A. (1978). The assessment of dental fear. Behavior Therapy, 9, 626-634.

Kleinknecht, R. A., Klepac, R. K., \& Alexander, L. D. (1973). Origins and characteristics of fear of dentistry. Journal of the American Dental Association, 86, 842-848.

Klem, L. (1995). Path analysis. In L. G. Grimm \& P. R. Yarnold (Eds.), Reading and understanding multivariate statistics (pp. 65-97). Washington, DC: American Psychological Association.

Klem, L. (2000). Structural equation modeling. In L. G. Grimm \& P. R. Yarnold (Eds.), Reading and understanding more multivariate statistics (pp. 227-259). Washington, DC: American Psychological Association.

Klepac, R., Dowling, J., \& Hauge, G. (1982). Characteristics of clients seeking therapy for the reduction of dental avoidance: reactions to pain. Journal of Behavior Therapy and Experimental Psychiatry, 13, 293-300. 
Klepac, R., McDonald, M., Hauge, G., \& Dowling, J. (1980). Reactions to pain among subjects high and low in dental fear. Journal of Behavioral Medicine, 3, 373-384.

Kremer, E., Atkinson, J., \& Ignelzi, R. (1981). Measurement of pain: Patient preference does not confound pain measurement. Pain, 10, 241-248.

Lautch, H. (1971). Dental phobia. British Journal of Psychiatry, 119, 151-158.

Liddell, A., \& May, B. (1984). Some characteristics of regular and irregular attenders for dental check-ups. The British Journal of Clinical Psychology, 23, 19-26.

Linton, S. J., \& Götestam, K. G. (1983). A clinical comparison of two pain scales: Correlation, remembering chronic pain and a measure of compliance. Pain, 17, 57-65.

Linton, S. J., \& Melin, L. (1982). The accuracy of remembering chronic pain. Pain, 13, 281-285.

Lowe, N. K., \& Roberts, J. E. (1988). The convergence between in-labour reports on post-partum recall of parturition pain. Research in Nursing and Health, 11, 11-21.

MacLeod, C., \& Mathews, A. (2004). Selective memory effects in anxiety disorders: An overview of research findings and their implications. In D. Reisberg \& P. Hertel (Eds.), Memory and emotion (pp. 155-185). New York: Oxford University Press.

Madigan, R. J., \& Bollenbach, A. K. (1982). Effects of induced mood on retrieval of personal episodic and semantic memories. Psychological Reports, 50, 147-157.

Maggirias, J., \& Locker, D. (2002a). Five-year incidence of dental anxiety in an adult population. Community Dental Health, 19, 173-179.

Maggirias, J., \& Locker, D. (2002b). Psychological factors and perceptions of pain associated with dental treatment. Community Dentistry and Oral Epidemiology, 30, 151-159.

McEwen, B. (2001). Plasticity of the hippocampus: Adaptation to chronic stress and allostatic load. Annals of the New York Academy of Sciences, 933, 265-277. 
McGlynn, F., McNeil, D., Gallagher, S., \& Vrana, S. (1987). Factor structure, stability, and internal consistency of the Dental Fear Survey. Behavioral Assessment, 9, 57-66.

McNally, R. J., Metzger, L. J., Lasko, N. B., Clancy, S. A., \& Pitman, R. K. (1998). Directed forgetting of trauma cues in adult survivors of childhood sexual abuse with and without posttraumatic stress disorder. Journal of Abnormal Psychology, 107, 596-601.

McNeil, D., \& Berryman, M. (1989). Components of dental fear in adults? Behaviour Research and Therapy, 27, 233-236.

McNeil, D. W., Helfer, A. J., Weaver, B. D., Graves, R. W., Kyle, B. N., \& Davis, A. M. (2010). Memory of pain and anxiety associated with tooth extraction. Manuscript resubmitted for publication.

McNeil, D. W., \& Rainwater, A. J. (1998). Development of the fear of pain questionnaire-III. Journal of Behavioral Medicine, 21, 389-410.

Melamed, B. G. (1979). Behavioral approaches to fear in dental settings. In M. Hersen, R. Eisler, \& P. Miller (Eds.), Progress in behavior modification (vol. 7, pp. 171-203). New York: Academic Press.

Melzack, R. (1987). The short form McGill Pain Questionnaire. Pain, 30, 191-197.

Mineka, S., \& Nugent, K. (1995). Mood-congruent memory biases in anxiety and depression. In D. L. Schacter (Ed.), Memory distortions: How minds, brains, and societies reconstruct the past (pp. 173-193). Cambridge, MA: Harvard University Press.

Mineka, S., Watson, D., \& Clark, L. A. (1998). Comorbidity of anxiety and unipolar mood disorders. Annual Review of Psychology, 49, 377-412.

Minigh, A., Fizer, M. McCormick, M. B., McPherson-Canizales, A., \& McNeil, D. W. (2008, April). Fear across specific dental procedures. Journal of Dental Research, 87, A-415. 
Mogg, K., Bradbury, K., \& Bradley, B. (2006). Interpretation of ambiguous information in clinical depression. Behaviour Research and Therapy, 44, 1411-1419.

Mogg, K. Mathews, A., \& Weinman, J. (1987). Memory bias in clinical anxiety. Journal of Abnormal Psychology, 96, 94-98.

Moore, R., Berggren, U., \& Carlsson, S. G. (1991). Reliability and clinical usefulness of psychometric measures in a self-referred population of odontophobics. Community Dentistry and Oral Epidemiology, 19, 347-351.

Morris, W. (1999). The mood system. In D. Kahneman, E. Diener, \& N. Schwarz (Eds.), Wellbeing: The foundations of hedonic psychology (pp. 169-189). New York: Russell Sage Foundation.

Muglali, M., \& Komerik, N. (2008). Factors related to patients' anxiety before and after oral surgery. Journal of Oral and Maxillofacial Surgery, 66, 870-877.

Muntaner, C., \& Barnett, E. (2000). Depressive symptoms in rural West Virginia: Labor market and health services correlates. Journal of Health Care for the Poor and Underserved, 11, 284-300.

Nelson, D. V., \& Novy, D. M. (1997). Self-report differentiation of anxiety and depression in chronic pain. Journal of Personality Assessment, 69, 392-407.

Niven, C. (1988). Labour pain: Long-term recall and consequences. Journal of Reproductive and Infant Psychology, 6, 83-87.

Niven, C., \& Murphy-Black, T. (2000). Memory for labor pain: A review of the literature. Birth: Issues in Perinatal Care, 27, 244-253.

Norvell, K. T., Gaston-Johansson, F., \& Fridh, G. (1987). Remembrance of labour pain: How valid are retrospective pain measurements? Pain, 31, 77-86. 
Nunn, J. D., Stevenson, R. J., \& Whalan, G. (1984). Selective memory effects in agoraphobic patients. British Journal of Clinical Psychology, 23, 195-201.

Nutt, D. (1997). Management of patients with depression associated with anxiety symptoms. Journal of Clinical Psychiatry, 58 (suppl. 8), 11-16.

Ostir, G. V., Smith, P. M., Smith, D., \& Ottenbacher, K. J. (2005). Reliability of the Positive and Negative Affect Schedule (PANAS) in medical rehabilitation. Clinical Rehabilitation, 19, 767-769.

Pelle, A. J., Denollet, J., Zwisler, A. D., Pedersen, S. S. (2009). Overlap and distinctiveness of psychological risk factors in patients with ischemic heart disease and chronic heart failure: Are we there yet? Journal of Affective Disorders, 113, 150-156.

Pincus, T., Pearce, S., McClelland, A., \& Isenberg, D. (1995). Endorsement and memory bias of self-referential pain stimuli in depressed pain patients. British Journal of Clinical Psychology, 34, 267-277.

Preacher, K. J., \& Hayes, A. F. (2004). SPSS and SAS procedures for estimating indirect effects in simple mediation models. Behavior Research Methods, Instruments, and Computers, 36, 717-731.

Price, D., Bush, F., Long, S., \& Harkins, S. (1994). A comparison of pain measurement characteristics of mechanical visual analogue and simple numerical rating scales. Pain, $56,217-226$.

Price, D., McGrath, P., Rafii, A., \& Buckingham, B. (1983). The validation of visual analogue scales as ratio scale measures for chronic and experimental pain. Pain, 17, 45-56.

Rachman, S., \& Bichard, S. (1988). The overprediction of fear. Clinical Psychology Review, 8, 303-312. 
Radloff, L. (1977). The CES-D Scale: A self-report depression scale for research in the general population. Applied Psychological Measurement, 1, 385-401.

Rainville, P., Doucet, J., Fortin, M., \& Duncan, G. (2004). Rapid deterioration of pain sensorydiscriminative information in short-term memory. Pain, 110, 605-615.

Raykov, T., Tomer, A., Nesselroade, J. R. (1991). Reporting structural equation modeling results in Psychology and Aging: Some proposed guidelines. Psychology and Aging, 6, 499-503.

Redelmeier, D., \& Kahneman, D. (1996). Patients' memories of painful medical treatments: Real-time and retrospective evaluations of two minimally invasive procedures. Pain, 66, $3-8$.

Rhudy, J. L., \& Meagher, M. W. (2000). Fear and anxiety: Divergent effects on human pain thresholds. Pain, 84, 65-75.

Robinson, M. E., \& Riley III, J. L. (1999). The role of emotion in pain. In R. J. Gatchel \& D. C. Turk (Eds.), Psychosocial factors in pain: Critical Perspectives (pp. 74-88). New York: Guilford Press.

Rofé, Y., \& Algom, D. (1985). Accuracy of remembering postdelivery pain. Perceptual and Motor Skills, 60, 99-105.

Roediger, H. L., McDermott, K. B. (1995). Creating false memories: Remembering words not presented in lists. Journal of Experimental Psychology: Learning, Memory, and Cognition, 21, 803-814.

Roelofs, J., Peters, M. L., Deutz, J., Spijker, C., \& Vlaeyen, J. W. S. (2005). The Fear of Pain Questionnaire (FPQ): Further psychometric examination in a non-clinical sample. Pain, 116, 339-346. 
Schmidt, S. R., \& Bohannon, J. N. (1988). In defense of the flashbulb-memory hypothesis: A comment on McCloskey, Wible, and Cohen (1988). Journal of Experimental Psychology: General, 117, 332-335.

Scott, D., \& Hirschman, R. (1982). Psychological aspects of dental anxiety in adults. Journal of the American Dental Association, 104, 27-31.

Singer, J. A., \& Salovey, P. (1988). Mood and memory: Evaluating the network theory of affect. Clinical Psychology Review, 8, 211-251.

Smith, T., \& Heaton, L. (2003). Fear of dental care: Are we making any progress? Journal of the American Dental Association, 134, 1101-1108.

Stabholz, A., \& Peretz, B. (1999). Dental anxiety among patients prior to different dental treatments. International Dental Journal, 49, 90-94.

Stone, A., Schwartz, J., Broderick, J., \& Shiffman, S. (2005). Variability of momentary pain predicts recall of weekly pain: A consequence of the peak (or salience) memory heuristic. Personality and Social Psychology Bulletin, 31, 1340-1346.

Tabachnick, B. G., \& Fidell, L. S. (2007). Using multivariate statistics (ed. 5). Boston: Pearson Education.

Teasdale, J. D., \& Russell, M. L. (1983). Differential effects of induced mood on the recall of positive, negative, and neutral words. British Journal of Clinical Psychology, 22, 163172.

Teasdale, J. D., Taylor, R., \& Fogarty, S. J. (1980). Effects of induced elation-depression on the accessibility of memories of happy and unhappy experiences. Behaviour Research and Therapy, 18, 339-346. 
Terry, R., Niven, C., Brodie, E., Jones, R., \& Prowse, M. (2008). Memory for pain? A comparison of nonexperiential estimates and patients' reports of the quality and intensity of postoperative pain. Journal of Pain, 9, 342-349.

Thompson, B. (2000). Ten commandments of structural equation modeling. In L. G. Grimm \& P. R. Yarnold (Eds.), Reading and understanding more multivariate statistics (pp. 261-283). Washington, DC: American Psychological Association.

Turk, D. C., Monarch, E. S., \& Williams, A. D. (2004). Assessment of chronic pain sufferers. In T. Hadjistavropoulous \& K. D. Craig (Eds.), Pain: Psychological perspectives (pp. 209-243). Mahwah, NJ: Lawrence Erlbaum.

Tversky, A., \& Kahneman, D. (1974). Judgment under uncertainty: Heuristics and biases. Science, 185, 1124-1131.

Wardle, J. (1982). Fear of dentistry. British Journal of Medical Psychology, 55, 119-126.

Wardle, J. (1984). Dental pessimism: Negative cognitions in fearful dental patients. Behaviour Research and Therapy, 22, 553-556.

Watkins, C., Logan, H., \& Kirchner, H. (2002). Anticipated and experienced pain associated with endodontic therapy. Journal of the American Dental Association, 133, 45-54.

Watson, D., \& Clark, L. A. (1984). Negative affectivity: The disposition to experience aversive emotional states. Psychological Bulletin, 96, 465-490.

Watson, D., \& Clark, L. A. (1994). The PANAS-X: Manual for the Positive and Negative Affect Schedule-Expanded Form. Iowa City, IA: University of Iowa Press.

Watson, D., Clark, L. A., \& Carey, G. (1988). Positive and negative affectivity and their relation to anxiety and depressive disorders. Journal of Abnormal Psychology, 97, 346-353. 
Watson, D., Clark, L. A., \& Tellegen, A. (1988). Development and validation of brief measures of positive and negative affect: The PANAS scales. Journal of Personality and Social Psychology, 54, 1063-1070.

Watson, D., O’Hara, M. W., \& Stuart, S. (2008). Hierarchical structures of affect and psychopathology and their implications for the classification of emotional disorders. Depression and Anxiety, 25, 282-288.

Watson, D., \& Pennebaker, J. W. (1989). Health complaints, stress, and distress: Exploring the central role of negative affectivity. Psychological Review, 96, 234-254.

Watts, F. N., Trezise, L., Sharrock, R. (1986). Processing of phobic stimuli. British Journal of Clinical Psychology, 25, 253-259.

Weissman, M., Sholomskas, D., Pottenger, M., Prusoff, B., \& Locke, B. (1977). Assessing depressive symptoms in five psychiatric populations: a validation study. American Journal of Epidemiology, 106, 203-214.

Wenzel, A., Pinna, K., \& Rubin, D. (2004). Autobiographical memories of anxiety-related experiences. Behaviour Research and Therapy, 42, 329-341.

Williams, J., Peeters, F., \& Zautra, A. (2004). Differential affect structures in depressive and anxiety disorders. Anxiety, Stress, and Coping, 17, 321-330.

Wolff, B. B. (1983). Laboratory methods of pain measurement. In R. Melzack (Ed.), Pain measurement and assessment (pp. 7-13). New York: Raven Press.

Wong, M., \& Lytle, W. R. (1991). A comparison of anxiety levels associated with root canal therapy and oral surgery treatment. Journal of Endodontics, 17, 461-465.

Zevon, M. A., \& Tellegen, A. (1982). The structure of mood change: An idiographic/nomothetic analysis. Journal of Personality and Social Psychology, 43, 111-122. 
Zinbarg, R. E., Barlow, D. H., Liebowitz, M., Street, L., Broadhead, E., Katon, W., et al. (1994). The DSM-IV field trial for mixed anxiety-depression. American Journal of Psychiatry, $151,1153-1162$. 


\section{Appendix A}

Flow Chart of Study Participants

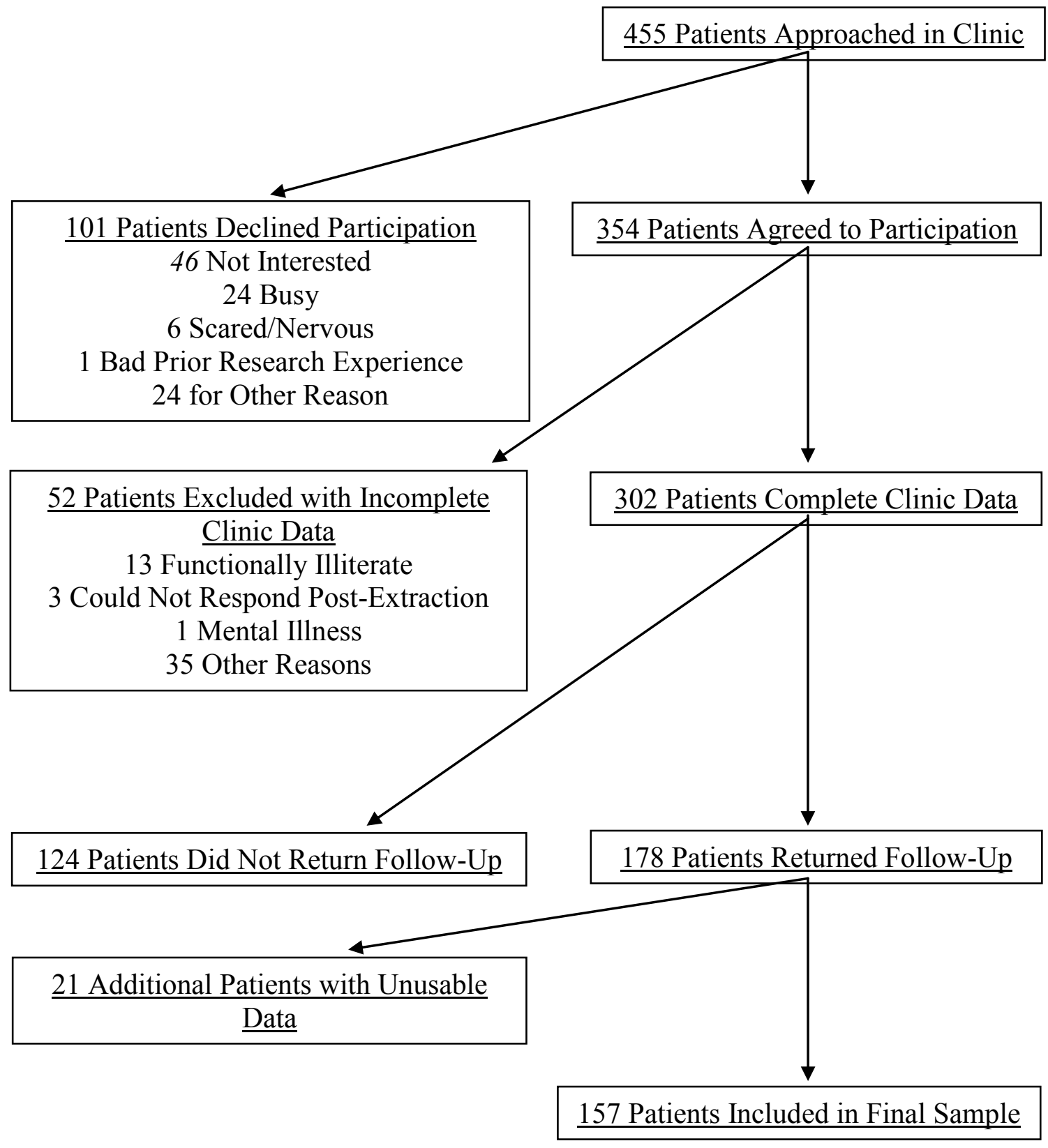




\section{Appendix B}

\section{DFS}

The items in this questionnaire refer to various situations, feelings, and reactions related to dental work. Please rate your feeling or reaction on these items by using the numbers 1-5, from the following scales. Put the appropriate number which most closely corresponds to your reaction in the space to the left of each item.

$\begin{array}{ccccc}1 & 2 & 3 & 4 & 5 \\ \text { never } & \text { once or twice } & \text { a few times } & \text { often } & \text { nearly every time }\end{array}$

1. Has fear of dental work ever caused you to put off making an appointment? $\begin{array}{lllll}.1 & 2 & 3 & 4 & 5\end{array}$

2. Has fear of dental work ever caused

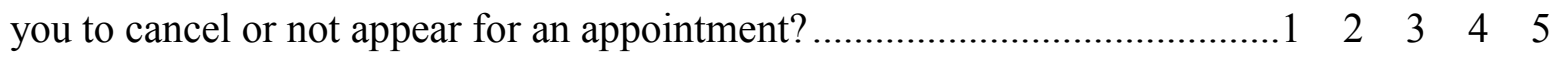

$\begin{array}{ccccc}1 & 2 & 3 & 4 & 5 \\ \text { not at all } & \text { a little } & \text { somewhat } & \text { much } & \text { very much }\end{array}$

\section{When having dental work done:}

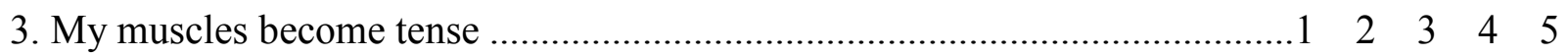

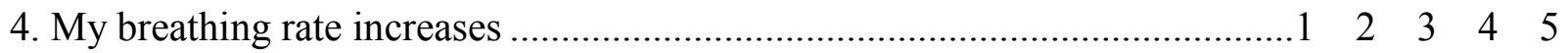

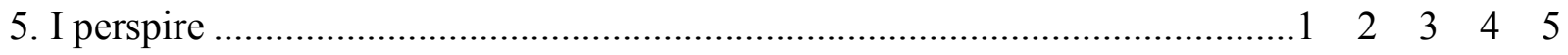

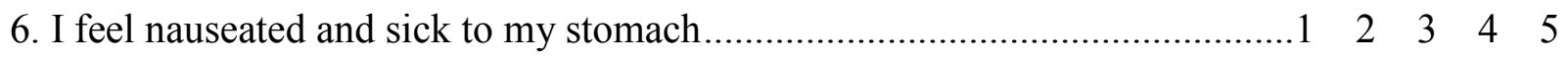

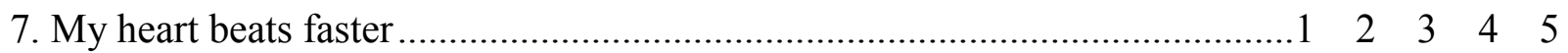

Following is a list of things, and situations that many people mention as being somewhat anxiety or fear producing. Please rate how much fear, anxiety, or unpleasantness each of them causes you. Use the numbers 1-5, from the above scale. (If it helps, try to imagine yourself in each of these situations and describe what your common reaction is.)

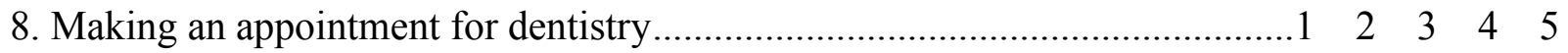

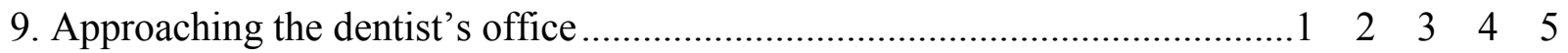

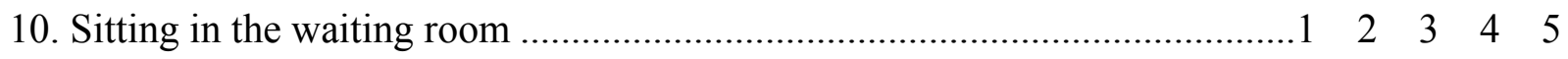

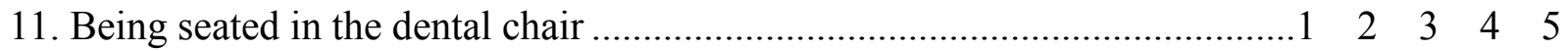




$\begin{array}{ccccc}1 & 2 & 3 & 4 & 5 \\ \text { not at all } & \text { a little } & \text { somewhat } & \text { much } & \text { very much }\end{array}$

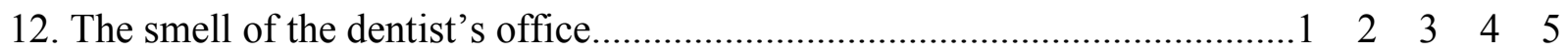

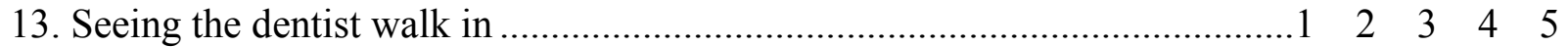

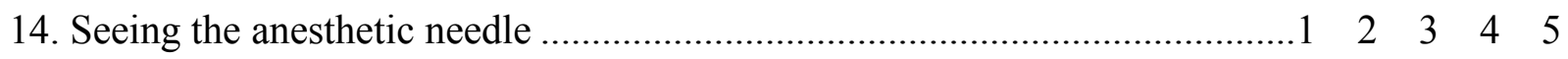

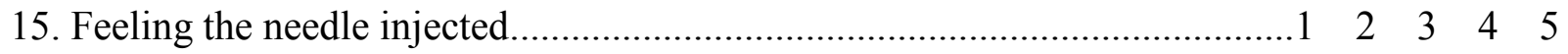

16. Seeing the drill .............................................................................

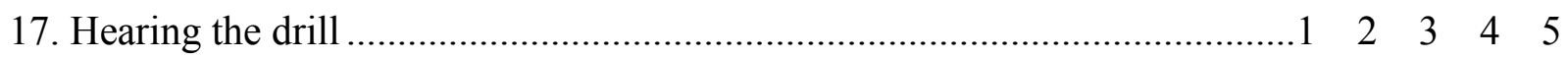

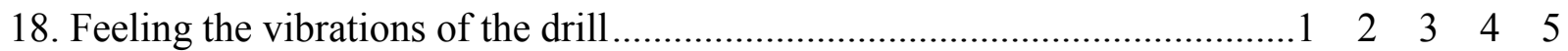

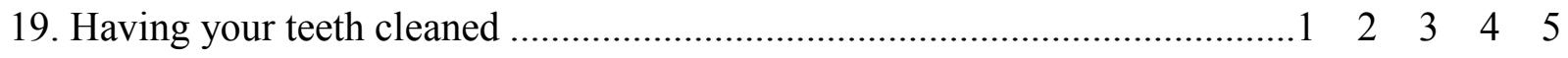

20. All things considered, how fearful are you of

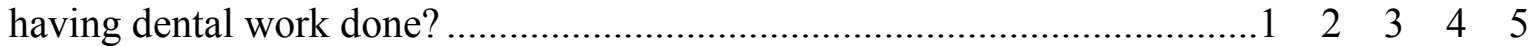




\section{Appendix C}

\section{SF-FPQ}

The items listed below describe painful experiences. Please look at each item and think about how FEARFUL you are of experiencing the PAIN associated with each item. If you have never experienced the PAIN of a particular item, please answer on the basis of how FEARFUL you expect you would be if you had such an experience. Circle the appropriate number next to each item to rate your FEAR OF PAIN in relation to each event.

$\begin{array}{ccccc}1 & 2 & 3 & 4 & 5 \\ \text { not at all } & \text { a little } & \text { a fair amount } & \text { very much } & \text { extreme }\end{array}$

\section{FEAR the PAIN associated with:}

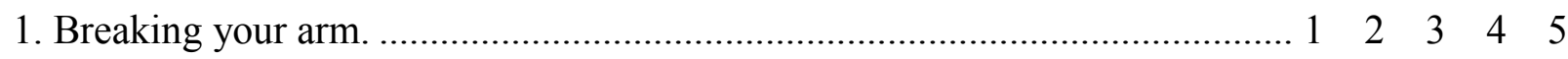

2. Having a foot doctor remove a wart from your foot with a sharp instrument. $1 \quad 2 \quad 3 \quad 4 \quad 5$

3. Getting a paper-cut on your finger................................................ $124 \quad 3 \quad 4 \quad 5$

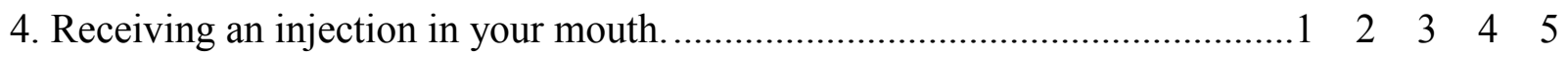

5. Getting strong soap in both your eyes while bathing or showering.............. $\quad 2 \quad 3 \quad 4 \quad 5$

6. Having someone slam a heavy car door on your hand. ........................... $2 \quad 2 \quad 3 \quad 4 \quad 5$

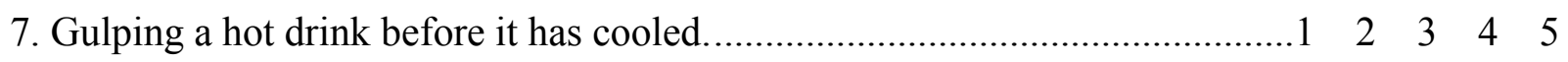

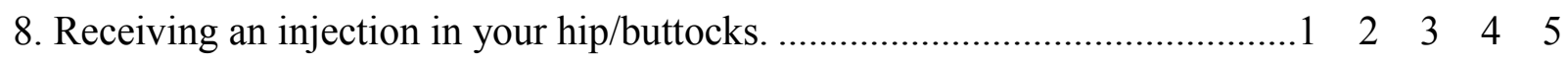

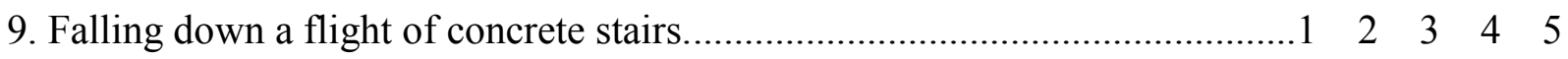




\section{Appendix D}

\section{CESDR}

Instructions: Below is a list of the ways you might have felt or behaved. Please indicate how often you have felt this way during the past week or so by placing a mark in the appropriate column. Please respond to all items.

\begin{tabular}{|c|c|c|c|c|c|}
\hline & $\begin{array}{l}\text { Rarely or } \\
\text { none of the } \\
\text { time (less } \\
\text { than } 1 \text { day) }\end{array}$ & $\begin{array}{l}\text { Some or a } \\
\text { little of } \\
\text { the time } \\
(1-2 \text { days })\end{array}$ & $\begin{array}{l}\text { Occasionally } \\
\text { or a moderate } \\
\text { amount of time } \\
(3-4 \text { days })\end{array}$ & $\begin{array}{l}\text { All of } \\
\text { the time } \\
\text { (5-7 } \\
\text { days) }\end{array}$ & $\begin{array}{l}\text { Nearly } \\
\text { every } \\
\text { day for } 2 \\
\text { weeks }\end{array}$ \\
\hline 1. My appetite was poor. & & & & & \\
\hline $\begin{array}{l}\text { 2. I could not shake off the } \\
\text { blues. }\end{array}$ & & & & & \\
\hline $\begin{array}{l}\text { 3. I had trouble keeping } \\
\text { my mind on what I was } \\
\text { doing. }\end{array}$ & & & & & \\
\hline 4. I felt depressed. & & & & & \\
\hline 5. My sleep was restless. & & & & & \\
\hline 6. I felt sad. & & & & & \\
\hline 7. I could not get going. & & & & & \\
\hline $\begin{array}{l}\text { 8. Nothing made me } \\
\text { happy. }\end{array}$ & & & & & \\
\hline 9. I felt like a bad person. & & & & & \\
\hline $\begin{array}{l}\text { 10. I lost interest in my } \\
\text { usual activities. }\end{array}$ & & & & & \\
\hline $\begin{array}{l}\text { 11. I slept much more than } \\
\text { usual. }\end{array}$ & & & & & \\
\hline $\begin{array}{l}\text { 12. I felt like I was } \\
\text { moving too slowly. }\end{array}$ & & & & & \\
\hline 13. I felt fidgety. & & & & & \\
\hline 14. I wished I were dead. & & & & & \\
\hline $\begin{array}{l}15 . \text { I wanted to hurt } \\
\text { myself. }\end{array}$ & & & & & \\
\hline 16. I was tired all the time. & & & & & \\
\hline 17. I did not like myself. & & & & & \\
\hline $\begin{array}{l}\text { 18. I lost a lot of weight } \\
\text { without trying to. }\end{array}$ & & & & & \\
\hline $\begin{array}{l}\text { 19. I had a lot of trouble } \\
\text { getting to sleep. }\end{array}$ & & & & & \\
\hline $\begin{array}{l}\text { 20. I could not focus on } \\
\text { the important things. }\end{array}$ & & & & & \\
\hline
\end{tabular}




\section{Appendix E}

\section{PANAS}

This scale consists of a number of words that describe feelings and emotions. Read each item and then circle the appropriate answer next to the word. Indicate to what extent you feel this way right now, that is, at the present moment. Use the following scale to record your answers.

$\begin{array}{ccccc}1 & 2 & 3 & 4 & 5 \\ \text { very slightly } & \text { a little } & \text { moderately } & \text { quite a bit } & \text { very much }\end{array}$
or not at all

1. interested $\begin{array}{lllll}.1 & 2 & 3 & 4 & 5\end{array}$

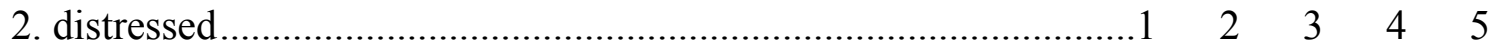

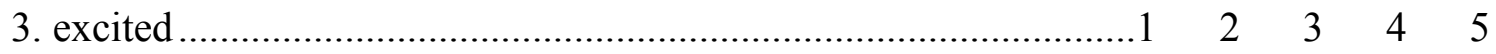

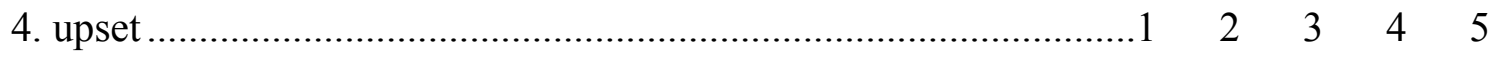

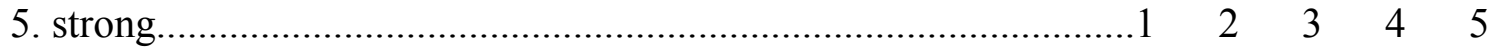

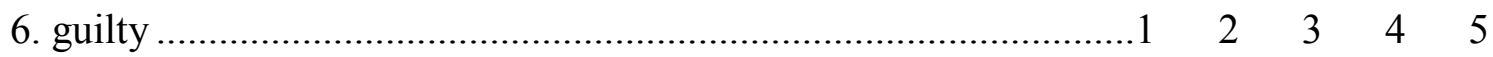

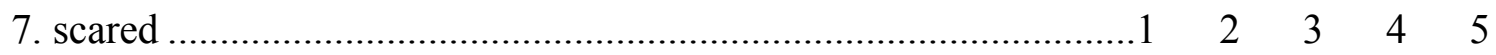

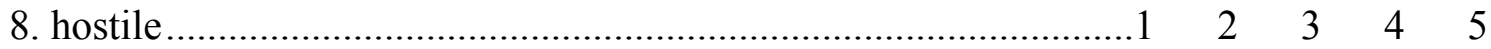

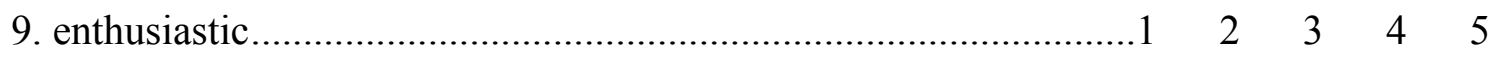

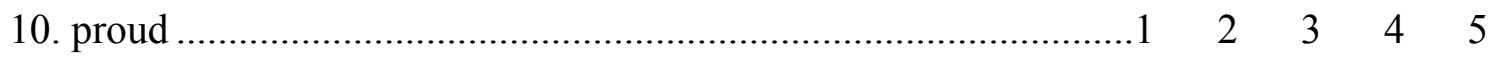

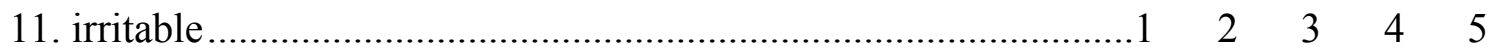

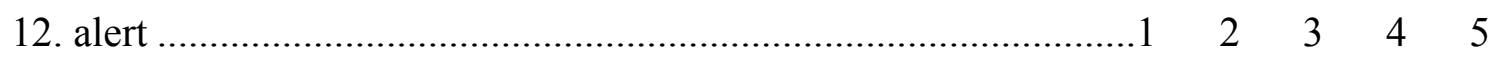

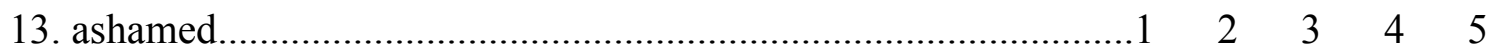

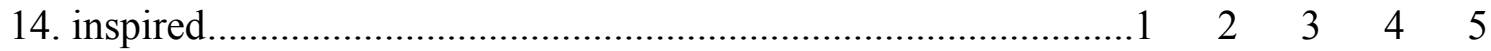

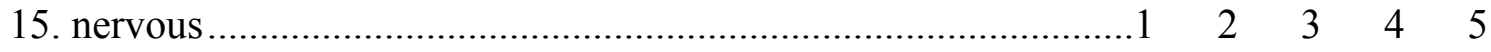

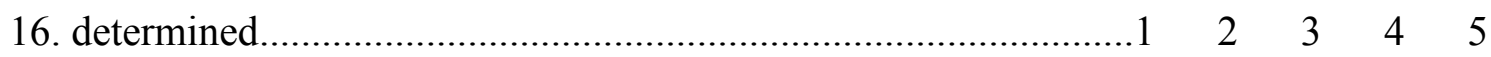

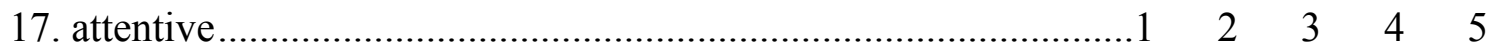

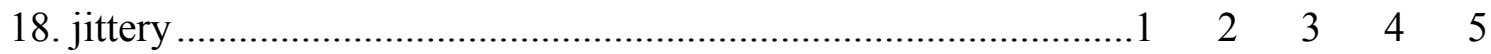

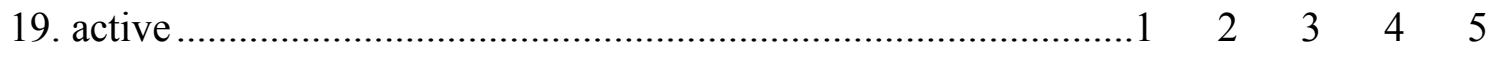

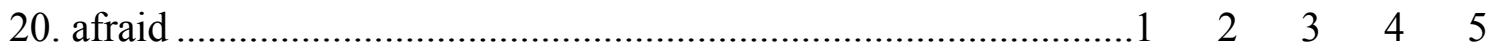




\section{Appendix F}

NRS

(Note: Each NRS was presented on a separate page)

On a scale of 0 to 100 , where $\mathbf{0}$ means no pain and $\mathbf{1 0 0}$ means the most intense pain you can imagine, how much dental pain (are you experiencing right now/ are you expecting during having your tooth pulled/ did you experience during the most painful part of having your tooth pulled)?

On a scale of 0 to 100 , where $\mathbf{0}$ means no anxiety and $\mathbf{1 0 0}$ means the most intense anxiety you can imagine, how much anxiety are you experiencing right now? 
Appendix G

VAS

(Note: Each VAS was presented on a separate page)

Please rate how much dental pain you (are experiencing right now/ are expecting during having your tooth pulled/ experienced during the most painful part of having your tooth pulled)by placing a mark through the line at the appropriate point

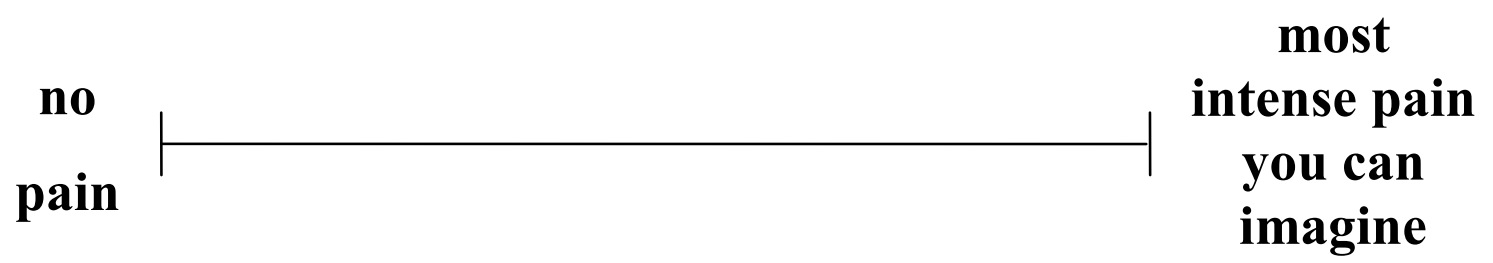

Please rate how much anxiety you are experiencing right now by

placing a mark through the line at the appropriate point

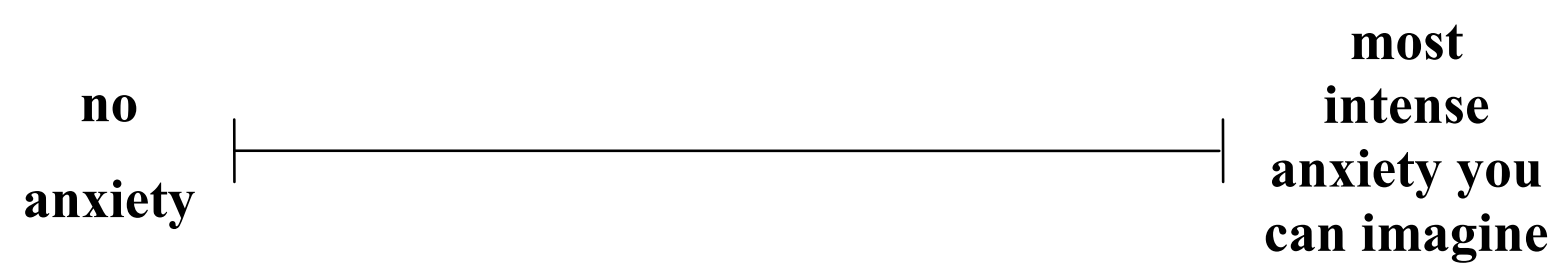




\section{Appendix $\mathrm{H}$}

Flow Chart of Data Collection

Note: Data for Current Pre-Surgery and Predicted Pre-Surgery were collected simultaneously but are presented separately for clarity.

Variables included in the initial path models are in regular font; additional variables of interest are in italicized font.

\begin{tabular}{|c|c|c|c|}
\hline 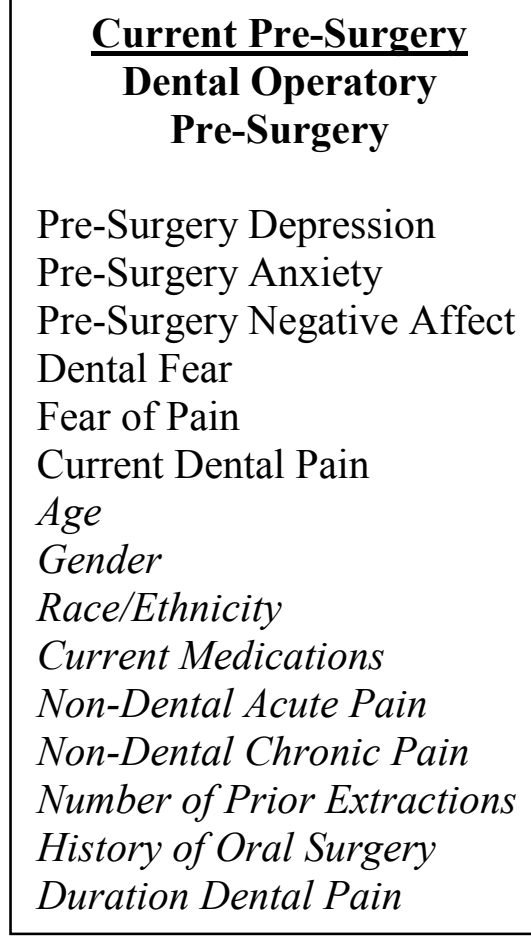 & $\begin{array}{c}\frac{\text { Predicted Pre-Surgery }}{\text { Dental Operatory }} \\
\text { Pre-Surgery } \\
\text { Predicted Dental Pain }\end{array}$ & $\begin{array}{c}\begin{array}{c}\text { Experienced Post-Surgery } \\
\text { Dental Operatory } \\
\text { During Surgery } \\
\text { (Evaluated Immediately } \\
\text { Post-Surgery) }\end{array} \\
\text { Experienced Dental Pain } \\
\text { Number of Teeth Extracted } \\
\text { Location Teeth Extracted } \\
\text { Reason for Extraction } \\
\text { Duration of Procedure } \\
\text { Who Performed Surgery } \\
\text { Incision: Yes/No } \\
\text { Medications Used } \\
\text { Anesthetics } \\
\text { Nerve Blocks }\end{array}$ & $\begin{array}{l}\text { One Month Recalled } \\
\quad \begin{array}{c}\text { One Month } \\
\text { Follow-up }\end{array} \\
\text { Recall Depression } \\
\text { Recall Anxiety } \\
\text { Recall Negative Affect } \\
\text { Recalled Dental Pain } \\
\text { Current Dental Pain } \\
\text { Alveolar Osteitis } \\
\text { Dental Follow- } U p \\
\text { Medical Follow- } U p\end{array}$ \\
\hline
\end{tabular}


Appendix I

Path Model with Anxiety and Depression

Current Pre-Surgery Predicted Pre-Surgery Experienced Post-Surgery One Month Recalled

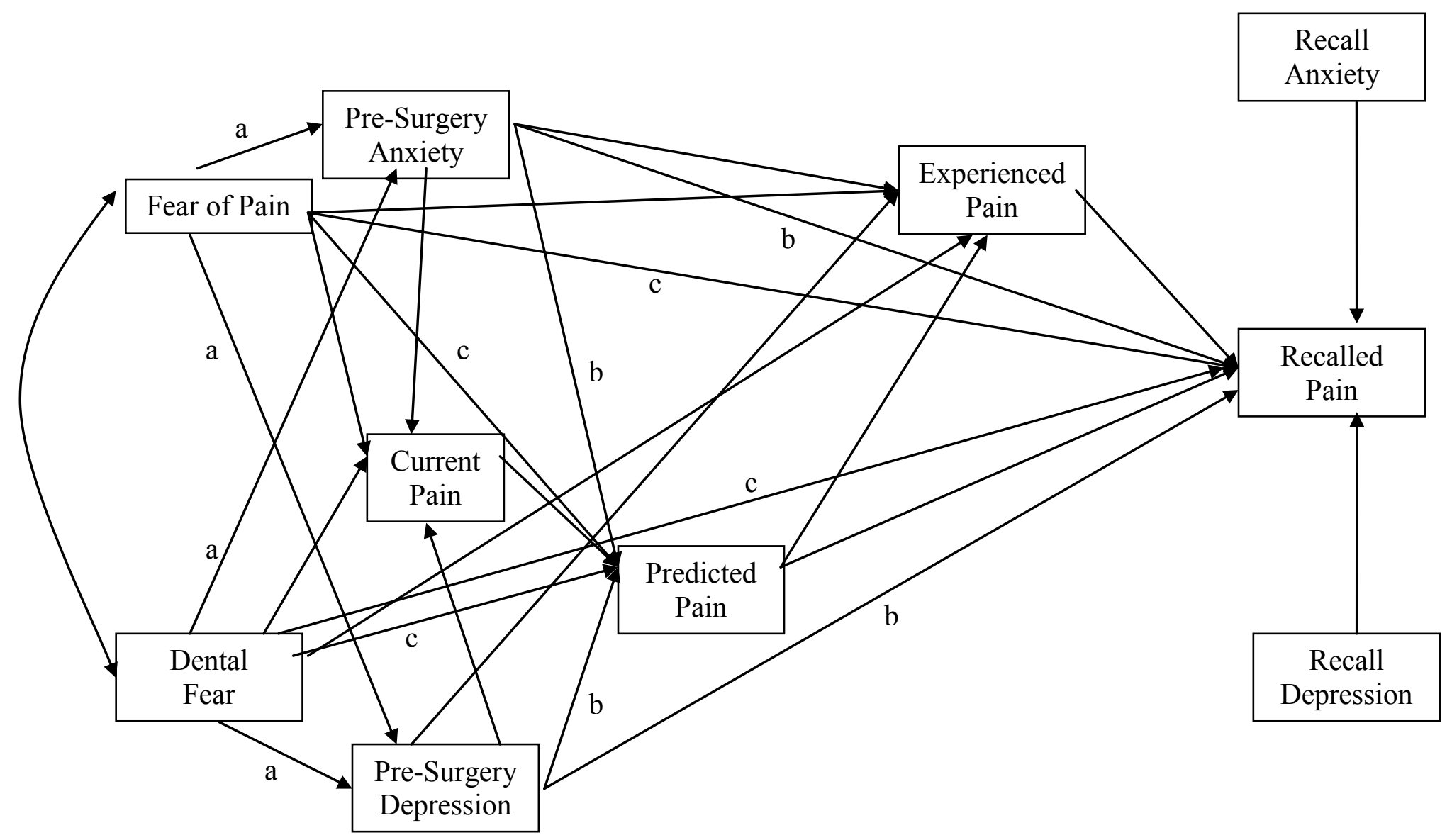


Appendix J

Path Model with Negative Affect

Current Pre-Surgery Predicted Pre-Surgery Experienced Post-Surgery One Month Recalled

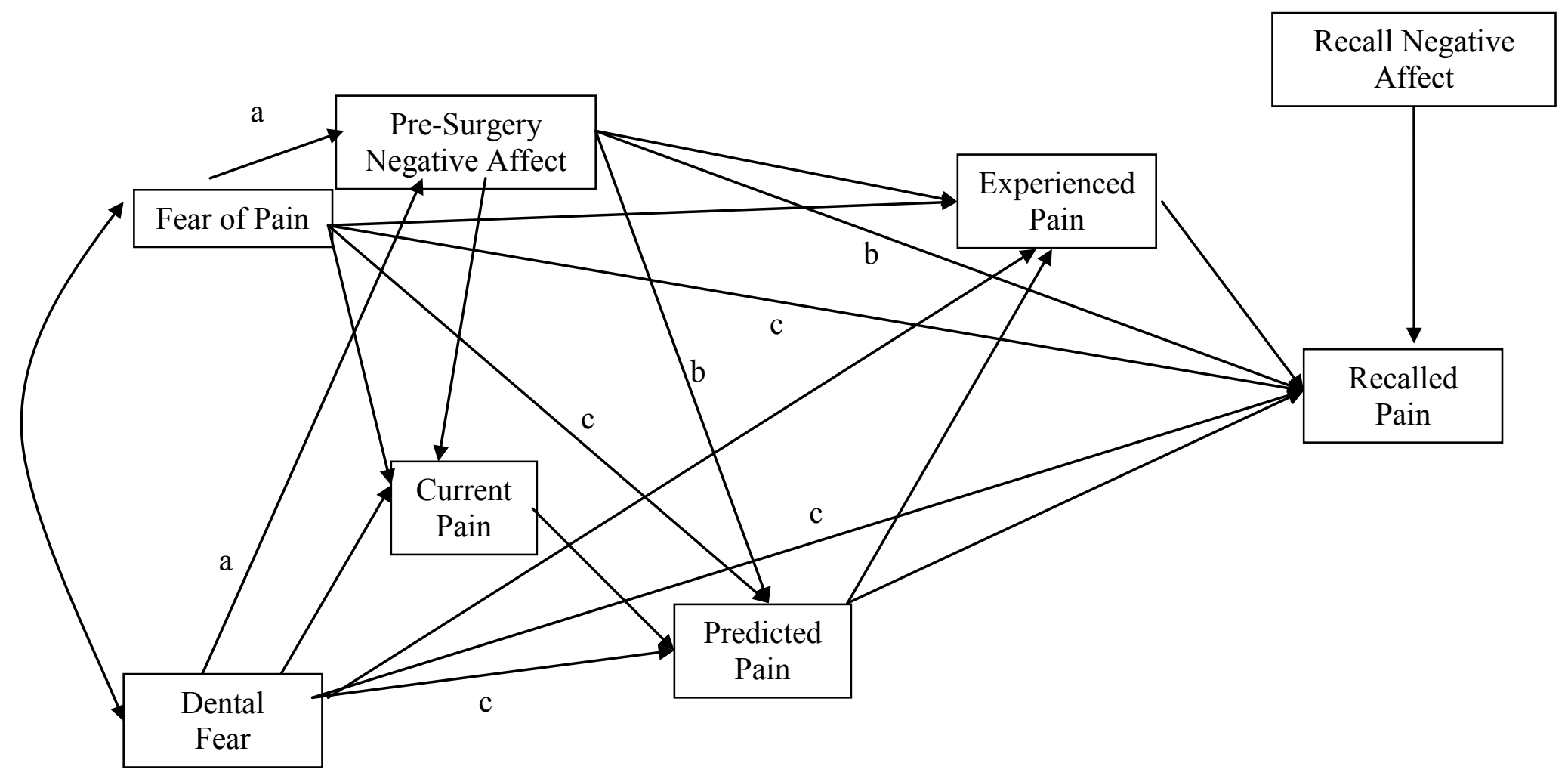


Table 1

Comparison of Participants Who Returned and Did Not Return Follow-Up Survey

Did Not Return Returned Survey Test Statistic

Survey $(N=124) \quad(N=178)$

Path Model Variables

$M(S D)$ or $n(\%) \quad M(S D)$ or $n(\%) \quad t$ or $\chi^{2}$

SF-FPQ Total Score

$24.0(7.4)$

$24.2(7.8)$

$t=-0.27$

DFS Total

$49.7(21.6)$

$49.2(20.2)$

$t=0.21$

Pre-Surgery Anxiety NRS Rating (0 -

$30.6(31.9)$

$32.7(31.7)$

$t=-0.55$

100)

Pre-Surgery Depression (CESDR Total 12.9 (11.4)

$13.9(13.6)$

$t=-0.68$

Score)

Pre-Surgery Negative Affect (PANAS 21.7 (8.6)

$21.0(8.5)$

$t=0.63$

Negative Affect Scale Total Score)

Current Dental Pain

$$
\begin{aligned}
& \operatorname{NRS}(0-100) * * \\
& \operatorname{VAS}(0-100) * * *
\end{aligned}
$$

Predicted Dental Pain

$$
\begin{aligned}
& \operatorname{NRS}(0-100)^{* *} \\
& \operatorname{VAS}(0-100)^{* *}
\end{aligned}
$$

$50.8(34.4)$

$t=2.75$

$47.4(32.1)$

$t=3.42$

Experienced Dental Pain
NRS $(0-100)$
29.1 (32.9)
$25.7(32.1)$
$t=0.89$
VAS $(0-100)$
$28.1(32.6)$
$23.2(30.3)$
$t=1.34$ 
Table 1 (Continued)

Comparison of Participants Who Returned and Did Not Return Follow-Up Survey

\begin{tabular}{|c|c|c|c|}
\hline & $\begin{array}{l}\text { Did Not Return } \\
\text { Survey }(N=124)\end{array}$ & $\begin{array}{l}\text { Returned Survey } \\
(N=178)\end{array}$ & Test Statistic \\
\hline Additional Variables of Interest & $M(S D)$ or $n(\%)$ & $M(S D)$ or $n(\%)$ & $t$ or $\chi^{2}$ \\
\hline Age (In Years)*** & $33.6(10.9)$ & $38.2(13.4)$ & $t=-3.21$ \\
\hline Gender (Number Female) & $58(46.8 \%)$ & $95(53.4 \%)$ & $\chi^{2}=1.27$ \\
\hline Race/Ethnicity & & & $\chi^{2}=1.73$ \\
\hline Caucasian & $115(93.5 \%)$ & $172(96.6 \%)$ & \\
\hline African American & $6(4.9 \%)$ & $4(2.2 \%)$ & \\
\hline Other & $2(1.6 \%)$ & $2(1.1 \%)$ & \\
\hline Taking Any Medications ( $\%$ Yes)** & $69(59.6 \%)$ & $129(72.9 \%)$ & $\chi^{2}=9.62$ \\
\hline Taking Opioids & $10(8.1 \%)$ & $15(8.6 \%)$ & $\chi^{2}=0.02$ \\
\hline Taking NSAIDS or Acetaminophen & $26(21.0 \%)$ & $51(29.1 \%)$ & $\chi^{2}=2.54$ \\
\hline Taking Psychoactives*** & $15(12.1 \%)$ & $51(29.1 \%)$ & $\chi^{2}=12.26$ \\
\hline $\begin{array}{l}\text { Experiencing Non-dental Acute Pain } \\
\qquad(\% \text { Yes })\end{array}$ & $24(19.4 \%)$ & $30(16.9 \%)$ & $\chi^{2}=0.31$ \\
\hline Non-dental Acute Pain Rating $(0-100)$ & $40.2(29.5)$ & $35.0(23.1)$ & $t=0.73$ \\
\hline $\begin{array}{l}\text { Experiencing Non-dental Chronic Pain } \\
\qquad(\% \text { Yes })\end{array}$ & $24(19.4 \%)$ & $44(24.7 \%)$ & $\chi^{2}=1.21$ \\
\hline $\begin{array}{l}\text { Non-dental Chronic Pain Rating } \\
\qquad(0-100)^{*}\end{array}$ & $29.5(29.7)$ & $48.5(29.8)$ & $t=-2.51$ \\
\hline
\end{tabular}


Table 1 (Continued)

Comparison of Participants Who Returned and Did Not Return Follow-Up Survey

\begin{tabular}{|c|c|c|c|}
\hline & $\begin{array}{l}\text { Did Not Return } \\
\text { Survey }(N=124)\end{array}$ & $\begin{array}{l}\text { Returned Survey } \\
(N=178)\end{array}$ & Test Statistic \\
\hline Additional Variables of Interest & $M(S D)$ or $n(\%)$ & $M(S D)$ or $n(\%)$ & $t$ or $\chi^{2}$ \\
\hline Number of Prior Extractions & $4.1(4.4)$ & $5.0(5.9)$ & $t=-1.50$ \\
\hline Number of Previous Root Canals & $0.7(1.6)$ & $0.8(1.7)$ & $t=-0.18$ \\
\hline Number of Prior Periodontal Surgeries & $0.0(0.2)$ & $0.0(0.2)$ & $t=0.53$ \\
\hline Duration of Current Dental Pain (Days) & $99.6(323.7)$ & $47.5(119.5)$ & $t=1.77$ \\
\hline Number of Teeth Extracted & $1.6(2.9)$ & $1.3(0.7)$ & $t=1.60$ \\
\hline Duration of Procedure (Minutes) & $43.5(15.4)$ & $45.0(16.2)$ & $t=-0.77$ \\
\hline \multicolumn{4}{|l|}{ Number of Providers Performing } \\
\hline \multicolumn{4}{|l|}{ Extraction } \\
\hline Students & $0.8(0.6)$ & $0.8(0.5)$ & $t=-0.44$ \\
\hline Residents/Interns & $0.6(0.6)$ & $0.5(0.5)$ & $t=1.75$ \\
\hline Assistants & $0.1(0.3)$ & $0.1(0.3)$ & $t=0.04$ \\
\hline Faculty & $0.1(0.3)$ & $0.1(0.3)$ & $t=-0.37$ \\
\hline $\begin{array}{l}\text { Extraction Required Incision/Surgery } \\
\qquad(\% \text { Yes })\end{array}$ & $18(14.5 \%)$ & $20(11.3 \%)$ & $\chi^{2}=0.68$ \\
\hline $\begin{array}{l}\text { Re-injected with Initial Anesthetic } \\
\qquad(\% \text { Yes) }\end{array}$ & $54(43.5 \%)$ & $74(41.6 \%)$ & $\chi^{2}=0.12$ \\
\hline $\begin{array}{l}\text { Injected with Additional Anesthetic } \\
\text { (\% Yes) }\end{array}$ & $20(16.1 \%)$ & $30(16.9 \%)$ & $\chi^{2}=0.03$ \\
\hline
\end{tabular}


Table 1 (Continued)

Comparison of Participants Who Returned and Did Not Return Follow-Up Survey

Did Not Return Returned Survey Test Statistic

Survey $(N=124) \quad(N=178)$

Additional Variables of Interest $\quad M(S D)$ or $n(\%) \quad M(S D)$ or $n(\%) \quad t$ or $\chi^{2}$

Additional Nerve Block (\% Yes) $\quad 24(19.4 \%) \quad 55(18.3 \%) \quad \chi^{2}=0.17$

Note. SF-FPQ = Short Form - Fear of Pain Questionnaire; DFS = Dental Fear Survey; NRS =

Numerical Rating Scale; CESDR = Center for Epidemiological Studies Depression Scale

Revised; PANAS = Positive Affect and Negative Affect Schedule; VAS = Visual Analogue

Scale.

${ }^{*} p<.05,{ }^{* *} p<.01, * * * p<.001$ 


\begin{tabular}{ll}
\hline Table 2 & \\
Means and Frequencies for Additional Variables of Interest in Final Sample \\
\hline & $M(S D)$ or $n(\%)$ \\
\hline Age (In Years) & $38.0(13.7)$ \\
Gender (Number Female) & $87(55.4 \%)$ \\
Race/Ethnicity & \\
$\quad$ Caucasian & $153(97.5 \%)$ \\
$\quad$ African American & $3(1.9 \%)$ \\
Other & $1(0.6 \%)$ \\
Taking Any Medications (\% Yes) & $112(71.3)$ \\
$\quad$ Taking Opioids & $14(8.9 \%)$ \\
$\quad$ Taking NSAIDS or acetaminophen & $43(27.4 \%)$ \\
Taking Psychoactives & $41(26.1 \%)$ \\
Experiencing Non-dental Acute Pain (\% Yes) & $24(15.3 \%)$ \\
Non-dental Acute Pain Rating (0 - 100) & $32.3(23.4)$ \\
Experiencing Non-dental Chronic Pain (\% Yes) & $39(24.8 \%)$ \\
Non-dental Chronic Pain Rating (0 - 100) & $45.8(29.0)$ \\
Number of Prior Extractions & $4.9(5.8)$ \\
Number of Previous Root Canals & $0.7(1.5)$ \\
Number of Prior Periodontal Surgeries & $0.0(0.2)$ \\
Duration of Current Dental Pain (Days) & $45.1(110.4)$ \\
\hline
\end{tabular}




\begin{tabular}{|c|c|}
\hline \multicolumn{2}{|c|}{$\begin{array}{l}\text { Table } 2 \text { (Continued) } \\
\text { Means and Frequencies for Additional Variables of Interest in Final Sample }\end{array}$} \\
\hline & $M(S D)$ or $n(\%)$ \\
\hline \multicolumn{2}{|l|}{ Number of Providers Performing Extraction } \\
\hline Students & $0.9(0.5)$ \\
\hline Residents/Interns & $0.4(.05)$ \\
\hline Assistants & $0.1(0.3)$ \\
\hline Faculty & $0.1(0.3)$ \\
\hline Extraction Required Incision or Surgery (\% Yes) & $16(10.2 \%)$ \\
\hline Re-injected with Initial Anesthetic (\% Yes) & $67(42.7 \%)$ \\
\hline Injected with Additional Anesthetic (\% Yes) & $26(16.6 \%)$ \\
\hline Additional Nerve Block (\% Yes) & $28(17.8 \%)$ \\
\hline Current Dental Pain at Recall $(0-100)$ & $9.7(21.8)$ \\
\hline Diagnosed with Alveolar Osteitis (\% Yes) & $13(8.3 \%)$ \\
\hline Reported Alveolar Osteitis Symptoms (\% Yes) & $58(36.9 \%)$ \\
\hline Followed Up with Oral Surgery Clinic (\% Yes) & $28(17.8 \%)$ \\
\hline Visited Other Medical or Dental Provider (\% Yes) & $32(20.4 \%)$ \\
\hline Number of Days from Oral Surgery to Recall & $29.9(5.7)$ \\
\hline
\end{tabular}




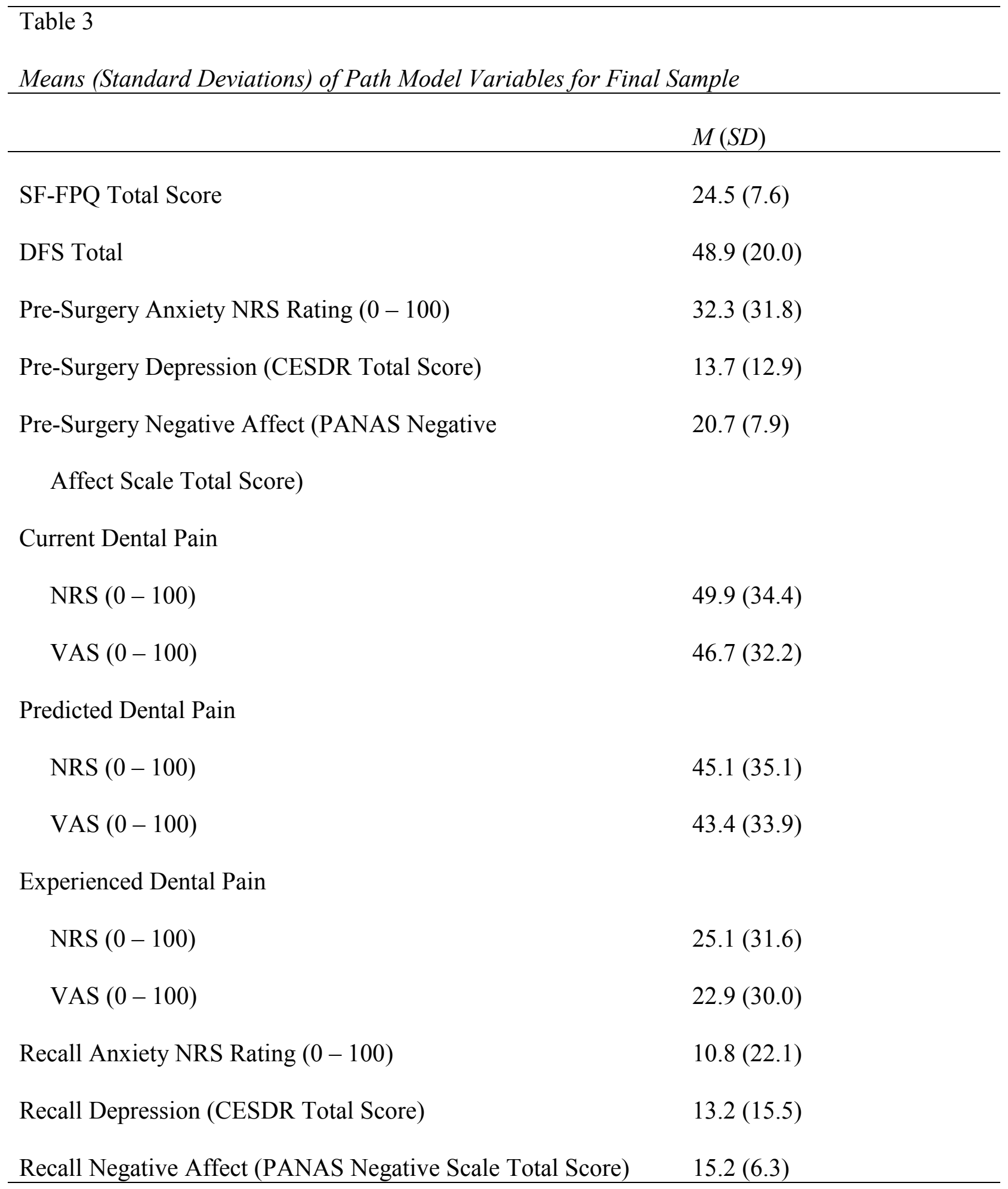


Table 3 (Continued)

Means (Standard Deviations) of Path Model Variables for Final Sample

$M(S D)$

Recalled Dental Pain

NRS

VAS

$37.9(32.7)$

Note. SF-FPQ = Short Form - Fear of Pain Questionnaire; DFS = Dental Fear Survey; NRS = Numerical Rating Scale; CESDR = Center for Epidemiological Studies Depression Scale Revised; PANAS = Positive Affect and Negative Affect Schedule; VAS = Visual Analogue Scale. 


\begin{tabular}{|c|c|}
\hline \multicolumn{2}{|c|}{$\begin{array}{l}\text { Table } 4 \\
\text { Means (Standard Deviations) for Extraction Naïve Participants of Final Sample }(\mathrm{N}=18)\end{array}$} \\
\hline & $M(S D)$ \\
\hline SF-FPQ Total Score & $23.2(6.1)$ \\
\hline DFS Total & $52.7(21.8)$ \\
\hline Pre-Surgery Anxiety NRS Rating $(0-100)$ & $39.6(38.5)$ \\
\hline Pre-Surgery Depression (CESDR Total Score) & $17.3(16.4)$ \\
\hline Pre-Surgery Negative Affect (PANAS Negative & $25.3(8.9)$ \\
\hline \multicolumn{2}{|l|}{ Affect Scale Total Score) } \\
\hline \multicolumn{2}{|l|}{ Current Dental Pain } \\
\hline NRS $(0-100)$ & $60.3(28.7)$ \\
\hline VAS $(0-100)$ & $57.0(26.7)$ \\
\hline \multicolumn{2}{|l|}{ Predicted Dental Pain } \\
\hline NRS $(0-100)$ & $76.9(24.7)$ \\
\hline $\operatorname{VAS}(0-100)$ & $72.9(27.0)$ \\
\hline \multicolumn{2}{|l|}{ Experienced Dental Pain } \\
\hline NRS $(0-100)$ & $35.6(35.2)$ \\
\hline $\operatorname{VAS}(0-100)$ & $32.8(34.4)$ \\
\hline Recall Anxiety NRS Rating $(0-100)$ & $10.6(18.6)$ \\
\hline Recall Depression (CESDR Total Score) & $16.2(20.2)$ \\
\hline Recall Negative Affect (PANAS Negative Scale Total Score) & $15.7(6.1)$ \\
\hline
\end{tabular}


Table 4 (Continued)

Means (Standard Deviations) for Extraction Nä̈ve Participants of Final Sample $(\mathrm{N}=18)$

$M(S D)$

Recalled Dental Pain

NRS

VAS

$49.3(33.5)$

Note. SF-FPQ = Short Form - Fear of Pain Questionnaire; DFS = Dental Fear Survey; NRS = Numerical Rating Scale; CESDR = Center for Epidemiological Studies Depression Scale Revised; PANAS = Positive Affect and Negative Affect Schedule; VAS = Visual Analogue Scale. 


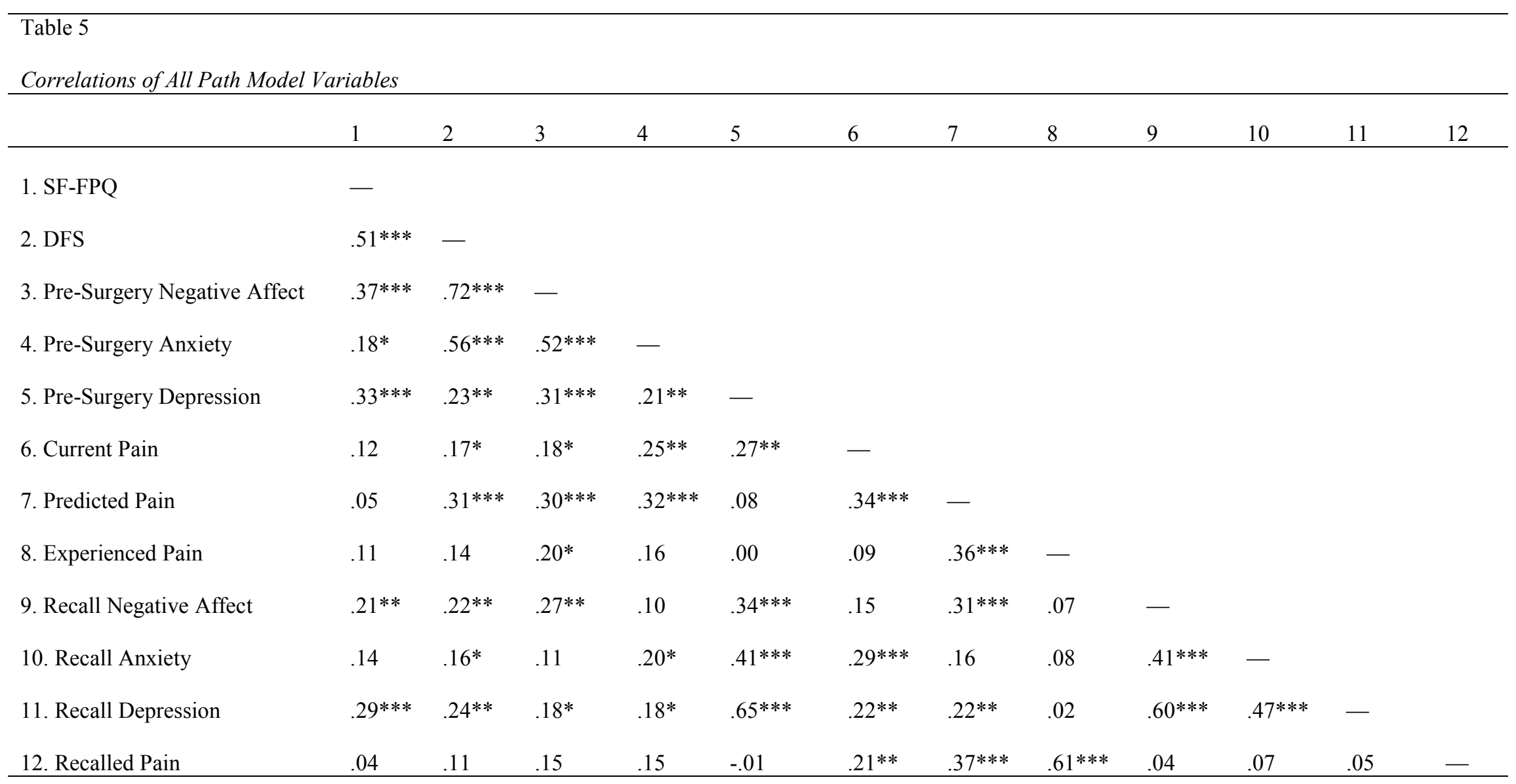

Note. SF-FPQ = Short Form - Fear of Pain Questionnaire, DFS = Dental Fear Survey.

$* p<.05, * * p<.01, * * * p<.001$ 


\begin{tabular}{|c|c|c|c|c|c|c|c|}
\hline \multicolumn{8}{|c|}{$\begin{array}{l}\text { Table } 6 \\
\text { Goodness-of-Fit Indicators of Models for Anxiety and Depression }(\mathrm{N}=157)\end{array}$} \\
\hline Model & $d f$ & $\chi^{2}$ & $p$ & $\chi^{2} / d f$ & GFI & SRMR & CFI \\
\hline Initial & 18 & 154.90 & .00 & 8.61 & .84 & .15 & .66 \\
\hline 2 & 20 & 154.95 & .00 & 7.75 & .84 & .15 & .66 \\
\hline 3 & 22 & 156.84 & .00 & 7.13 & .84 & .16 & .66 \\
\hline 4 & 24 & 157.01 & .00 & 6.54 & .84 & .15 & .67 \\
\hline 5 & 26 & 157.57 & .00 & 6.06 & .84 & .15 & .67 \\
\hline 6 & 28 & 157.90 & .00 & 5.64 & .84 & .16 & .67 \\
\hline Final & 13 & 10.01 & .69 & .77 & .99 & .03 & 1.00 \\
\hline
\end{tabular}

Note. GFI = Goodness of Fit Index, SRMR = Standardized Root Mean Square Residual, CFI = Comparative Fit Index. 
Table 7

Summary of Path Coefficients for Initial Anxiety and Depression Model

\begin{tabular}{|c|c|c|c|c|c|}
\hline Dependent & Predictor & $B$ & $S E B$ & $\mathrm{CR}$ & $\beta$ \\
\hline Pre-Surgery Anxiety & Fear of Pain & -.62 & .32 & -1.95 & -.15 \\
\hline Pre-Surgery Anxiety & Dental Fear & 1.02 & .12 & 8.39 & $.64^{* * *}$ \\
\hline Pre-Surgery Depression & Fear of Pain & .47 & .15 & 3.19 & $.28^{* *}$ \\
\hline Pre-Surgery Depression & Dental Fear & .06 & .06 & 1.02 & .09 \\
\hline Current Pain & Fear of Pain & .08 & .41 & .19 & .02 \\
\hline Current Pain & Dental Fear & .00 & .18 & -.00 & .00 \\
\hline Current Pain & Pre-Surgery Anxiety & .22 & .10 & 2.21 & $.21 *$ \\
\hline Current Pain & Pre-Surgery Depression & .58 & .21 & 2.73 & $.22 * *$ \\
\hline Predicted Pain & Fear of Pain & -.57 & .40 & -1.42 & -.12 \\
\hline Predicted Pain & Dental Fear & .45 & .18 & 2.58 & $.26^{*}$ \\
\hline Predicted Pain & Pre-Surgery Anxiety & .15 & .10 & 1.52 & .13 \\
\hline Predicted Pain & Pre-Surgery Depression & -.14 & .21 & -.66 & -.05 \\
\hline Predicted Pain & Current Pain & .30 & .08 & 3.85 & $.29^{* * *}$ \\
\hline Experienced Pain & Fear of Pain & .51 & .38 & 1.37 & .12 \\
\hline Experienced Pain & Dental Fear & -.08 & .17 & -.47 & -.05 \\
\hline Experienced Pain & Pre-Surgery Anxiety & .06 & .09 & .69 & .06 \\
\hline Experienced Pain & Pre-Surgery Depression & -.17 & .19 & -.86 & -.07 \\
\hline Experienced Pain & Predicted Pain & .32 & .07 & 4.40 & $.35^{* * *}$ \\
\hline Recalled Pain & Fear of Pain & -.05 & .34 & -.14 & -.01 \\
\hline Recalled Pain & Dental Fear & -.04 & .15 & -.26 & -.02 \\
\hline
\end{tabular}




\begin{tabular}{|c|c|c|c|c|c|}
\hline \multicolumn{6}{|c|}{$\begin{array}{l}\text { Table } 7 \text { (continued) } \\
\text { Summary of Path Coefficients for Initial Anxiety and Depression Model }\end{array}$} \\
\hline Dependent & Predictor & $B$ & $S E B$ & $\mathrm{CR}$ & $\beta$ \\
\hline Recalled Pain & Pre-Surgery Anxiety & .03 & .08 & .31 & .02 \\
\hline Recalled Pain & Pre-Surgery Depression & -.11 & .17 & -.66 & -.04 \\
\hline Recalled Pain & Predicted Pain & .16 & .07 & 2.42 & $.17^{*}$ \\
\hline Recalled Pain & Experienced Pain & .59 & .07 & 8.24 & $.55 * * *$ \\
\hline Recalled Pain & Recall Anxiety & .00 & .09 & .01 & .00 \\
\hline Recalled Pain & Recall Depression & .06 & .14 & .48 & .03 \\
\hline
\end{tabular}

Note. $S E=$ Standard Error, $\mathrm{CR}=$ Critical Ratio.

$* p<.05, * * p<.01, * * * p<.001$ 


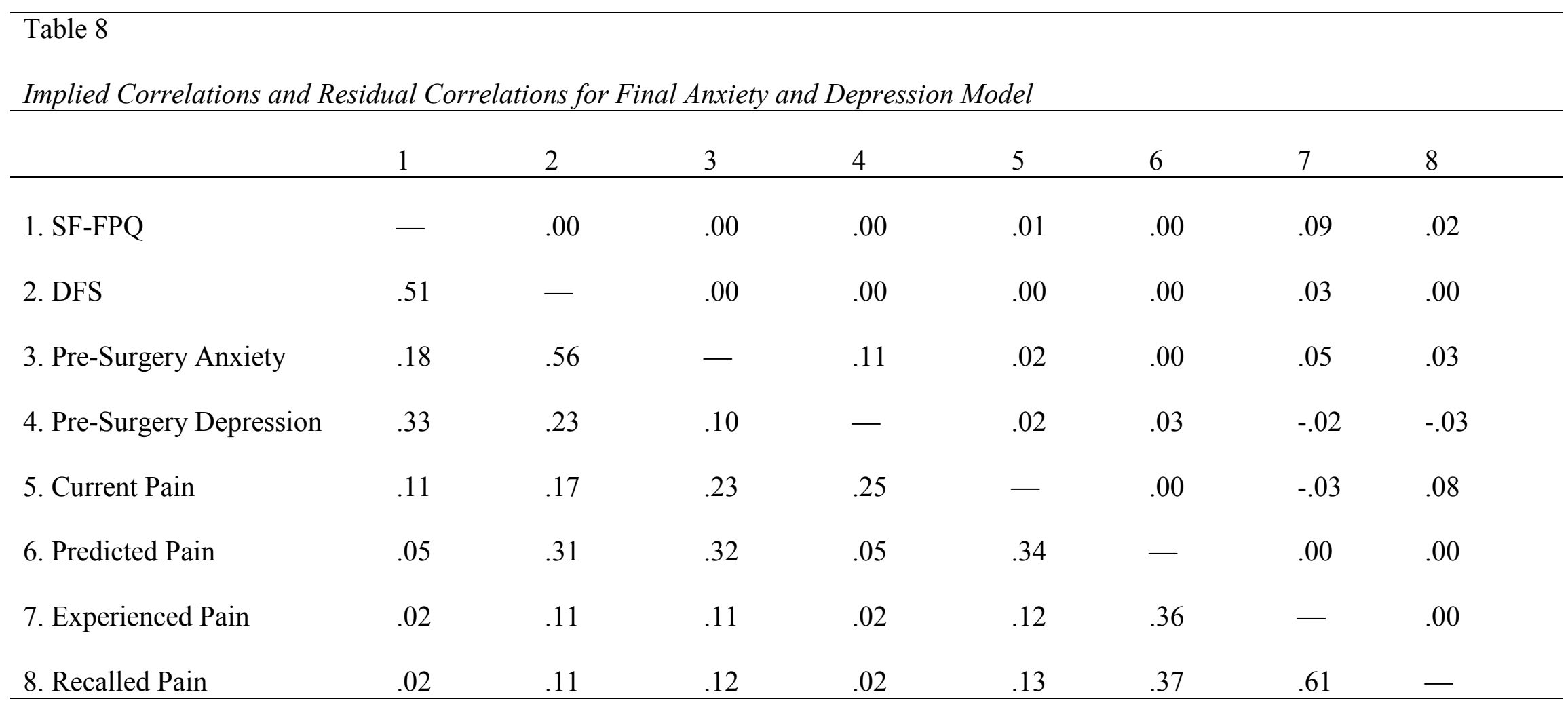

Note. Implied correlations are below the diagonal and residual correlations are above the diagonal. SF-FPQ $=$ Short Form - Fear of Pain Questionnaire, DFS = Dental Fear Survey 


\begin{tabular}{llllll}
\hline Table 9 & & & & & \\
Summary of Path Coefficients for Final Anxiety & and & Depression Model & & \\
\hline Dependent & Predictor & $B$ & $S E$ B & CR & B \\
\hline Pre-Surgery Anxiety & Fear of Pain & -.62 & .32 & -1.95 & -.15 \\
Pre-Surgery Anxiety & Dental Fear & 1.02 & .12 & 8.39 & $.64^{* * *}$ \\
Pre-Surgery Depression & Fear of Pain & .47 & .15 & 3.19 & $.28^{* * *}$ \\
Pre-Surgery Depression & Dental Fear & .06 & .06 & 1.02 & .09 \\
Current Pain & Pre-Surgery Anxiety & .22 & .08 & 2.71 & $.21^{* *}$ \\
Current Pain & Pre-Surgery Depression & .60 & .20 & 2.95 & $.23^{* *}$ \\
Predicted Pain & Fear of Pain & -.57 & .40 & -1.42 & -.12 \\
Predicted Pain & Dental Fear & .45 & .18 & 3.51 & $.26^{* *}$ \\
Predicted Pain & Pre-Surgery Anxiety & .15 & .10 & 1.52 & .13 \\
Predicted Pain & Pre-Surgery Depression & -.14 & .21 & -.66 & -.05 \\
Predicted Pain & Current Pain & .30 & .08 & 3.85 & $.29^{* * *}$ \\
Experienced Pain & Predicted Pain & .32 & .07 & 4.78 & $.36^{* * *}$ \\
Recalled Pain & Predicted Pain & .17 & .06 & 2.63 & $.18^{* *}$ \\
Recalled Pain & Experienced Pain & .59 & .07 & 8.27 & $.55^{* * *}$ \\
\hline
\end{tabular}

Note. $S E=$ Standard Error, $\mathrm{CR}=$ Critical Ratio.

$* p<.05, * * p<.01, * * * p<.001$ 


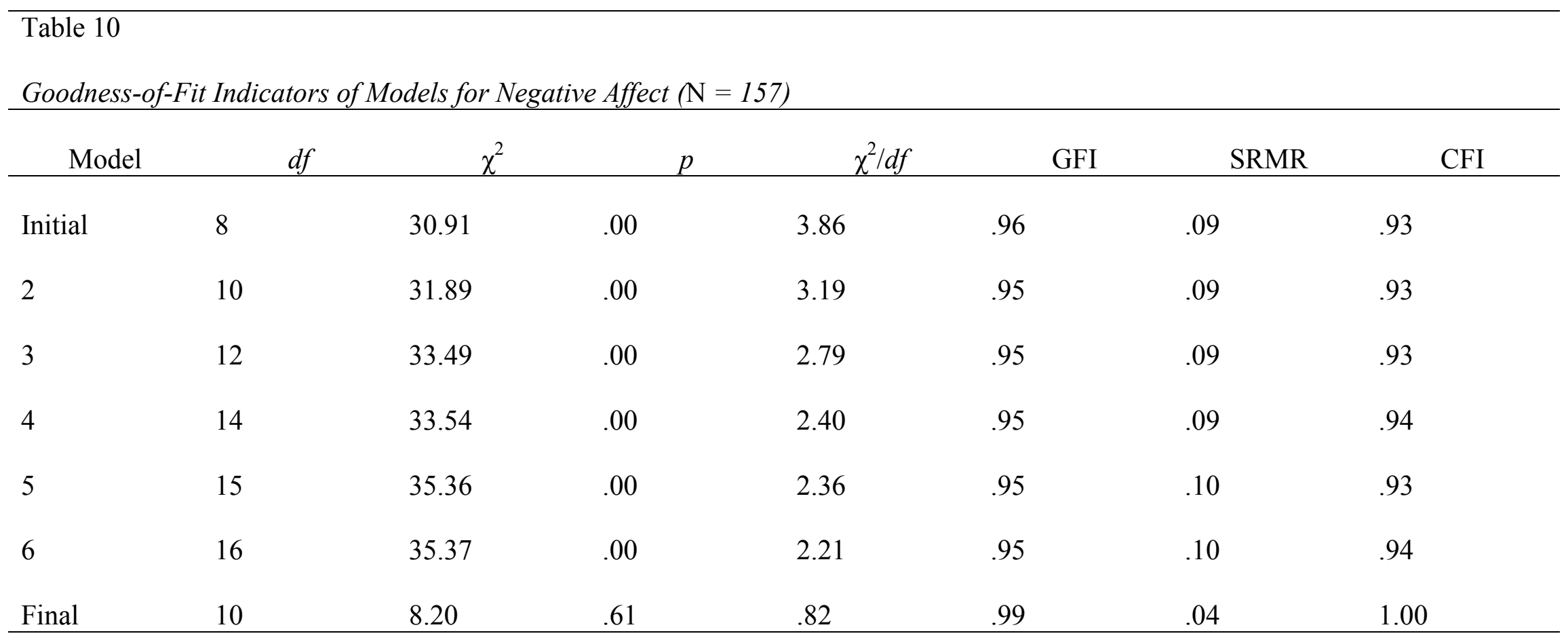

Note. GFI = Goodness of Fit Index, SRMR = Standardized Root Mean Square Residual, CFI = Comparative Fit Index. 


\begin{tabular}{|c|c|c|c|c|c|}
\hline Dependent & Predictor & $B$ & $S E B$ & $\mathrm{CR}$ & $\beta$ \\
\hline Pre-Surgery Negative Affect & Fear of Pain & .01 & .07 & .08 & .01 \\
\hline Pre-Surgery Negative Affect & Dental Fear & .28 & .03 & 10.98 & $.71 * * *$ \\
\hline Current Pain & Fear of Pain & .21 & .41 & .52 & .05 \\
\hline Current Pain & Dental Fear & .12 & .21 & .59 & .07 \\
\hline Current Pain & Pre-Surgery Negative Affect & .48 & .49 & .97 & .11 \\
\hline Predicted Pain & Fear of Pain & -.73 & .38 & -1.90 & -.16 \\
\hline Predicted Pain & Dental Fear & .44 & .20 & 2.26 & $.25^{*}$ \\
\hline Predicted Pain & Pre-Surgery Negative Affect & .56 & .46 & 1.22 & .13 \\
\hline Predicted Pain & Current Pain & .30 & .07 & 4.04 & $.29 * * *$ \\
\hline Experienced Pain & Fear of Pain & .39 & .36 & 1.08 & .09 \\
\hline Experienced Pain & Dental Fear & -.19 & .18 & -1.04 & -.12 \\
\hline Experienced Pain & Pre-Surgery Negative Affect & .61 & .43 & 1.42 & .15 \\
\hline Experienced Pain & Predicted Pain & .31 & .07 & 4.37 & $.35 * * *$ \\
\hline Recalled Pain & Fear of Pain & -.04 & .32 & -.12 & -.01 \\
\hline Recalled Pain & Dental Fear & -.02 & .17 & -.13 & -.01 \\
\hline Recalled Pain & Pre-Surgery Negative Affect & .02 & .38 & .06 & .01 \\
\hline Recalled Pain & Predicted Pain & .19 & .07 & 2.79 & $.19 * *$ \\
\hline Recalled Pain & Experienced Pain & .58 & .07 & 8.18 & $.54 * * *$ \\
\hline Recalled Pain & Recall Negative Affect & -.30 & .33 & -.90 & -.06 \\
\hline
\end{tabular}

Note. $S E=$ Standard Error, $\mathrm{CR}=$ Critical Ratio.

$* p<.05,{ }^{* *} p<.01, * * * p<.001$ 
Table 12

Implied Correlations and Residual Correlations for Final Negative Affect Model

\begin{tabular}{|c|c|c|c|c|c|c|c|}
\hline & 1 & 2 & 3 & 4 & 5 & 6 & 7 \\
\hline 1. SF-FPQ & - & .00 & .00 & .04 & .01 & .10 & .03 \\
\hline 2. DFS & .51 & - & .00 & .04 & .01 & .03 & .00 \\
\hline 3. Pre-Surgery Negative Affect & .37 & .72 & - & .00 & .00 & .09 & .04 \\
\hline 4. Current Pain & .07 & .13 & .18 & - & .00 & .03 & .08 \\
\hline 5. Predicted Pain & .04 & .30 & .30 & .34 & - & .00 & .00 \\
\hline 6. Experienced Pain & .01 & .11 & .11 & .12 & .36 & - & .00 \\
\hline 7. Recalled Pain & .01 & .11 & .11 & .13 & .37 & .61 & - \\
\hline
\end{tabular}

Note. Implied correlations are below the diagonal and residual correlations are above the diagonal. SF-FPQ $=$ Short Form

- Fear of Pain Questionnaire, DFS = Dental Fear Survey. 


\begin{tabular}{llllll}
\hline Table 13 & & & & & \\
Summary of Path Coefficients for Final Negative Affect Model & & & & \\
\hline & Predictor & $B$ & $S E B$ & CR & $\beta$ \\
\hline Dependent & & .01 & .07 & .08 & .01 \\
\hline Pre-Surgery Negative Affect & Fear of Pain & & & & \\
Pre-Surgery Negative Affect & Dental Fear & .28 & .03 & 10.98 & $.71^{* * *}$ \\
Current Pain & Pre-Surgery Negative Affect & .78 & .34 & 2.26 & $.18^{*}$ \\
Predicted Pain & Fear of Pain & -.73 & .38 & -1.90 & -.16 \\
Predicted Pain & Dental Fear & .44 & .19 & 2.26 & $.25^{*}$ \\
Predicted Pain & Pre-Surgery Negative Affect & .56 & .46 & 1.21 & .13 \\
Predicted Pain & Current Pain & .30 & .07 & 4.06 & $.29^{* * *}$ \\
Experienced Pain & Predicted Pain & .32 & .07 & 4.78 & $.36^{* * *}$ \\
Recalled Pain & Predicted Pain & .17 & .06 & 2.63 & $.18^{* *}$ \\
Recalled Pain & Experienced Pain & .59 & .07 & 8.27 & $.55^{* * *}$ \\
\hline
\end{tabular}

Note. $S E=$ Standard Error, $\mathrm{CR}=$ Critical Ratio.

$* p<.05, * * p<.01, * * * p<.001$ 


\begin{tabular}{llll}
\hline Table 14 & & \\
Moderation Effects of Dental Fear and Recall Depression for Recalled Dental Pain & \\
\hline \multicolumn{1}{c}{ Variable } & $B$ & $S E B$ & $\beta$ \\
\hline Dental Fear & .21 & .14 & .12 \\
Recall Depression & .12 & .18 & .05 \\
Dental Fear x Recall Depression & -.02 & .01 & $-.20 *$ \\
\hline
\end{tabular}

Note. $R^{2}=.05(N=157, p<.05)$. All variables centered.

${ }^{*} p<.05$ 
Table 15

Standardized Indirect Effects for Final Path Model with Anxiety and Depression

\begin{tabular}{|c|c|c|c|c|c|c|c|}
\hline & SF-FPQ & DFS & $\begin{array}{c}\text { Pre-Surgery } \\
\text { Anxiety }\end{array}$ & $\begin{array}{l}\text { Pre-Surgery } \\
\text { Depression }\end{array}$ & $\begin{array}{c}\text { Current } \\
\text { Pain }\end{array}$ & $\begin{array}{c}\text { Predicted } \\
\text { Pain }\end{array}$ & $\begin{array}{c}\text { Experienced } \\
\text { Pain }\end{array}$ \\
\hline Pre-Surgery Anxiety & - & - & & & & & \\
\hline Pre-Surgery Depression & - & - & & & & & \\
\hline Current Pain & .03 & .15 & - & - & & & \\
\hline Predicted Pain & -.03 & .13 & .06 & .07 & - & & \\
\hline Experienced Pain & -.05 & .14 & .07 & .01 & .10 & - & \\
\hline Recalled Pain & -.06 & .14 & .07 & .01 & .11 & .20 & - \\
\hline
\end{tabular}

Note. SF-FPQ $=$ Short Form - Fear of Pain Questionnaire, DFS $=$ Dental Fear Survey. 
Table 16

Standardized Indirect Effects for Final Path Model with Negative Affect

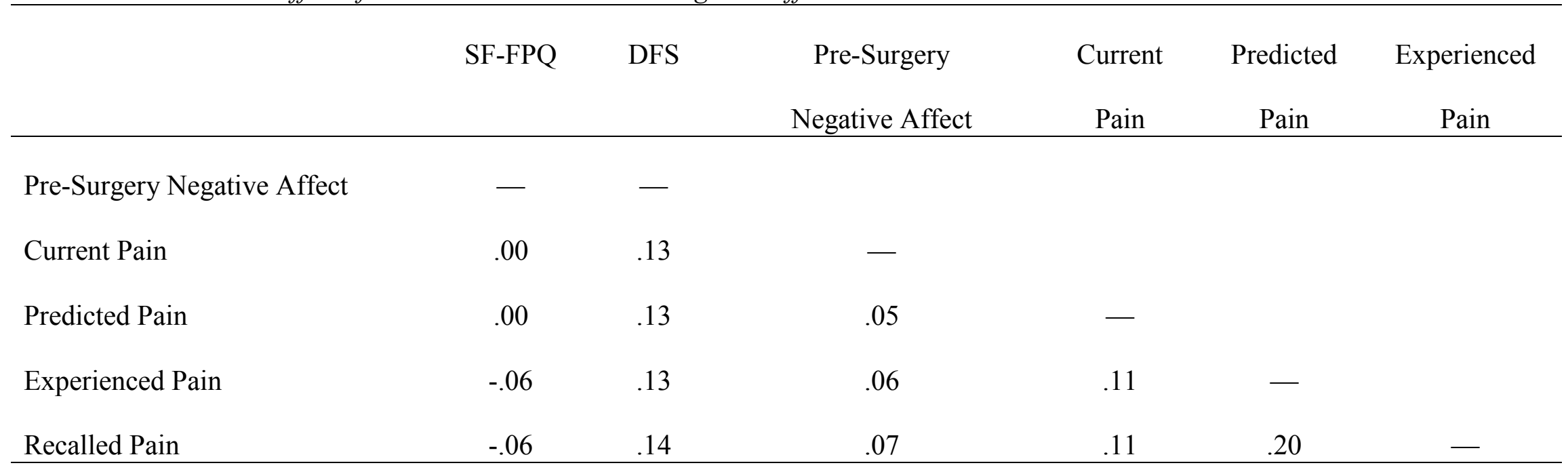

Note. SF-FPQ = Short Form - Fear of Pain Questionnaire, DFS = Dental Fear Survey. 
Table 17

Sample Correlations with VAS Pain Ratings

\begin{tabular}{|c|c|c|c|c|c|c|c|c|c|}
\hline & 1 & 2 & 3 & 4 & 5 & 6 & 7 & 8 & 9 \\
\hline 1. SF-FPQ & - & & & & & & & & \\
\hline 2. DFS & $.51 * * *$ & - & & & & & & & \\
\hline 3. Pre-Surgery Anxiety & $.18^{*}$ & $.56^{* * *}$ & - & & & & & & \\
\hline 4. Pre-Surgery Depression & $.33 * * *$ & $.23 * *$ & $.21 * *$ & - & & & & & \\
\hline 5. Pre-Surgery Negative Affect & $.37 * * *$ & $.72 * * *$ & $.52 * * *$ & $.31 * * *$ & - & & & & \\
\hline 6. Current Pain & .14 & $.18^{*}$ & $.26 * * *$ & $.25^{* *}$ & $.18^{*}$ & - & & & \\
\hline 7. Predicted Pain & .09 & $.34 * * *$ & $.34 * * *$ & .08 & $.32 * * *$ & $.35 * * *$ & - & & \\
\hline 8. Experienced Pain & .10 & $.16^{*}$ & .12 & -.03 & $.20^{*}$ & .08 & $.38 * * *$ & - & \\
\hline 9. Recalled Pain & .08 & .14 & .13 & -.02 & .15 & $.23 * *$ & $.37 * * *$ & $.63^{* * *}$ & - \\
\hline
\end{tabular}

Note. VAS $=$ Visual Analogue Scale, SF-FPQ = Short Form - Fear of Pain Questionnaire, DFS = Dental Fear Survey.

$* p<.05, * * p<.01, * * * p<.001$ 
Table 18

Implied Correlations and Residual Correlations for Final Anxiety and Depression Model with VAS Pain Ratings

\begin{tabular}{|c|c|c|c|c|c|c|c|c|}
\hline & 1 & 2 & 3 & 4 & 5 & 6 & 7 & 8 \\
\hline 1. SF-FPQ & - & .00 & .00 & .00 & .03 & .01 & .07 & .05 \\
\hline 2. DFS & .51 & - & .00 & .00 & .01 & .00 & .03 & 02 \\
\hline 3. Pre-Surgery Anxiety & .18 & .56 & - & .11 & .03 & .00 & -.01 & .00 \\
\hline 4. Pre-Surgery Depression & .33 & .23 & .10 & - & .02 & .02 & -.05 & -.04 \\
\hline 5. Current Pain & .11 & .17 & .23 & .23 & - & .00 & -.05 & .10 \\
\hline 6. Predicted Pain & .08 & .34 & .34 & .06 & .35 & - & .00 & .00 \\
\hline 7. Experienced Pain & .03 & .13 & .13 & .02 & .13 & .38 & - & .00 \\
\hline 8. Recalled Pain & .03 & .12 & .13 & .02 & .13 & .37 & .63 & - \\
\hline
\end{tabular}

Note. Implied correlations are below the diagonal and residual correlations are above the diagonal. VAS = Visual Analogue Scale, $\mathrm{SF}-\mathrm{FPQ}=$ Short Form - Fear of Pain Questionnaire, DFS = Dental Fear Survey. 


\begin{tabular}{|c|c|c|c|c|c|}
\hline Dependent & Predictor & $B$ & $S E B$ & $\mathrm{CR}$ & $\mathrm{B}$ \\
\hline Pre-Surgery Anxiety & Fear of Pain & -.62 & .32 & -1.95 & -.15 \\
\hline Pre-Surgery Anxiety & Dental Fear & 1.02 & .12 & 8.39 & $.64 * * *$ \\
\hline Pre-Surgery Depression & Fear of Pain & .47 & .15 & 3.19 & $.28 * * *$ \\
\hline Pre-Surgery Depression & Dental Fear & .06 & .06 & 1.02 & .09 \\
\hline Current Pain & Pre-Surgery Anxiety & .22 & .08 & 2.79 & $.21^{* *}$ \\
\hline Current Pain & Pre-Surgery Depression & .51 & .19 & 2.70 & $.21^{* *}$ \\
\hline Predicted Pain & Fear of Pain & -.41 & .38 & -1.08 & -.09 \\
\hline Predicted Pain & Dental Fear & .45 & .17 & 2.69 & $.27 * *$ \\
\hline Predicted Pain & Pre-Surgery Anxiety & .15 & .09 & 1.65 & .15 \\
\hline Predicted Pain & Pre-Surgery Depression & -.15 & .20 & -.74 & -.06 \\
\hline Predicted Pain & Current Pain & .31 & .08 & 3.92 & $.29 * * *$ \\
\hline Experienced Pain & Predicted Pain & .34 & .07 & 5.14 & $.38^{* * *}$ \\
\hline Recalled Pain & Predicted Pain & .15 & .06 & 2.29 & $.15^{*}$ \\
\hline Recalled Pain & Experienced Pain & .62 & .07 & 8.64 & $.57 * * *$ \\
\hline
\end{tabular}

Note VAS = Visual Analogue Scale, $S E=$ Standard Error, $\mathrm{CR}=$ Critical Ratio.

$* p<.05, * * p<.01, * * * p<.001$ 
Table 20

Implied Correlations and Residual Correlations for Final Negative Affect Model with VAS Pain Ratings

\begin{tabular}{|c|c|c|c|c|c|c|c|}
\hline & 1 & 2 & 3 & 4 & 5 & 6 & 7 \\
\hline 1. SF-FPQ & - & .00 & .00 & .07 & .02 & .07 & .05 \\
\hline 2. DFS & .51 & - & .00 & .00 & .01 & .04 & .12 \\
\hline 3. Pre-Surgery Negative Affect & .37 & .72 & - & .00 & $\begin{array}{l}.00 \\
35\end{array}$ & .08 & .03 \\
\hline 4. Current Pain & .07 & .13 & .18 & - & .00 & -.05 & .10 \\
\hline 5. Predicted Pain & .07 & .33 & .32 & .35 & - & .00 & .00 \\
\hline 6. Experienced Pain & .03 & .12 & .12 & .13 & .38 & - & .00 \\
\hline 7. Recalled Pain & .03 & .12 & .12 & .13 & .37 & .63 & - \\
\hline
\end{tabular}

Note. Implied correlations are below the diagonal and residual correlations are above the diagonal. VAS = Visual Analogue Scale, $\mathrm{SF}-\mathrm{FPQ}=$ Short Form - Fear of Pain Questionnaire, DFS = Dental Fear Survey. 
Table 21

Summary of Path Coefficients for Final Negative Affect Model with VAS

\begin{tabular}{|c|c|c|c|c|c|}
\hline Dependent & Predictor & $B$ & $S E B$ & $\mathrm{CR}$ & $\beta$ \\
\hline Pre-Surgery Negative Affect & Fear of Pain & .01 & .07 & .08 & .01 \\
\hline Pre-Surgery Negative Affect & Dental Fear & .28 & .03 & 10.98 & $.71 * * *$ \\
\hline Current Pain & Pre-Surgery Negative Affect & .74 & .32 & 2.32 & $.18^{*}$ \\
\hline Predicted Pain & Fear of Pain & -.58 & .37 & -1.59 & -.13 \\
\hline Predicted Pain & Dental Fear & .45 & .19 & 2.44 & $.27^{*}$ \\
\hline Predicted Pain & Pre-Surgery Negative Affect & .51 & .44 & 1.15 & .12 \\
\hline Predicted Pain & Current Pain & .31 & .08 & 4.14 & $.30 * * *$ \\
\hline Experienced Pain & Predicted Pain & .34 & .07 & 5.13 & $.38 * * *$ \\
\hline Recalled Pain & Predicted Pain & .15 & .06 & 2.29 & $.15^{*}$ \\
\hline Recalled Pain & Experienced Pain & .62 & .07 & 8.64 & $.57 * * *$ \\
\hline
\end{tabular}

Note. VAS = Visual Analogue Scale, $S E=$ Standard Error, $\mathrm{CR}=$ Critical Ratio.

$* p<.05, * * p<.01, * * * p<.001$ 
Table 22

Correlations for Additional Variables of Interest

\begin{tabular}{|c|c|c|c|c|c|c|c|c|c|c|}
\hline & 1 & 2 & 3 & 4 & 5 & 6 & 7 & 8 & 9 & 10 \\
\hline 1. Age & - & & & & & & & & & \\
\hline 2. Number of Prior Extractions & $.46 * * *$ & - & & & & & & & & \\
\hline 3. Duration of Current Dental Pain & .04 & .09 & - & & & & & & & \\
\hline 4. Non-dental Chronic Pain Rating & .05 & -.08 & .13 & - & & & & & & \\
\hline 5. Taking Opioids & $.17^{*}$ & .16 & -.10 & $.44^{* *}$ & - & & & & & \\
\hline 6. Re-injected with Initial & -.10 & -.06 & -.01 & -.09 & .04 & - & & & & \\
\hline \multicolumn{11}{|l|}{ Anesthetic } \\
\hline 7. Injected with Additional & -.02 & .00 & -.14 & .10 & -.02 & $.38 * * *$ & - & & & \\
\hline \multicolumn{11}{|l|}{ Anesthetic } \\
\hline 8. Additional Nerve Block & -.03 & .01 & -.08 & -.09 & -.03 & $.30 * * *$ & $.28 * * *$ & - & & \\
\hline 9. Duration of Procedure & -.03 & -.01 & .07 & .21 & -.01 & $.33 * * *$ & $.25 * * *$ & $.35 * * *$ & - & \\
\hline 10. Reported Alveolar Osteitis & -.18 & -.02 & -.02 & .24 & $.17^{*}$ & .08 & .08 & -.02 & .16 & - \\
\hline \multicolumn{11}{|l|}{ Symptoms } \\
\hline 11. SF-FPQ & .03 & .06 & .03 & .10 & -.01 & -.01 & .11 & .02 & $.23 * *$ & $.20^{*}$ \\
\hline
\end{tabular}


Table 22 (continued)

Correlations for Additional Variables of Interest

\begin{tabular}{|c|c|c|c|c|c|c|c|c|c|c|}
\hline & 1 & 2 & 3 & 4 & 5 & 6 & 7 & 8 & 9 & 10 \\
\hline 12. DFS & -.13 & -.04 & .11 & $.35^{*}$ & .10 & .12 & .13 & .01 & $.23 * *$ & $.23 * *$ \\
\hline 13. Pre-Surgery Negative Affect & -.11 & -.10 & .09 & .19 & .07 & .11 & .09 & .11 & $.19 *$ & $.24 * *$ \\
\hline 14. Pre-Surgery Anxiety & .03 & .04 & .09 & $.37 *$ & .09 & .09 & .13 & .05 & .07 & .15 \\
\hline 15. Pre-Surgery Depression & -.15 & .06 & .12 & .08 & .03 & .14 & -.01 & .07 & .12 & $.19 * *$ \\
\hline 16. Current Pain & $-.36 * * *$ & -.15 & -.06 & $.33^{*}$ & .12 & .09 & .07 & -.05 & .01 & $.29 * * *$ \\
\hline 17. Predicted Pain & $-.19 *$ & $-.24 * *$ & $-.19 *$ & $.40^{*}$ & .08 & .14 & .03 & -.04 & .05 & .12 \\
\hline 18. Experienced Pain & -.15 & -.02 & -.09 & .06 & .08 & $.37 * * *$ & $.27 * * *$ & .13 & $.20^{*}$ & $.19 * *$ \\
\hline 19. Recalled Pain & -.10 & -.10 & -.13 & $.40^{*}$ & $.18^{*}$ & $.28 * * *$ & $.33 * * *$ & $.18^{*}$ & $.20 *$ & $.19 * *$ \\
\hline
\end{tabular}

Note. SF-FPQ = Short Form - Fear of Pain Questionnaire, DFS = Dental Fear Survey.

$* p<.05, * * p<.01, * * * p<.001$ 


\begin{tabular}{|c|c|c|c|c|c|c|c|c|c|c|c|c|}
\hline & 1 & 2 & 3 & 4 & 5 & 6 & 7 & 8 & 9 & 10 & 11 & 12 \\
\hline 1. SF-FPQ & - & .00 & .00 & .00 & .01 & .06 & .03 & .10 & -.01 & .09 & .11 & .02 \\
\hline 2. DFS & .51 & - & .00 & .00 & .00 & -.04 & .11 & .35 & -.01 & .03 & .13 & .00 \\
\hline 3. Pre-Surgery Anxiety & .18 & .56 & - & .11 & .02 & .04 & .09 & .37 & -.02 & .04 & .13 & .03 \\
\hline 4. Pre-Surgery Depression & .33 & .23 & .10 & - & .02 & .06 & .12 & .08 & .00 & -.03 & -.01 & -.04 \\
\hline 5. Current Pain & .11 & .17 & .23 & .25 & - & -.15 & -.06 & .33 & .04 & -.02 & .07 & .10 \\
\hline 6. Number of Prior Extractions & .00 & .00 & .00 & .00 & .00 & - & .09 & -.08 & -.05 & .05 & .00 & -.03 \\
\hline 7. Duration of Current Dental Pain & .00 & .00 & .00 & .00 & .00 & .00 & - & .13 & .01 & -.02 & -.14 & -.06 \\
\hline 8. Non-dental Chronic Pain Rating & .00 & .00 & .00 & .00 & .00 & .00 & .00 & - & .40 & .06 & .10 & .01 \\
\hline 9. Predicted Pain & .06 & .32 & .34 & .08 & .30 & -.19 & -.20 & .00 & - & .00 & .03 & .02 \\
\hline 10. Experienced Pain & .02 & .11 & .12 & .03 & .11 & -.07 & -.07 & .00 & .36 & - & .27 & .03 \\
\hline 11. Injected with Additional Anesthetic & .00 & .00 & .00 & .00 & .00 & .00 & .00 & .00 & .00 & .00 & - & .14 \\
\hline 12. Recalled Pain & .02 & .11 & .12 & .03 & .11 & -.07 & -.07 & .39 & .35 & .58 & .19 & - \\
\hline
\end{tabular}

Note. Implied correlations are below the diagonal and residual correlations are above the diagonal. SF-FPQ $=$ Short Form - Fear of

Pain Questionnaire, DFS = Dental Fear Survey 


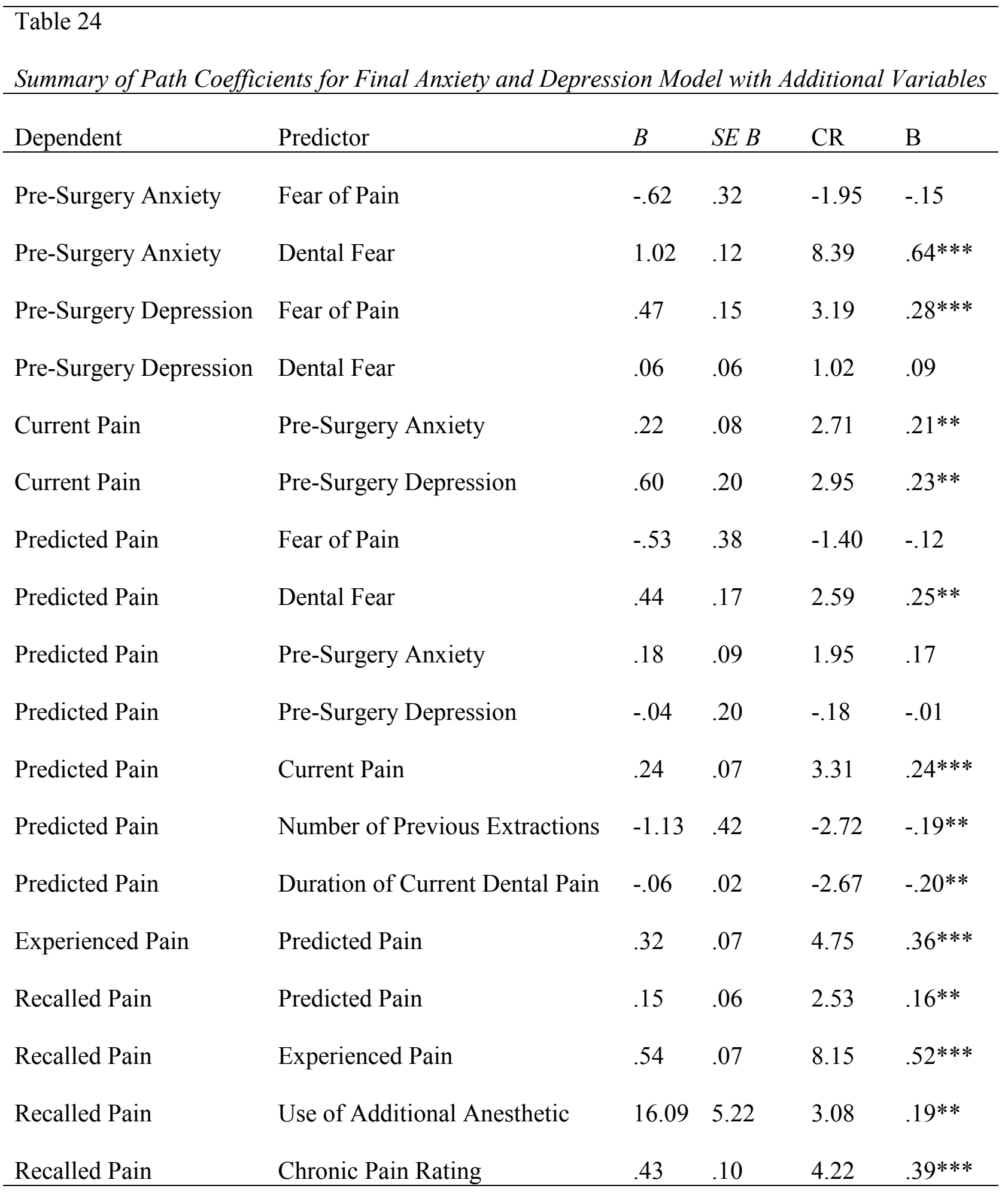

Note. $S E=$ Standard Error, $\mathrm{CR}=$ Critical Ratio.

$* p<.05, * * p<.01, * * * p<.001$ 
Table 25

Implied Correlations and Residual Correlations for Final Negative Affect Model with Additional Variables

\begin{tabular}{|c|c|c|c|c|c|c|c|c|c|c|c|}
\hline & 1 & 2 & 3 & 4 & 5 & 6 & 7 & 8 & 9 & 10 & 11 \\
\hline 1. SF-FPQ & - & .00 & .00 & .05 & .06 & .03 & .10 & .00 & .09 & .11 & .02 \\
\hline 2. DFS & .51 & - & .00 & .04 & -.04 & .11 & .35 & .00 & .03 & .13 & .00 \\
\hline 3. Pre-Surgery Negative Affect & .37 & .72 & - & .00 & -.10 & .09 & .19 & .00 & .09 & .09 & .05 \\
\hline 4. Current Pain & .07 & .13 & .18 & - & -.15 & -.06 & .33 & .03 & -.02 & .07 & .10 \\
\hline 5. Number of Prior Extractions & .00 & .00 & .00 & .00 & - & .09 & -.08 & -.07 & .04 & .00 & -.04 \\
\hline 6. Duration of Current Dental Pain & .00 & .00 & .00 & .00 & .00 & - & .13 & .01 & -.02 & -.14 & -.06 \\
\hline 7. Non-dental Chronic Pain Rating & .00 & .00 & .00 & .00 & .00 & .00 & - & .40 & .06 & .10 & .01 \\
\hline 8. Predicted Pain & .05 & .31 & .30 & .31 & -.17 & -.20 & .00 & - & .00 & .03 & .02 \\
\hline 9. Experienced Pain & .02 & .11 & .11 & .11 & -.06 & -.07 & .00 & .36 & - & .27 & .03 \\
\hline 10. Injected with Additional Anesthetic & .00 & .00 & .00 & .00 & .00 & .00 & .00 & .00 & .00 & - & .14 \\
\hline 11. Recalled Pain & .02 & .11 & .10 & .11 & -.06 & -.07 & .39 & .35 &. .58 & .19 & - \\
\hline
\end{tabular}

Note. Implied correlations are below the diagonal and residual correlations are above the diagonal. SF-FPQ $=\mathrm{Short} \mathrm{Form}-$

Fear of Pain Questionnaire, DFS = Dental Fear Survey 
Table 26

Summary of Path Coefficients for Final Negative Affect Model with Additional Variables

\begin{tabular}{llcccc} 
Dependent & Predictor & $B$ & $S E B$ & CR & $\beta$ \\
\hline Pre-Surgery Negative Affect & Fear of Pain & .01 & .07 & .08 & .01 \\
Pre-Surgery Negative Affect & Dental Fear & .28 & .03 & 10.98 & $.71^{* * *}$ \\
Current Pain & Pre-Surgery Negative Affect & .78 & .34 & 2.26 & $.18^{*}$ \\
Predicted Pain & Fear of Pain & -.68 & .37 & -1.86 & -.16 \\
Predicted Pain & Dental Fear & .48 & .19 & 2.56 & $.27^{*}$ \\
Predicted Pain & Pre-Surgery Negative Affect & .49 & .44 & 1.22 & .11 \\
Predicted Pain & Current Pain & .27 & .07 & 3.74 & $.26^{* * *}$ \\
Predicted Pain & Number of Previous & -1.00 & .42 & -2.38 & $-.17^{*}$ \\
& Extractions & & & & \\
Predicted Pain & Duration of Current Dental & -.06 & .02 & -2.64 & $-.20^{* *}$ \\
& Pain & & & & \\
Experienced Pain & Predicted Pain & & & & \\
Recalled Pain & Predicted Pain & .32 & .07 & 4.74 & $.36^{* * *}$ \\
Recalled Pain & Experienced Pain & .15 & .06 & 2.52 & $.16^{*}$ \\
Recalled Pain & Use of Additional Anesthetic & 16.09 & 5.22 & 3.08 & $.19^{* *}$ \\
Recalled Pain & Chronic Pain Rating & .43 & .10 & 4.22 & $.39^{* * *}$ \\
\hline
\end{tabular}

Note. $S E=$ Standard Error, $\mathrm{CR}=$ Critical Ratio.

$* p<.05, * * p<.01, * * * p<.001$ 


\begin{tabular}{|c|c|c|c|c|c|c|c|c|c|c|c|c|c|}
\hline & 1 & 2 & 3 & 4 & 5 & 6 & 7 & 8 & 9 & 10 & 11 & 12 & 13 \\
\hline 1. SF-FPQ & - & .00 & .00 & .00 & .00 & .01 & .06 & .03 & .10 & -.01 & .09 & .11 & .02 \\
\hline 2. DFS & .51 & - & .00 & .00 & .00 & .00 & -.04 & .11 & .22 & -.01 & .03 & .13 & -.04 \\
\hline 3. Pre-Surgery Negative Affect & .37 & .72 & - & .12 & .14 & .06 & -.10 & .09 & .10 & .03 & .10 & .09 & .03 \\
\hline 4. Pre-Surgery Anxiety & .18 & .56 & .40 & - & .11 & .02 & .04 & .09 & .29 & -.01 & .04 & .13 & .01 \\
\hline 5. Pre-Surgery Depression & .33 & .23 & .17 & .10 & - & .02 & .06 & .12 & .07 & .01 & -.03 & -.01 & -.04 \\
\hline 6. Current Pain & .11 & .17 & .12 & .23 & .25 & - & -.15 & -.06 & .31 & .04 & -.02 & .07 & .10 \\
\hline 7. Number of Prior Extractions & .00 & .00 & .00 & .00 & .00 & .00 & - & .09 & -.08 & -.06 & .04 & .00 & -.04 \\
\hline 8. Duration of Current Dental Pain & .00 & .00 & .00 & .00 & .00 & .00 & .00 & - & .13 & .01 & -.02 & -.14 & -.06 \\
\hline 9. Non-dental Chronic Pain Rating & .00 & .13 & .09 & .08 & .01 & .02 & .00 & .00 & - & .35 & .04 & -.14 & .04 \\
\hline 10. Predicted Pain & .06 & .32 & .27 & .33 & .07 & .30 & -.18 & -.20 & .05 & - & .00 & .03 & .01 \\
\hline 11. Experienced Pain & .02 & .11 & .10 & .12 & .03 & .11 & -.06 & -.07 & .02 & .36 & - & .27 & .03 \\
\hline 12. Injected with Additional Anesthetic & .00 & .00 & .00 & .00 & .00 & .00 & .00 & .00 & .00 & .00 & .00 & - & .15 \\
\hline 13. Recalled Pain & .02 & .15 & .12 & .14 & .03 & .11 & -.06 & -.07 & .36 & .36 & .58 & .18 & - \\
\hline
\end{tabular}

Note. Implied correlations are below the diagonal and residual correlations are above the diagonal. SF-FPQ $=$ Short Form - Fear of

Pain Questionnaire, DFS = Dental Fear Survey 
Table 28

Summary of Path Coefficients for Exploratory Model

\begin{tabular}{|c|c|c|c|c|c|}
\hline Dependent & Predictor & $B$ & $S E B$ & $\mathrm{CR}$ & B \\
\hline Pre-Surgery Anxiety & Fear of Pain & -.62 & .32 & -1.95 & -.15 \\
\hline Pre-Surgery Anxiety & Dental Fear & 1.02 & .12 & 8.39 & $.64 * * *$ \\
\hline Pre-Surgery Depression & Fear of Pain & .47 & .15 & 3.19 & $.28 * * *$ \\
\hline Pre-Surgery Depression & Dental Fear & .06 & .06 & 1.02 & .09 \\
\hline Pre-Surgery Negative Affect & Fear of Pain & .01 & .07 & .08 & .01 \\
\hline Pre-Surgery Negative Affect & Dental Fear & .28 & .03 & 10.98 & $.71 * * *$ \\
\hline Current Pain & Pre-Surgery Anxiety & .22 & .09 & 2.47 & $.21^{*}$ \\
\hline Current Pain & Pre-Surgery Depression & .59 & .20 & 2.91 & $.22 * *$ \\
\hline Current Pain & Pre-Surgery Negative Affect & .02 & .36 & .05 & .00 \\
\hline Predicted Pain & Fear of Pain & -.53 & .38 & -1.41 & -.12 \\
\hline Predicted Pain & Dental Fear & .35 & .21 & 1.69 & 20 \\
\hline Predicted Pain & Pre-Surgery Anxiety & .17 & .09 & 1.80 & .15 \\
\hline Predicted Pain & Pre-Surgery Depression & -.07 & .20 & -.34 & -.03 \\
\hline Predicted Pain & Pre-Surgery Negative Affect & .36 & .43 & .84 & .08 \\
\hline Predicted Pain & Current Pain & .25 & .07 & 3.34 & $.24 * * *$ \\
\hline Predicted Pain & Number of Previous & -1.09 & .42 & -2.61 & $-.18 * *$ \\
\hline \multirow{3}{*}{ Predicted Pain } & Extractions & \multirow{3}{*}{-.06} & \multirow{3}{*}{.02} & \multirow{3}{*}{-2.69} & \multirow{3}{*}{$-.20 * *$} \\
\hline & Duration of Current Dental & & & & \\
\hline & Pain & & & & \\
\hline Experienced Pain & Predicted Pain & .32 & .07 & 4.74 & $.36^{* * *}$ \\
\hline
\end{tabular}


Table 28 (continued)

Summary of Path Coefficients for Exploratory Model

\begin{tabular}{llllll}
\hline Dependent & Predictor & $B$ & $S E B$ & CR & B \\
\hline Recalled Pain & Predicted Pain & .15 & .06 & 2.35 & $.15^{*}$ \\
Recalled Pain & Experienced Pain & .54 & .07 & 8.03 & $.52^{* * *}$ \\
Recalled Pain & Use of Additional Anesthetic & 15.89 & 5.28 & 3.01 & $.18^{* *}$ \\
Recalled Pain & Chronic Pain Rating & .39 & .11 & 3.45 & $.34^{* * *}$ \\
\hline
\end{tabular}

Note. $S E=$ Standard Error, $\mathrm{CR}=$ Critical Ratio.

$* p<.05, * * p<.01, * * * p<.001$ 


\section{Figure Captions}

Figure 1. Initial Path Model with Anxiety and Depression. Standardized path coefficients and SMCs shown, with unstandardized coefficients and error variances in parentheses. Path coefficients significant at the $p<.05$ level have asterisks.

Figure 2. Final Path Model with Anxiety and Depression. Standardized path coefficients and SMCs shown, with unstandardized coefficients and error variances in parentheses. Path coefficients significant at the $p<.05$ level have asterisks.

Figure 3. Initial Path Model with Negative Affect. Standardized path coefficients and SMCs shown, with unstandardized coefficients and error variances in parentheses. Path coefficients significant at the $p<.05$ level have asterisks.

Figure 4. Final Path Model with Negative Affect. Standardized path coefficients and SMCs shown, with unstandardized coefficients and error variances in parentheses. Path coefficients significant at the $p<.05$ level have asterisks.

Figure 5. Moderation Effects of Dental Fear on Recall Depression for Recalled Dental Pain. The figure is a plot of recalled dental pain as a function of recall depression for different levels of dental fear.

Figure 6. Final Path Model with Anxiety and Depression with Visual Analogue Scale Pain Ratings. Standardized path coefficients and SMCs shown, with unstandardized coefficients and error variances in parentheses. Path coefficients significant at the $p<.05$ level have asterisks. $\chi^{2}$ $(13, N=157)=12.57, p=.48, \chi^{2} / \mathrm{df}=.97, \mathrm{GFI}=.98, \mathrm{CFI}=1.00, \mathrm{SRMR}=.03$. 


\section{Figure Captions (Continued)}

Figure 7. Final Path Model with Negative Affect with Visual Analogue Scale Pain Ratings. Standardized path coefficients and squared multiple correlations shown, with unstandardized coefficients and error variances in parentheses. Path coefficients significant at the $p<.05$ level have asterisks. $\chi^{2}(10, N=157)=9.72, p=.47, \chi^{2} / \mathrm{df}=.97, \mathrm{GFI}=.98, \mathrm{CFI}=1.00, \mathrm{SRMR}=.04$. Figure 8. Final Anxiety and Depression Model with Additional Variables of Interest. Standardized path coefficients and squared multiple correlations shown, with unstandardized coefficients and error variances in parentheses. Path coefficients significant at the $p<.05$ level have asterisks. $\chi^{2}(47, N=157)=52.76, p=.26, \chi^{2} / \mathrm{df}=1.12$, IFI $=.98 ; \mathrm{CFI}=.98 ;$ RMSEA $=$ $.03(95 \% \mathrm{CI}=.00-.06)$.

Figure 9. Final Negative Affect Model with Additional Variables of Interest. Standardized path coefficients and squared multiple correlations shown, with unstandardized coefficients and error variances in parentheses. Path coefficients significant at the $p<.05$ level have asterisks. $\chi^{2}$ (40, $N=157)=45.67, p=, 25, \chi^{2} / \mathrm{df}=1.14, \mathrm{IFI}=.98 ; \mathrm{CFI}=.98 ; \mathrm{RMSEA}=.03(95 \% \mathrm{CI}=.00-.07)$. Figure 10. Exploratory Combined Model. Standardized path coefficients and squared multiple correlations shown, with unstandardized coefficients and error variances in parentheses. Path coefficients significant at the $p<.05$ level have asterisks. $\chi^{2}(54, N=157)=69.89, p=.07, \chi^{2} / \mathrm{df}$ $=1.29, \mathrm{IFI}=.96 ; \mathrm{CFI}=.96 ; \mathrm{RMSEA}=.04(95 \% \mathrm{CI}=.00-.07)$. 


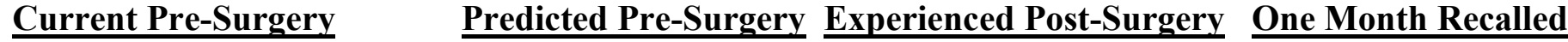

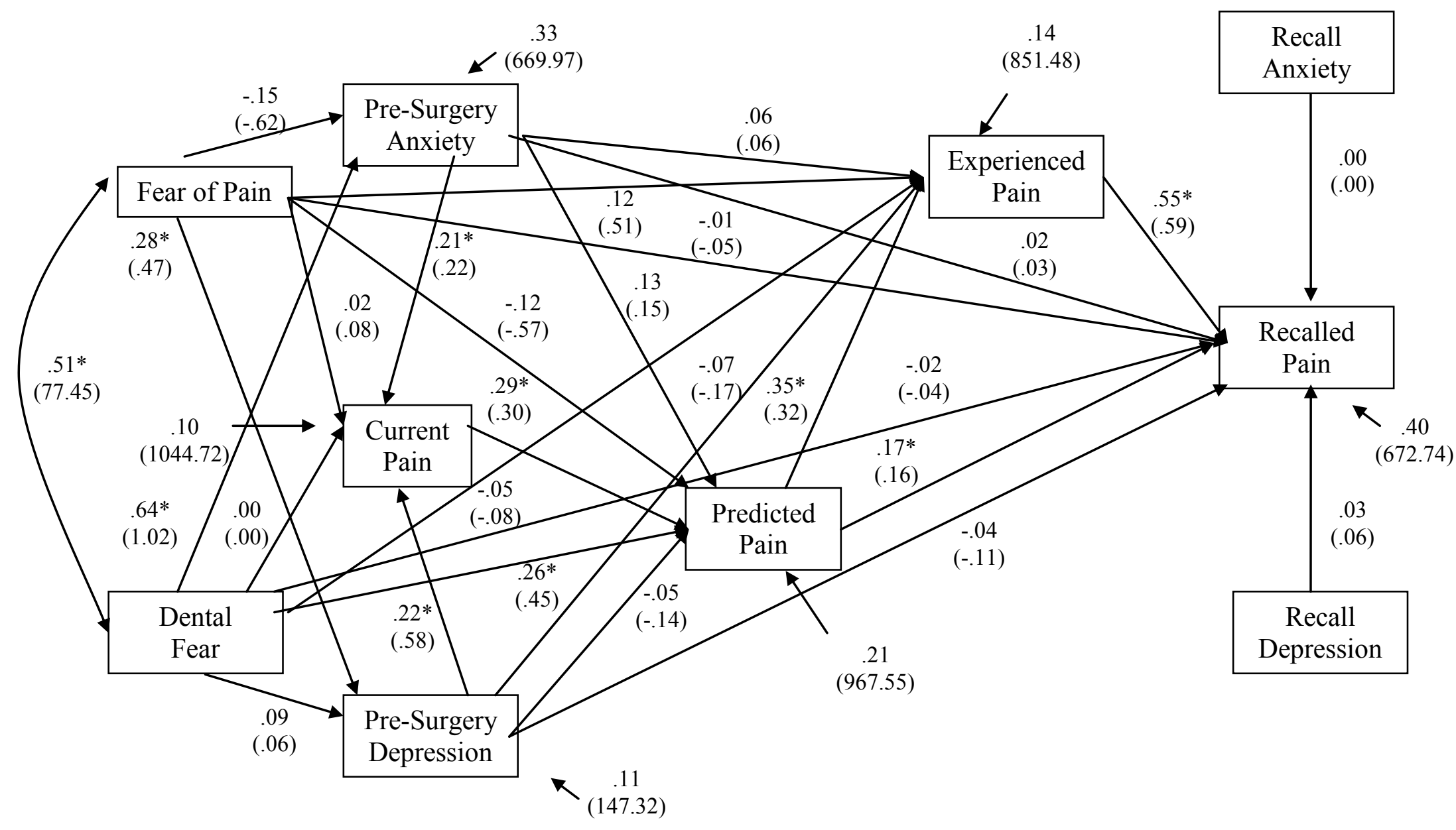




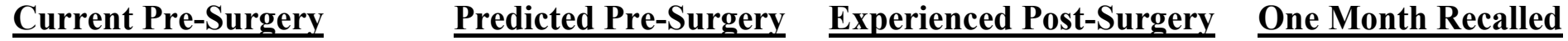

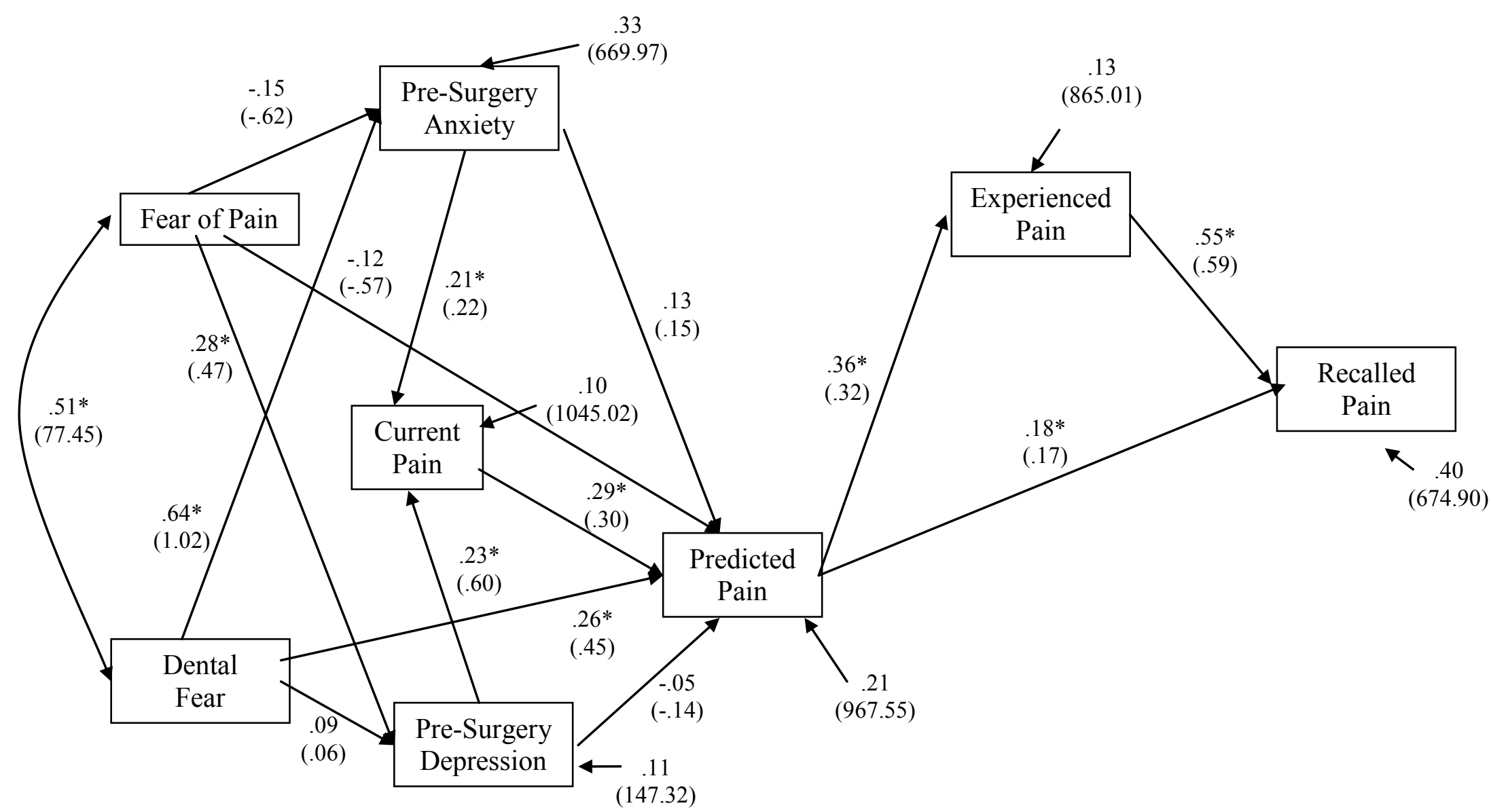




\section{$\underline{\text { Current Pre-Surgery } \quad \text { Predicted Pre-Surgery Experienced Post-Surgery One Month Recalled }}$}

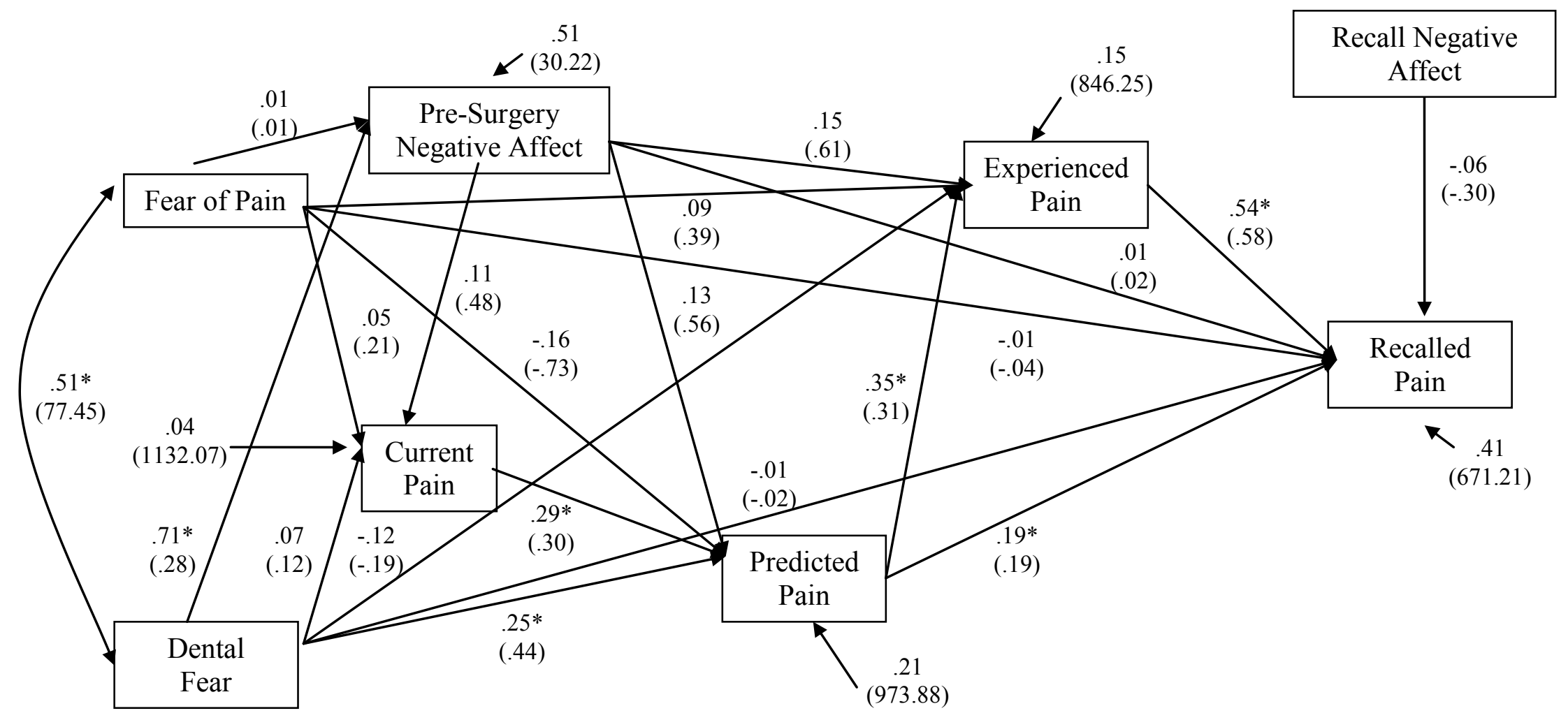




\section{Current Pre-Surgery \\ Predicted Pre-Surgery Experienced Post-Surgery One Month Recalled}

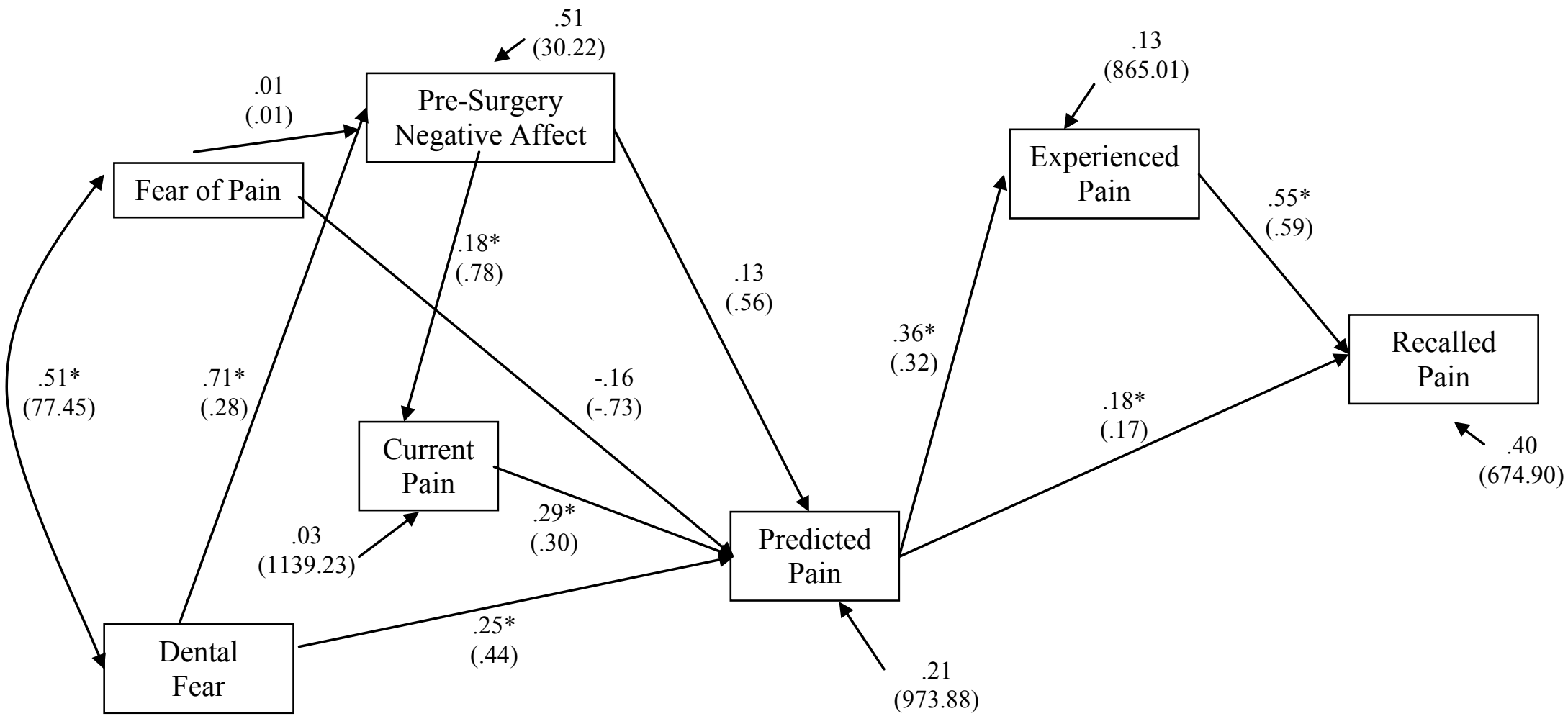




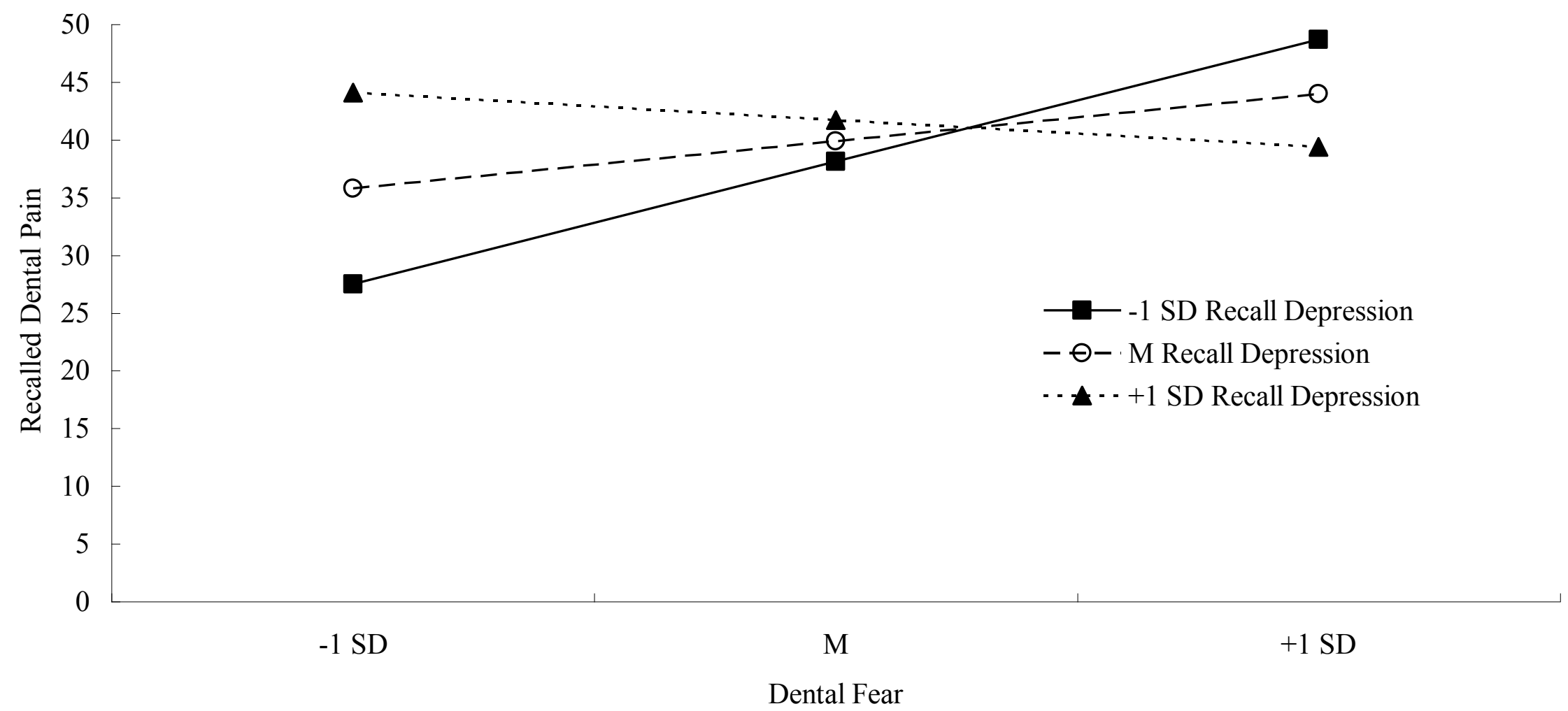




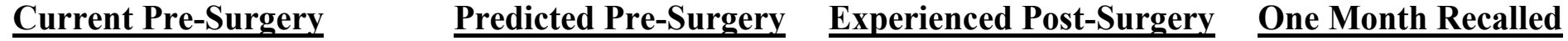

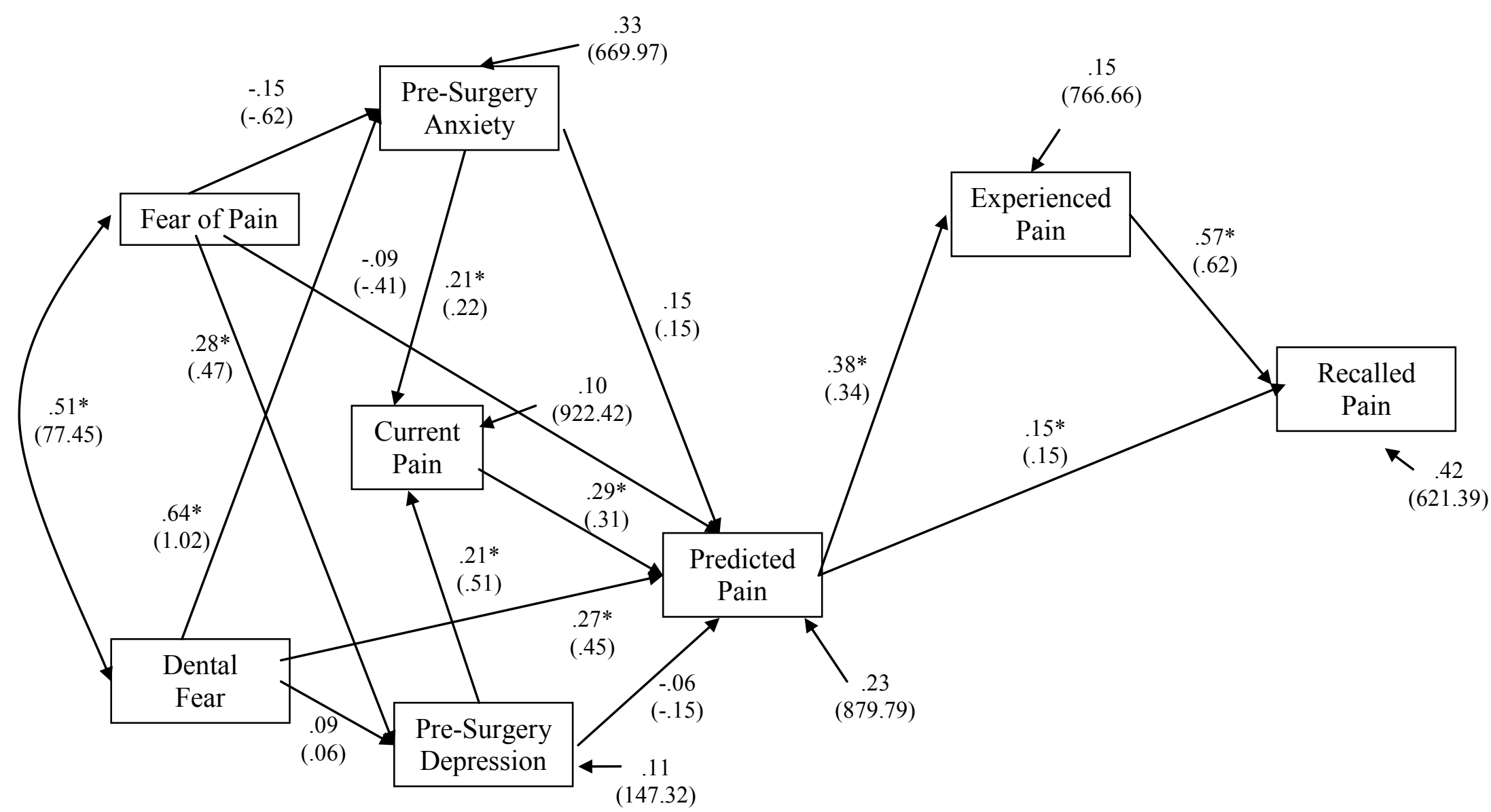




\section{Current Pre-Surgery \\ Predicted Pre-Surgery Experienced Post-Surgery One Month Recalled}

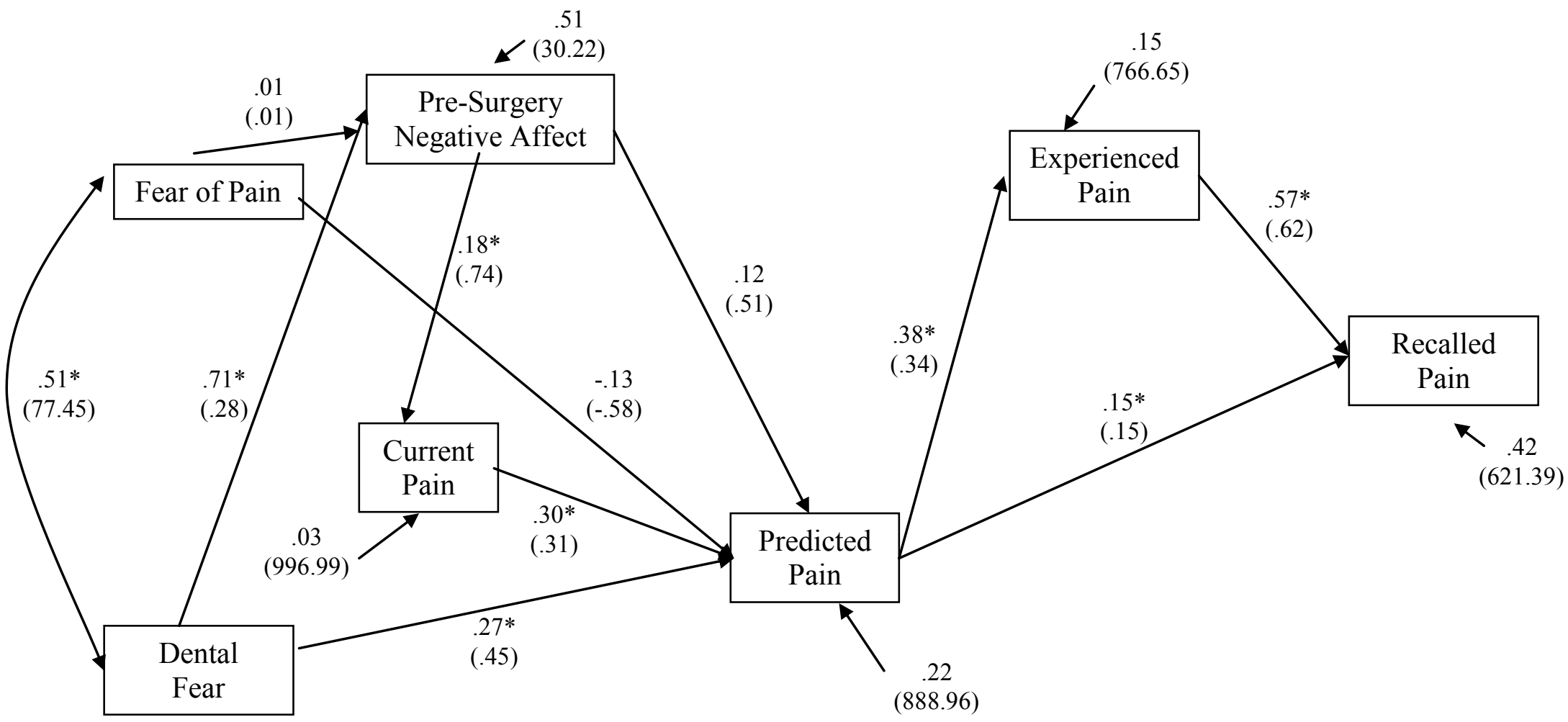




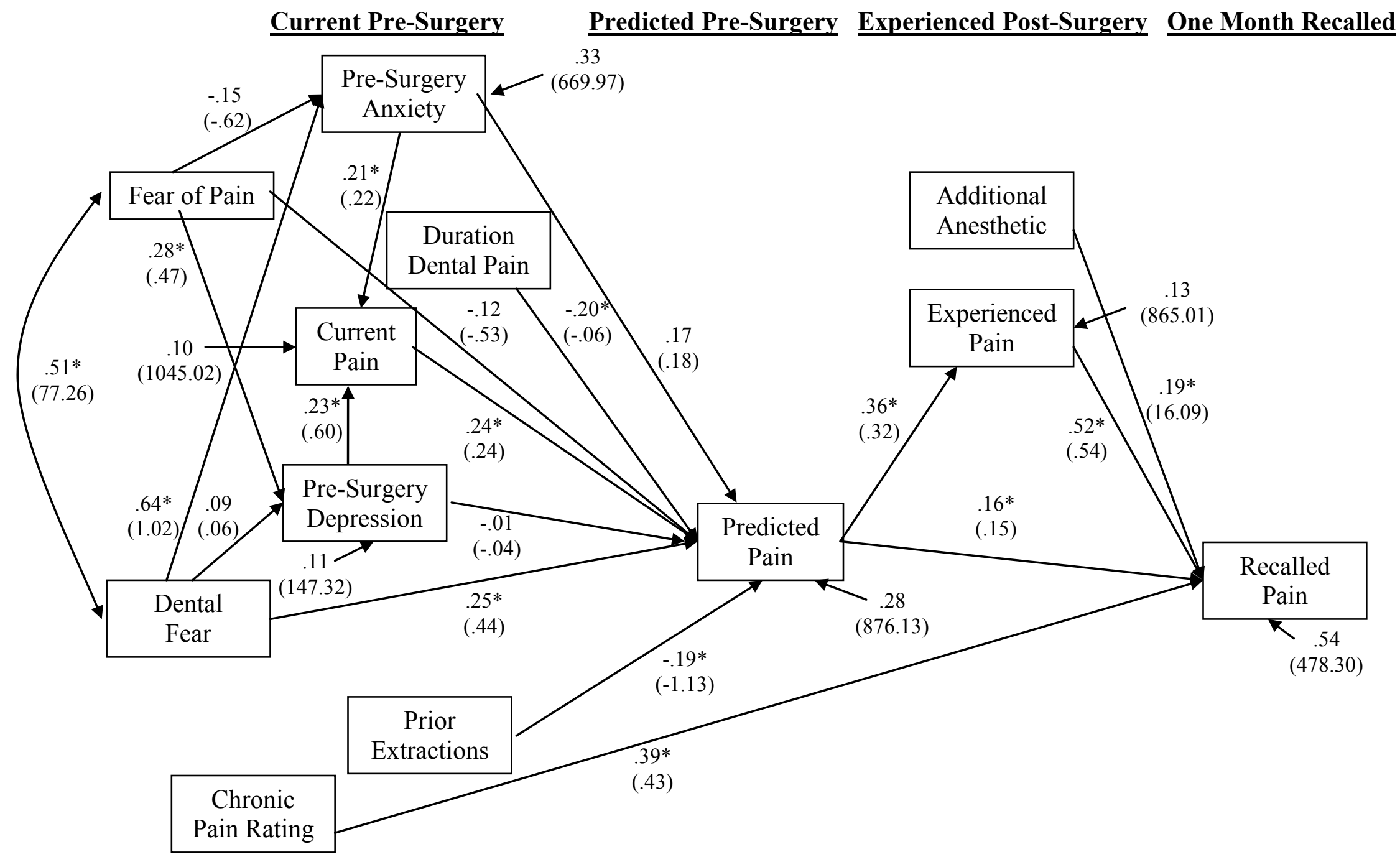




\section{Current Pre-Surgery \\ Predicted Pre-Surgery Experienced Post-Surgery One Month Recalled}

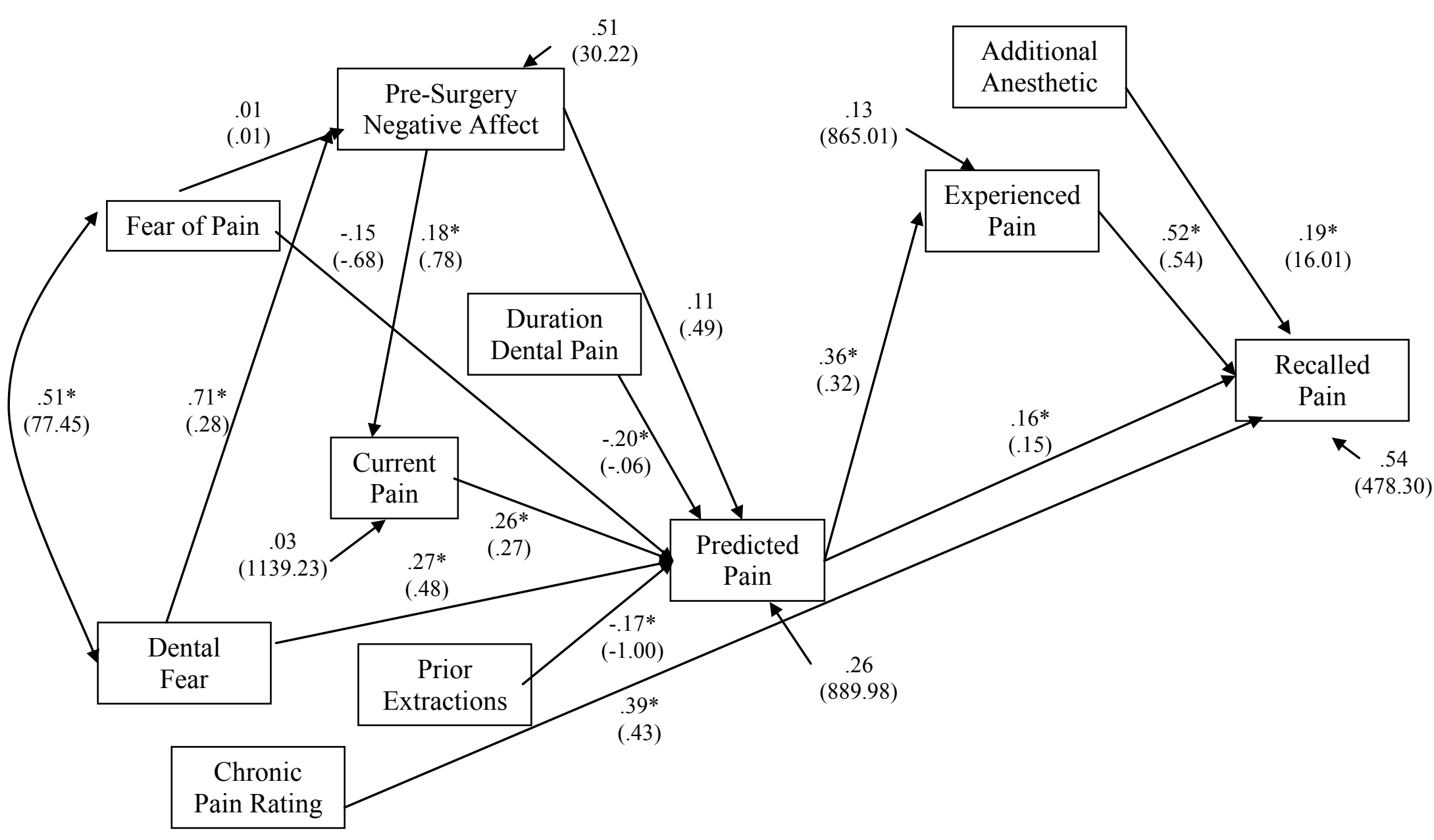




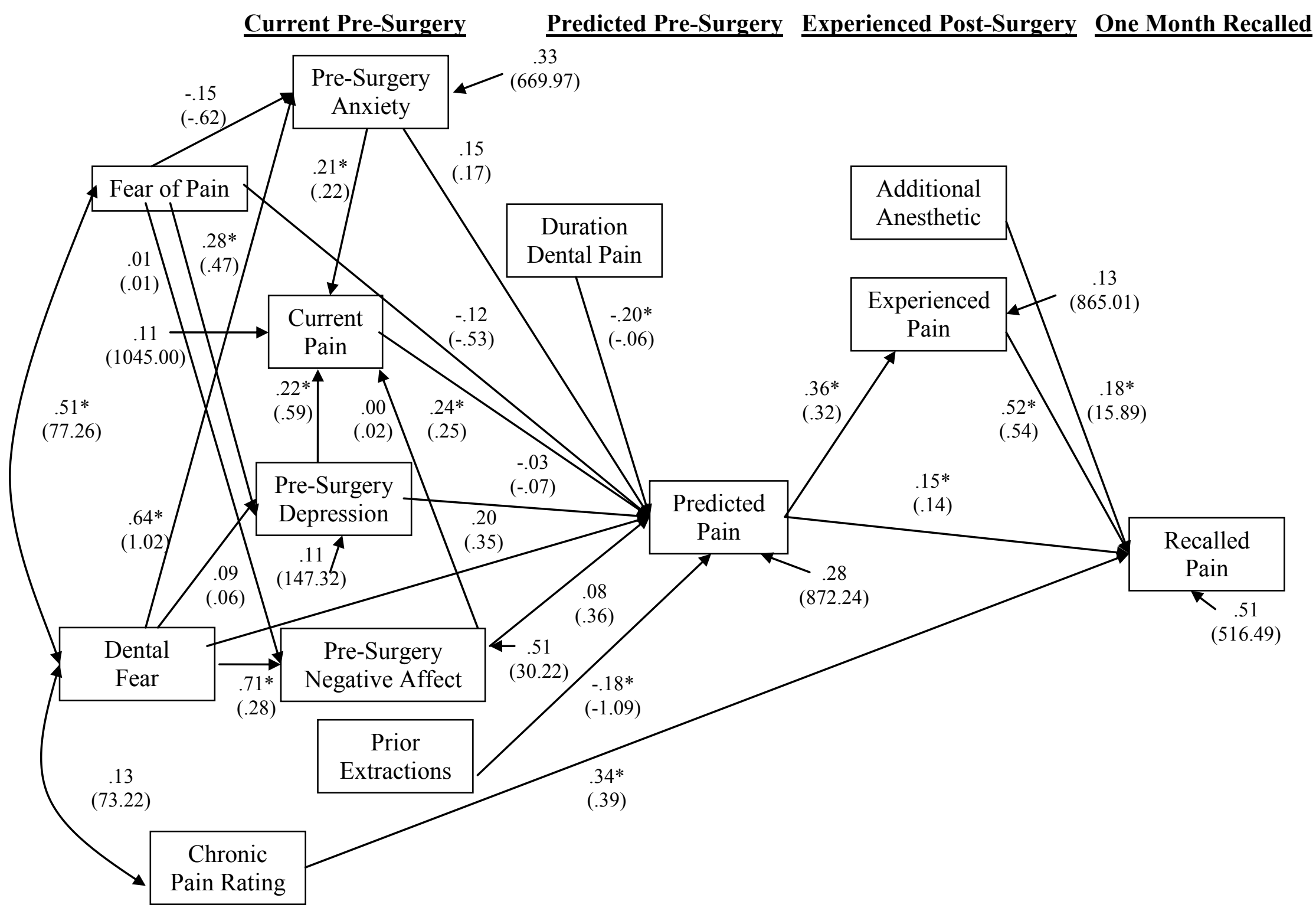

John $\mathrm{H}$.

Hagen 